UNIVERSIDADE DE SÃO PAULO

FACULDADE DE ECONOMIA, ADMINISTRAÇÃO E CONTABILIDADE DEPARTAMENTO DE ADMINISTRAÇÃO PROGRAMA DE PÓS-GRADUACAO EM ADMINISTRAÇÃO

GESTÃO DA INOVAÇÃO EM EMPRESAS DE MICRO, PEQUENO E MÉDIO PORTE: UM ESTUDO DE EMPRESAS DO APL DE SANTA RITA DO SAPUCAÍ

Bruno Giovanni Mazzola

Orientador: Prof. Dr. Moacir de Miranda Oliveira Jr.

SÃO PAULO 
Prof. Dr. João Grandino Rodas

Reitor da Universidade de São Paulo

Prof. Dr. Reinaldo Guerreiro

Diretor da Faculdade de Economia, Administração e Contabilidade

Prof. Dr. Adalberto Américo Fischmann

Chefe do Departamento de Administração

Prof. Dr. Lindolfo Galvao de Albuquerque

Coordenador do Programa de Pós Graduação em Administração 


\title{
GESTÃO DA INOVAÇÃO EM EMPRESAS DE MICRO, PEQUENO E MÉDIO PORTE: UM ESTUDO DE EMPRESAS DO APL DE SANTA RITA DO SAPUCAÍ
}

\author{
Dissertação apresentada ao Programa de Pós- \\ Graduação em Administração da Faculdade de \\ Economia, Administração e Contabilidade da \\ Universidade de São Paulo, para obtenção do \\ título de Mestre em Ciências.
}

Orientador: Prof. Dr. Moacir de Miranda Oliveira Jr.

\author{
Versão Corrigida \\ (Versão original disponível na FEA-USP)
}

SÃO PAULO 
FICHA CATALOGRÁFICA

Elaborada pela Seção de Processamento Técnico do SBD/FEA/USP

Mazzola, Bruno Giovanni

Gestão da inovação em empresas de micro, pequeno e médio porte: um estudo de empresas do APL de Santa Rita do Sapucaí / Bruno Giovanni Mazzola. -- São Paulo, 2013.

$110 \mathrm{p}$.

Dissertação (Mestrado) - Universidade de São Paulo, 2013.

Orientador: Moacir de Miranda Oliveira Júnior.

1. Administração de pequenas e médias empresas 2. Gestão da inovação 3. Arranjo produtivo local 4. Desempenho inovativo I. Universidade de São Paulo. Faculdade de Economia, Administração e Contabilidade. II. Título.

CDD -658.022 
Aos meus pais e irmãs, por todo o amor que dedicaram a mim.

À Juliana, pela infinita paciência e incansável apoio. 


\section{AGRADECIMENTO}

Agradeço ao professor e orientador Moacir de Miranda Oliveira Júnior, pela oportunidade aberta em minha vida acadêmica e profissional, por todo auxílio prestado e pela motivação nos meus momentos de dúvidas ou esmorecimento.

Agradeço também à amiga pós-graduanda Claudia Pavani por todas as conversas, fossem de conteúdo acadêmico e profissional ou apenas divagações sobre a vida, ao longo das inúmeras viagens para Santa Rita.

Gostaria de agradecer aos professores Roberto Sbragia e José Roberto Cunha pelos valiosos insights e sugestões no momento do exame de qualificação.

Agradeço à equipe da FAI, Sandra Carvalho, Aline Faria e Natália Vasconcelos, por todo suporte oferecido a este trabalho.

Por fim, também gostaria de agradecer a todos aqueles que conviveram comigo no período do mestrado e que, de uma forma ou de outra, contribuíram para a superação de mais esta etapa em minha vida.

Obrigado! 
"Twenty years from now you will be more disappointed by the things that you didn't do than by the ones you did do. So throw off the bowlines. Sail away from the safe harbor. Catch the trade winds in your sails. Explore. Dream. Discover." 


\section{RESUMO}

A inovação é um importante meio para que as empresas possam aumentar sua competitividade e assim sobreviver em um cenário de economia global e mercados cada vez mais exigentes. Partindo de uma extensa pesquisa na literatura sobre inovação, nota-se uma abundância de estudos sobre este tema. Porém, a quase totalidade deles está direcionada para grandes empresas. Para minimizar esta lacuna, este trabalho teve como foco o estudo da Gestão da Inovação em empresas de micro, pequeno e médio porte. Esta delimitação justificase por este segmento representar uma parcela significativa da economia nacional, mas, como já é sabido, seus índices de sobrevivência ainda são baixos. O objetivo deste estudo é avaliar o grau de maturidade no tocante à Gestão da Inovação das empresas pertencentes ao Arranjo Produtivo Local do Vale da Eletrônica, localizado em Santa Rita do Sapucaí. Para tanto, estudou-se as práticas da Gestão da Inovação das empresas da amostra. Foram analisadas cinco dimensões que a compõe: Estratégia, Processos Internos, Ambiente Externo, Organização e Cultura. Outro indicador analisado foi o Desempenho Inovativo alcançado por essas empresas nos três anos anteriores à coleta. $\mathrm{O}$ resultado foi que todas as dimensões da Gestão da Inovação possuem uma associação direta com o Desempenho Inovativo, quando analisadas separadamente. No entanto, a análise de regressão múltipla revelou que devido à alta correlação entre as variáveis independentes, bastou a variável Cultura para demonstrar a relação positiva e linear com o Desempenho Inovativo. Ao final do estudo, concluiu-se que empresas que adotam práticas ligadas à Gestão da Inovação tem um Desempenho Inovativo superior. 


\begin{abstract}
Innovation is an important way for companies to increase competitiveness and thus survive in a global economy environment with increasingly demanding markets. From extensive research in innovation literature, we noticed an abundance of studies on this topic. However, almost all are directed to large companies. To reduce this gap, this paper focuses on innovation management in micro, small and medium businesses. This delimitation is justified since this segment represents a significant portion of the national economy, but, as is well known, their survival rates are still low. The aim of this study is to assess the degree of maturity with respect to Innovation Management of enterprises belonging to the Local Productive Arrangement of the Electronics Valley, located in Santa Rita do Sapucaí. To this end, Innovation Management practices of the companies in the sample were studied. Five dimensions were considered: Strategy, Internal Processes, External Environment, Organization and Culture. Innovative Performance achieved by these companies in the three years prior to collection was also analyzed. Results showed that all dimensions of Innovation Management have a direct relationship with Innovative Performance when analyzed separately. However, because of the high correlation between the independent variables, multiple linear regression analysis proved Culture alone was enough to show a positive linear relationship with Innovative Performance. In conclusion, companies adopting practices related to Innovation Management display higher Innovative Performance.
\end{abstract}




\section{SUMÁRIO}

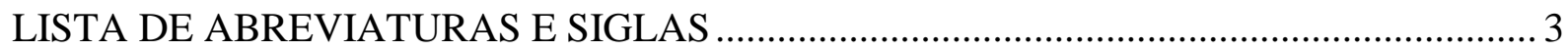

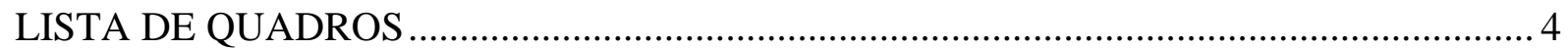

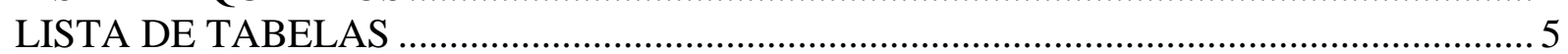

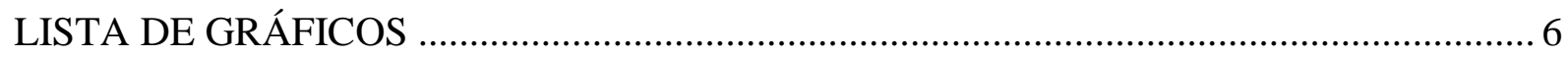

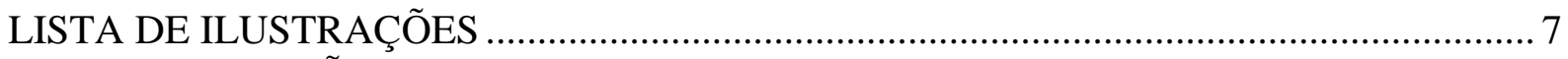

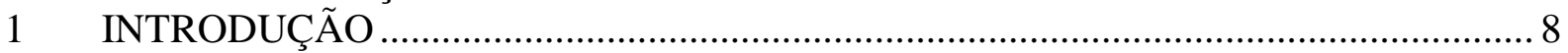

1.1 Problema de pesquisa e objetivos do estudo............................................................ 10

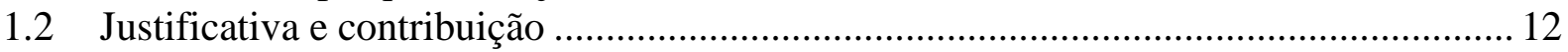

1.3 Histórico do município de Santa Rita do Sapucaí MG ................................................ 13

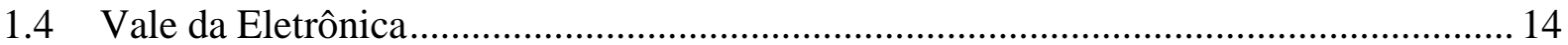

1.5 Governança no APL Eletroeletrônico de Santa Rita do Sapucaí ..................................... 16

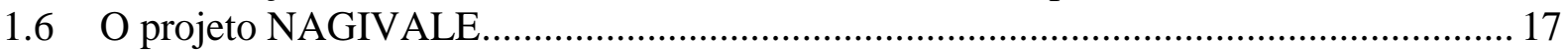

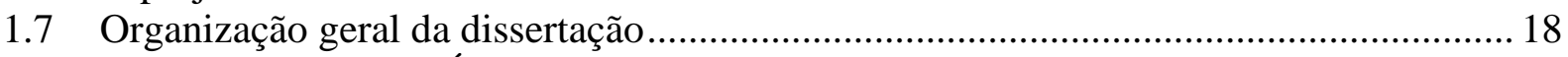

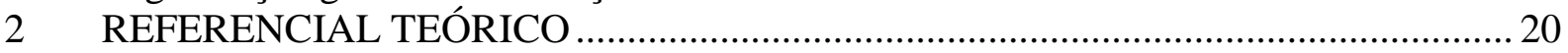

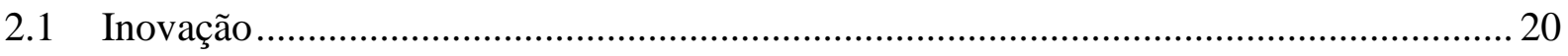

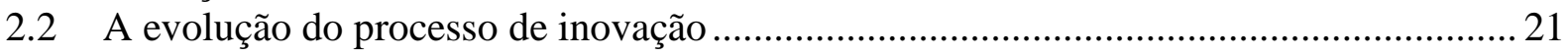

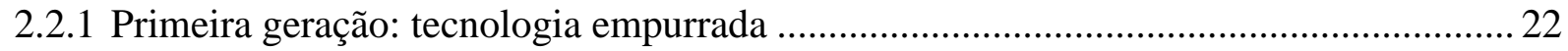

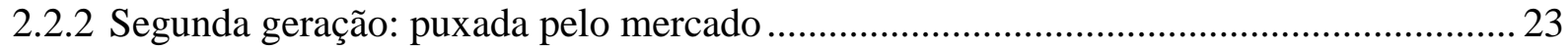

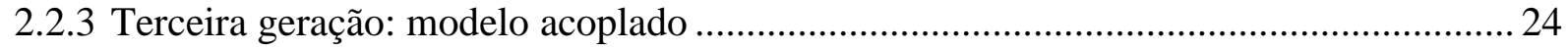

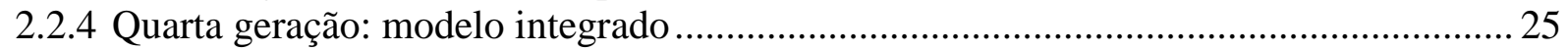

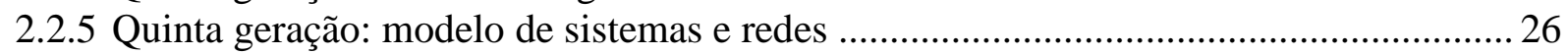

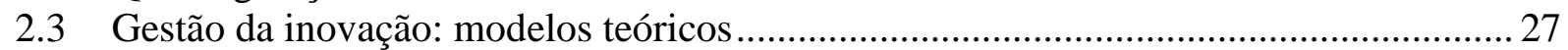

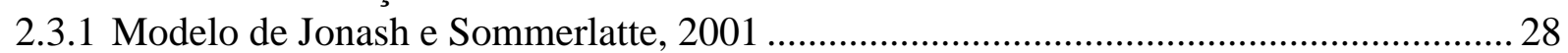

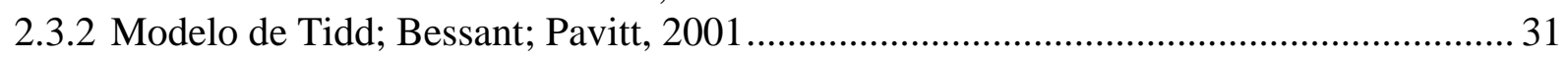

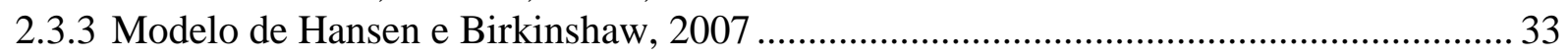

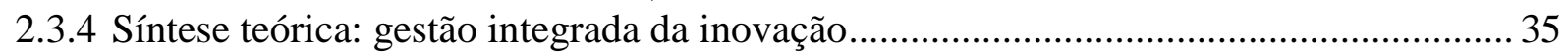

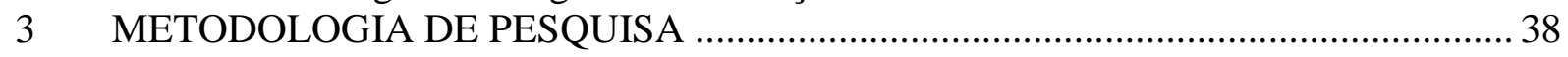

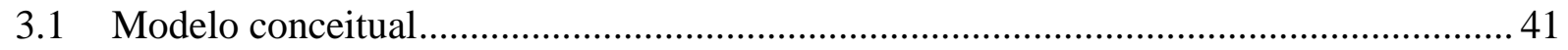

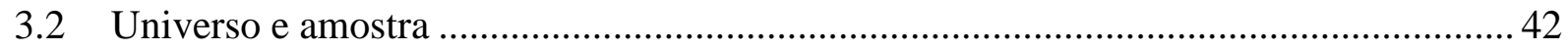

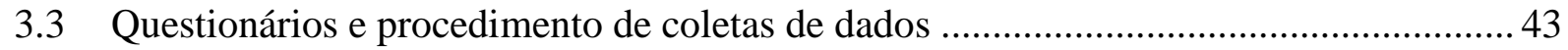

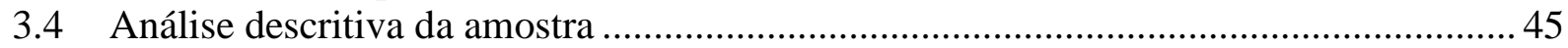

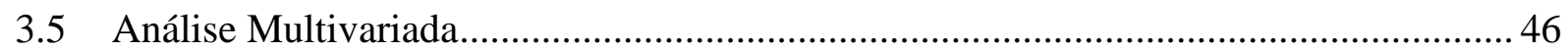

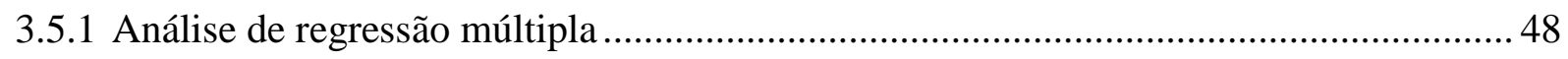

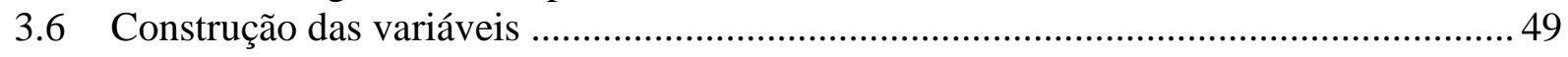

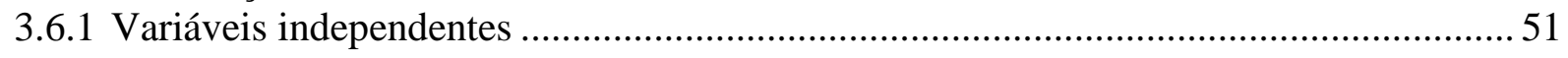

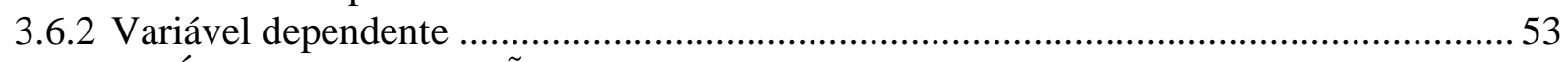

4 ANÁLISE E DISCUSSÃO DOS RESULTADOS OBSERVADOS ….......................... 54

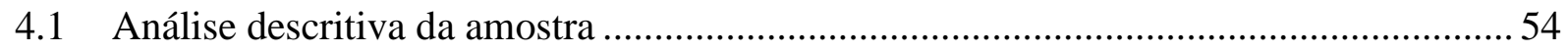

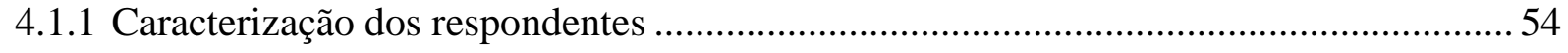

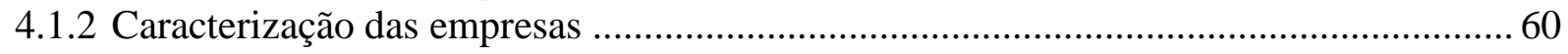

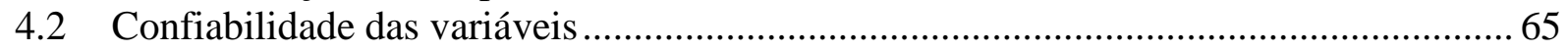

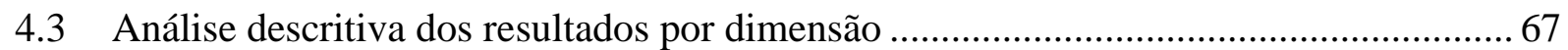

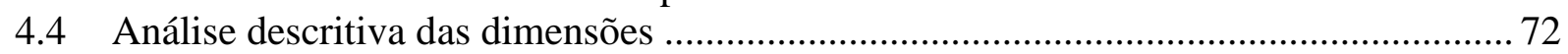

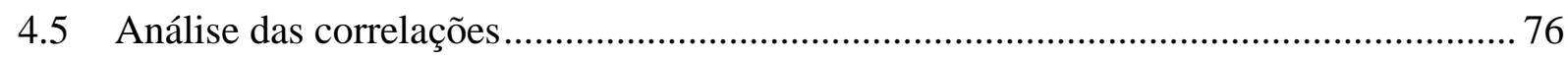

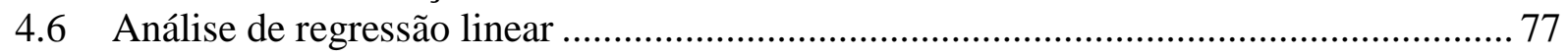

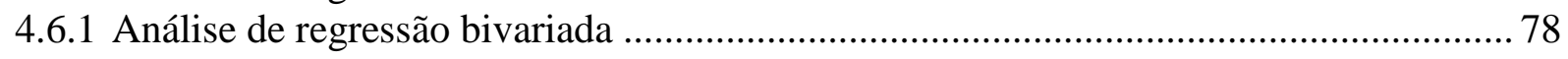

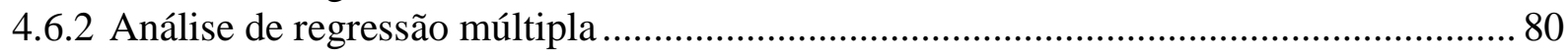




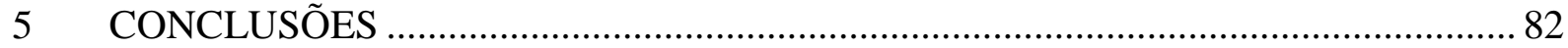

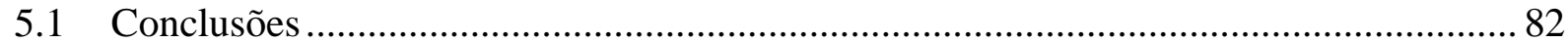

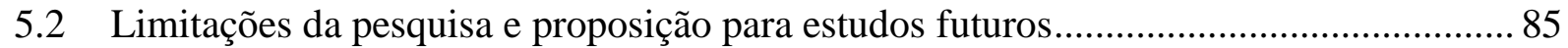

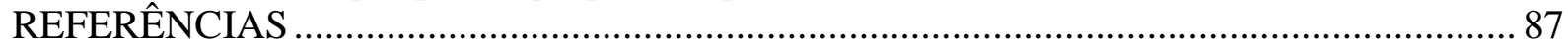

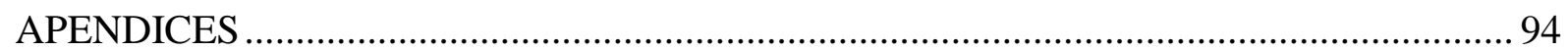




\section{LISTA DE ABREVIATURAS E SIGLAS}

AE: Ambiente Externo

APL: Arranjo Produtivo Local

BIDI-FAI: Bureau de Informação, Desenvolvimento e Inovação da FAI

BNDES: Banco Nacional de Desenvolvimento Econômico e Social

CNPq: Conselho Nacional de Desenvolvimento Científico e Tecnológico

CIS: Community Innovation Surveys

C: Cultura

E: Estratégia

O: Organizacão

ETE: Escola Técnica de Eletrônica

FAI: Centro de Ensino Superior em Gestão, Tecnologia e Educação

FAPEMIG: Fundação de Amparo à Pesquisa do estado de Minas Gerais

FIA: Fundação Instituto de Administração

FIEMG: Federação das Indústrias do Estado de Minas Gerais

FINEP: Financiadora de Estudos e Projetos

FNDCT: Fundo Nacional de Desenvolvimento Científico e Tecnológico

GEM: Global Entrepreneurship Monitor

IBGE: Instituto Brasileiro de Geografia e Estatística

IEL: Instituto Euvaldo Lodi

INATEL: Instituto Nacional de Telecomunicações

MCTI: Ministério de Ciência, Tecnologia e Inovação

MG: Minas Gerais

NAGI: Núcleo de Apoio à Gestão da Inovação

NAGIVALE: Núcleo de Apoio à Gestão da Inovação do Vale da Eletrônica

OCDE: Organization for Economic Co-operation and Development

P,D\&E: Pesquisa, Desenvolvimento e Engenharia

PI: Processos Internos

PIB: Produto Interno Bruto

PIB': Perspectiva do Investimento Brasileiro

PGT-USP: Núcleo de Política e Gestão Tecnológica da USP

PRÓ-INOVA: Programa Nacional de Sensibilização e Mobilização para a Inovação

PROINTEC: Programa Municipal de Incubação de Empresas

P\&D: Pesquisa e Desenvolvimento

RS: Rio Grande do Sul

SINDVEL: Sindicato das Indústrias de Aparelhos Elétricos, Eletrônicos e Similares do Vale da Eletrônica

SEBRAE: Serviço Brasileiro de Apoio às Micro e Pequenas Empresas

SENAI: Serviço Nacional de Aprendizagem Industrial

SESI: Serviço Social da Indústria

SRS: Santa Rita do Sapucaí

TIC: Tecnologias de Informação e Comunicação

TPP: Tecnológica em Produtos e Processos

USP: Universidade de São Paulo 


\section{LISTA DE QUADROS}

Quadro 1 - Pergunta de Pesquisa e Objetivo Específico ........................................................ 10

Quadro 2 - Definições operacionais dos termos da pergunta de pesquisa............................... 11

Quadro 3 - Características dos modelos de gestão da inovação .............................................. 36

Quadro 4 - Dimensões da gestão da inovação .................................................................... 37

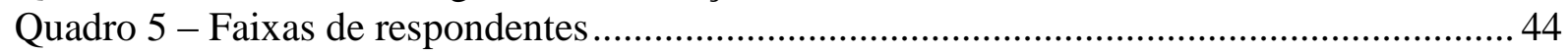

Quadro 6 - Variáveis para medir o constructo Estratégia................................................... 51

Quadro 7 - Variáveis para medir o constructo Processos Internos ..........................................51

Quadro 8 - Variáveis para medir o constructo Ambiente Externo .........................................52

Quadro 9 - Variáveis para medir o constructo Organização ................................................52

Quadro 10 - Variáveis para medir o constructo Cultura..........................................................53

Quadro 11 - Variáveis para medir o constructo Desempenho Inovativo ................................. 53 


\section{LISTA DE TABELAS}

Tabela 1 - Classificação de porte de empresa segundo a receita operacional bruta anual ...... 60

Tabela 2 - Faturamento, idade e pessoas ocupadas segundo o porte de empresa.................... 62

Tabela 3 - Regras práticas sobre a dimensão do coeficiente Alfa de Cronbach.......................65

Tabela 4 - Estatística de Confiabilidade para as dimensões da Gestão da Inovação................ 66

Tabela 5 - Estatísticas de Confiabilidade para o Desempenho Inovativo ................................66

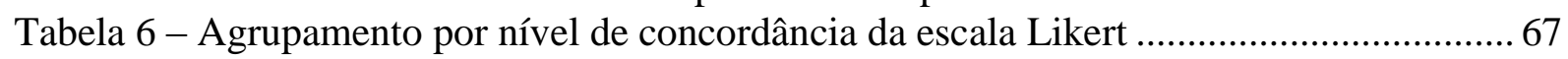

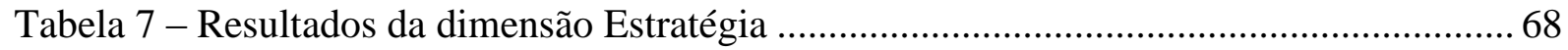

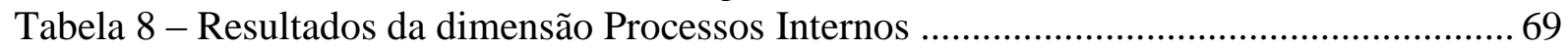

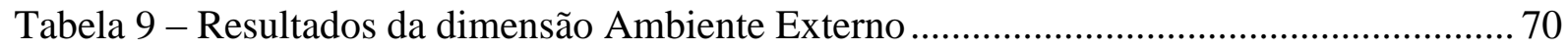

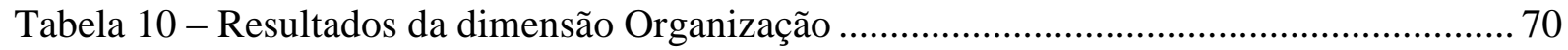

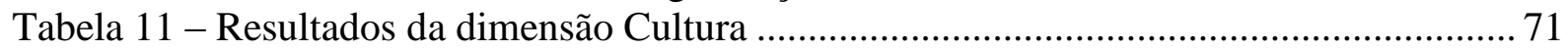

Tabela 12 - Resultados da variável independente Desempenho Inovativo ............................ 72

Tabela 13 - Estatísticas descritivas das variáveis independentes e dependente. ..................... 75

Tabela 14 - Correlação das variáveis da gestão da inovação. .............................................. 77

Tabela 15 - Resumo do modelo de cada análise de regressão bivariada ................................ 79

Tabela 16 - Coeficientes de cada análise de regressão bivariada .......................................... 79

Tabela 17 - Resumo do modelo da análise de regressão múltipla ............................................ 80

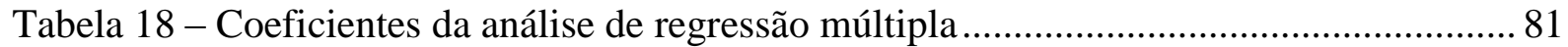

Tabela 19 - Variáveis excluídas da análise de regressão múltipla ......................................... 81 


\section{LISTA DE GRÁFICOS}

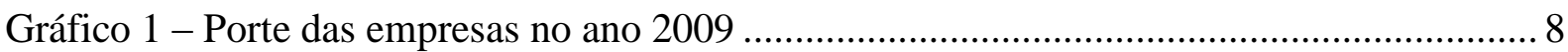

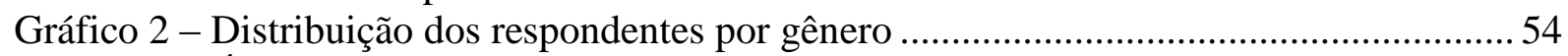

Gráfico 3 - Áreas ou departamentos onde os respondentes atuam ......................................... 55

Gráfico 4 - Áreas ou departamentos ocupados por pessoas do gênero masculino ................... 55

Gráfico 5 - Áreas ou departamentos ocupados por pessoas do gênero feminino ......................56

Gráfico 6 - Cargos ou posições ocupados pelos respondentes ................................................. 56

Gráfico 7 - Cargos ou posições ocupados pelos respondentes, segundo o gênero ................... 57

Gráfico 8 - Áreas ou departamentos nos quais sócios e proprietários atuam ............................57

Gráfico 9 - Grau de instrução dos respondentes................................................................. 58

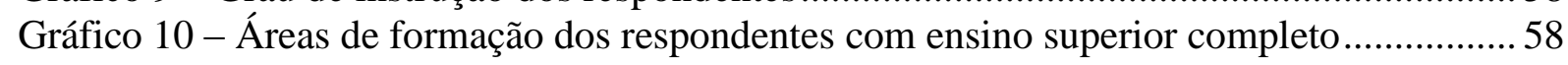

Gráfico 11 - Distribuição da experiência profissional dos respondentes (eixo x em anos)..... 59

Gráfico 12 - Distribuição do tempo de atuação na empresa (eixo x em anos) .........................59

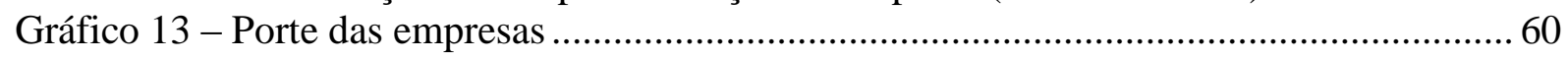

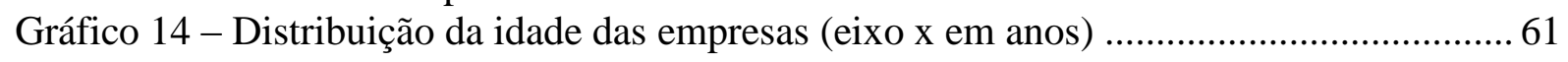

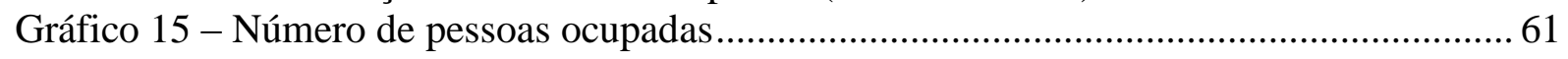

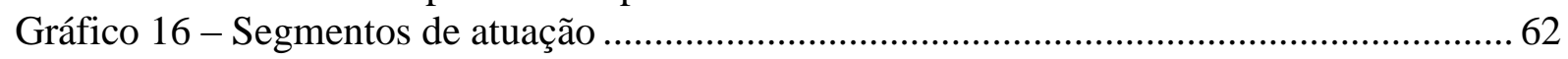

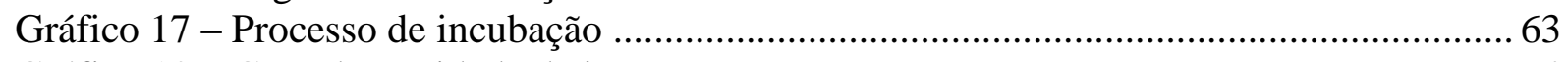

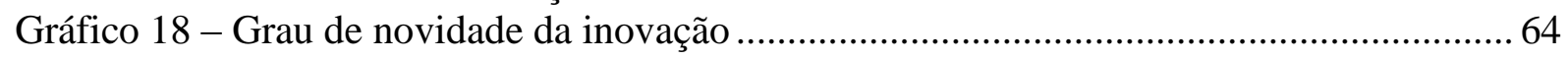

Gráfico 19 - Meios empregados como proteção da propriedade intelectual ............................ 64

Gráfico 20 - Frequência de respostas da dimensão Estratégia. ............................................. 73

Gráfico 21 - Frequência de respostas da dimensão Processos Internos. .................................. 73

Gráfico 22 - Frequência de respostas da dimensão Ambiente Externo.................................... 73

Gráfico 23 - Frequência de respostas da dimensão Organização. .......................................... 74

Gráfico 24 - Frequência de respostas da dimensão Cultura. .................................................... 74

Gráfico 25 - Frequência de respostas da variável resultado Desempenho Inovativo............... 75

Gráfico 26 - Diagrama de dispersão entre Gestão da Inovação e Desempenho Inovativo ..... 84 


\section{LISTA DE ILUSTRAÇÕES}

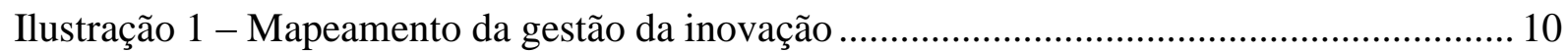

Ilustração 2 - Primeira geração: tecnologia empurrada ........................................................... 23

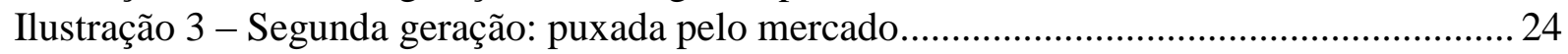

Ilustração 4 - Terceira geração: modelo acoplado ................................................................. 24

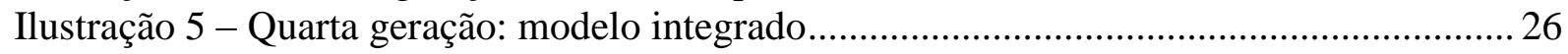

Ilustração 6 - Estrutura da inovação de geração mais avançada e de alto desempenho ........... 29

Ilustração 7 - Representação simplificada do processo de inovação ........................................ 31

Ilustração 8 - Comportamentos ou rotinas para a inovação.................................................... 32

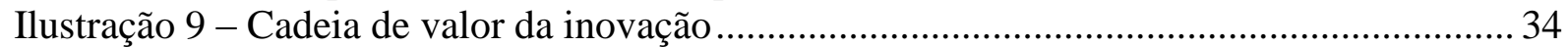

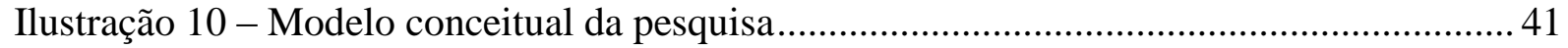

Ilustração 11 - Tipos de análise de dados em função do número de variáveis ........................ 46

Ilustração 12 - Seleção de uma técnica multivariada ............................................................ 47

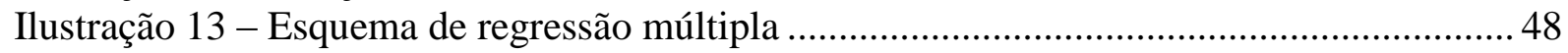




\section{INTRODUÇÃO}

O objetivo desta dissertação é analisar como empresas de micro, pequeno e médio porte gerenciam seu processo de inovação. Para isso, foi realizada uma pesquisa quantitativa no APL, Arranjo Produtivo Local, do Vale da Eletrônica, localizado no município mineiro de Santa Rita do Sapucaí, devido a sua alta concentração de MPME; micro, pequenas e médias empresas; conforme observado no Gráfico 1. Estas empresas operam principalmente nos segmentos de eletrônicos, informática e telecomunicações.

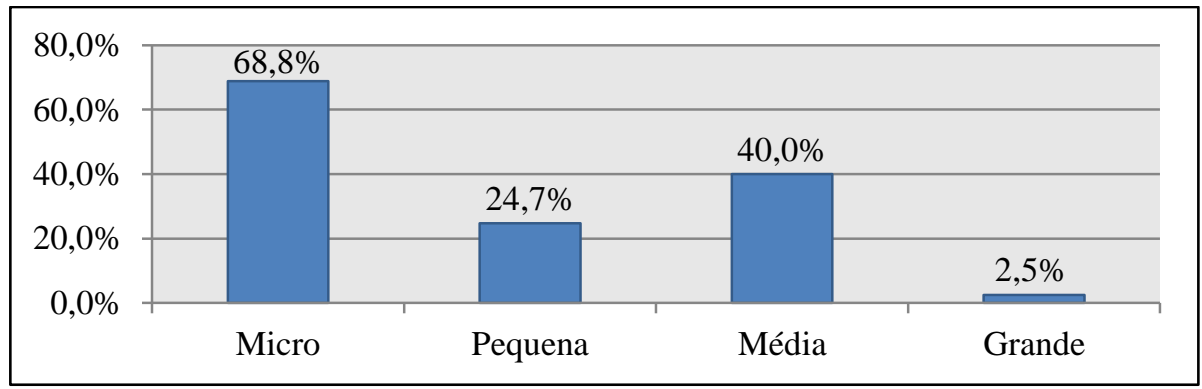

Gráfico 1 - Porte das empresas no ano 2009

Fonte: adaptado de FIEMG; IEL MINAS; SINDVEL, 2010, p. 51

A inovação é considerada a força propulsora para que organizações e nações alcancem ou sustentem sua vantagem competitiva (JONASH; SOMMERLATTE, 2001). Por meio dela é possível se diferenciar dos concorrentes, proporcionar maior valor aos clientes e acionistas, ganhar novos mercados e até mesmo criar outros, completamente novos (CHRISTENSEN, 1997).

Para Papaconstantinou (1997, p. 7), não só as empresas inovadoras, mas também a sociedade como um todo se beneficia com as inovações. Conforme os desenvolvimentos alcançados pelas inovações são difundidos, isto acaba por contribuir para o aumento da produtividade, competitividade, emprego e condições de vida na economia como um todo.

Mas afinal, o que é inovação? Ernest Gundling, autor do livro “The 3M Way to Innovation”, diz que "inovação é mais do que apenas uma ideia brilhante; é uma ideia que foi 
implementada e teve um impacto real"1 (3M, 2012, p. 7). O pesquisador do MIT, Edward B. Roberts (1988), define inovação em termos semelhantes. Ele expressa a inovação em uma fórmula matemática: "inovação = invenção + exploração"2.

Se entendermos que inovação depende apenas do surgimento de boas ideias, corremos o risco de ficar a mercê do acaso, à espera de inspiração ou que uma onda de criatividade varra a empresa. Para que a inovação aconteça de forma contínua, deve-se partir de processos formais e estruturados e que envolvam o maior número de áreas dentro da empresa e fora dela. Neste caso, a empresa estará efetivamente gerenciando a inovação.

No entanto, a competitividade alcançada por meio da inovação logo volta ao ponto de partida, na medida em que os demais competidores as copiam para si (TIDD et al., 2008). Daí a necessidade de a organização estar sempre buscando se renovar para manter sua vantagem competitiva, conforme anunciou Schumpeter no começo do século XX. Para ele, a inovação abrange todo o processo que começa com uma ideia, passa pelo desenvolvimento, até chegar ao mercado e mudar a economia. Dois caminhos poderão conduzir a empresa à continuidade de sua existência, o primeiro é fazendo melhor o que ela já sabe fazer, o segundo é fazer algo de um modo diferente. O desafio reside em a empresa saber percorrer ambos os caminhos de forma complementar (TIDD et al., 2008).

O processo inovativo, para que seja efetivo, deve estar presente em toda a organização. A integração e o trabalho conjunto é um dos componentes de maior impacto que irão influenciar a capacidade de sucesso de uma gestão orientada para o desenvolvimento de inovações (CORAL et al., 2011). Então, se a inovação eficaz é uma questão de gestão, na medida em que a empresa deverá fazer escolhas constantemente, podemos estudá-la a partir de diferentes dimensões a fim de avaliar sua maturidade e como isto reflete no sucesso alcançado por ela.

\footnotetext{
1 "innovation is more than just a bright idea; it is an idea that gets implemented and has a real impact"

2 "innovation = invention + exploitation"
} 
Há muitas ferramentas que se prestam a medir a "gestão da inovação" segundo diversos critérios. Neste estudo, utiliza-se um modelo que, apesar de não ser exaustivo, poderá nos dar uma boa ideia de como a empresa gerencia a inovação. Este modelo é composto de cinco dimensões, conforme a Ilustração 1. Não basta saber como este complexo processo funciona, é importante saber como isto se reflete no Desempenho Inovativo.

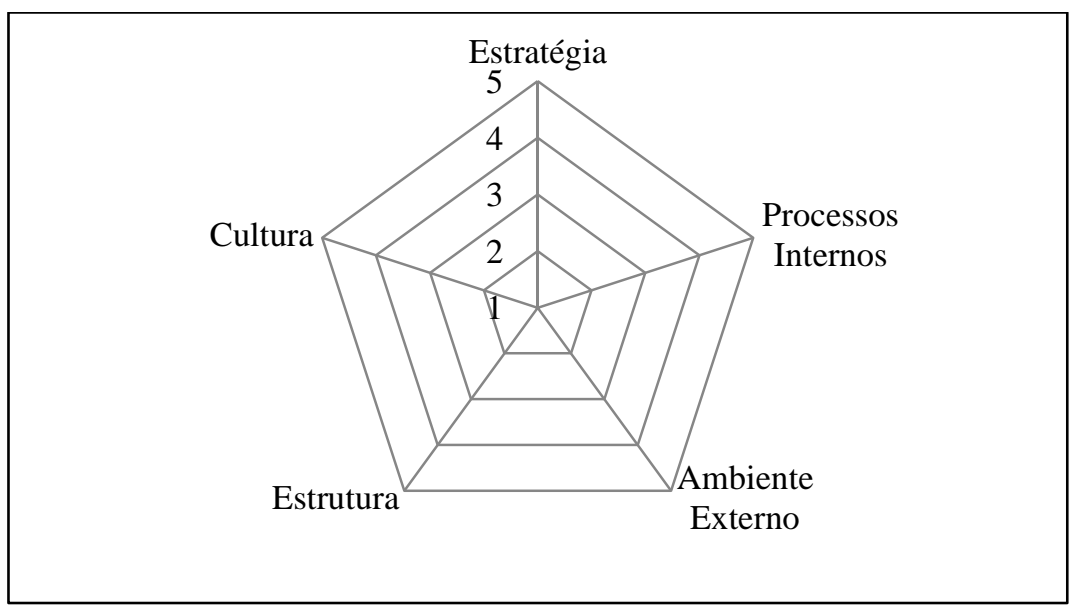

Ilustração 1 - Mapeamento da gestão da inovação

Este estudo tem como foco principal o estudo da gestão da inovação no cotidiano das MPMEs. A proposta é justamente entender como as práticas adotadas se correlacionam com o sucesso alcançado pela organização em termos de inovação.

\subsection{Problema de pesquisa e objetivos do estudo}

Diante do contexto anteriormente exposto, chegou-se à pergunta de pesquisa que norteará a condução do presente trabalho rumo ao objetivo geral, expressa no Quadro 1.

Quadro 1 - Pergunta de Pesquisa e Objetivo Específico

\begin{tabular}{|c|l|}
\hline Pergunta de pesquisa & $\begin{array}{l}\text { Em qual medida as práticas da gestão da inovação na empresa influenciam o seu } \\
\text { desempenho inovativo? }\end{array}$ \\
\hline \multirow{2}{*}{ Objetivo geral } & $\begin{array}{l}\text { Identificar como os fatores da gestão da inovação abordados no trabalho (Estratégia, } \\
\text { Processos Internos, Ambiente Externo, Organização e Cultura) se associam para } \\
\text { refletir no Desempenho Inovativo e quais são os preponderantes no contexto das } \\
\text { MPMEs pesquisadas. }\end{array}$ \\
\hline
\end{tabular}


As definições operacionais dos termos da pergunta de pesquisa estão no Quadro 2:

\begin{tabular}{|c|l|}
\multicolumn{1}{c|}{ Quadro 2 - Definições operacionais dos termos da pergunta de pesquisa } \\
\hline TERMO & \multicolumn{1}{c|}{ DEFINIÇÃO } \\
\hline $\begin{array}{c}\text { Gestão da } \\
\text { inovação }\end{array}$ & $\begin{array}{l}\text { É um processo estruturado adotado pela empresa, envolvendo suas diversas áreas, com o } \\
\text { objetivo de desenvolver inovações de qualquer tipo, abrangência ou intensidade e que } \\
\text { estejam alinhadas com a estratégia de inovação previamente definida, contribuindo para o } \\
\text { aumento da competitividade (TID et al., 2008, p. 7-8). Neste estudo, assumimos que a } \\
\text { gestão da inovação pode se manifestar em cinco distintas dimensões: Estratégia, Processos } \\
\text { Internos, Ambiente Externo, Organização e Cultura. }\end{array}$ \\
\hline \multirow{2}{*}{$\begin{array}{l}\text { Eão as organizações do setor industrial que operam nos segmentos de eletrônica, } \\
\text { telecomunicações e informática. Devem estar enquadradas como micro, pequenas ou } \\
\text { médias empresas, segundo o critério adotado pelo IBGE/SEBRAE de número de } \\
\text { funcionários, onde: até 19 funcionários - microempresa; de 20 a 99 funcionários - pequena } \\
\text { empresa; de 100 a 499 funcionários - média empresa (LIMA, 2001, p. 433). }\end{array}$} \\
\hline $\begin{array}{l}\text { É o conjunto de resultados alcançados pelo processo de inovação e que, direta ou } \\
\text { indiretamente, impactam positivamente no desempenho global do negócio. Como a } \\
\text { inovação não é fruto de uma ocorrência pontual, mas sim de um processo sustentado ao } \\
\text { inovativo }\end{array}$ \\
$\begin{array}{l}\text { longo do tempo, utilizamos os três últimos anos anteriores à coleta de dados para analisar o } \\
\text { Desempenho Inovativo. }\end{array}$ \\
\hline
\end{tabular}

Este estudo busca compreender quais são as principais dimensões em que a gestão da inovação se manifesta e em que grau influenciam o Desempenho Inovativo destas empresas. Os objetivos específicos são analisar cada dimensão da Gestão da Inovação individualmente, e qual a sua relação com o Desempenho Inovativo. As dimensões consideradas neste trabalho, a partir de uma revisão da literatura (JONASH; SOMMERLATTE, 2001; TIDD et al., 2001; HANSEN; BIRKINSHAW, 2007), são:
a) Estratégia
b) Processos Internos
c) Ambiente Externo
d) Organização
e) Cultura

Com isto, espera-se avançar na criação de conhecimento sobre a gestão de MPMEs de base tecnológica, principalmente aquelas localizadas em APLs, com suas especificidades associadas à concentração geográfica. 


\subsection{Justificativa e contribuição}

A motivação para este estudo reside em entender como MPMES de base tecnológica gerenciam o seu processo de inovação. As empresas objeto desta dissertação possuem porte reduzido e por isso o modo como gerenciam o seu processo de inovação é menos sofisticado do que em grandes corporações.

Ao mesmo tempo em que apresentam certas vantagens, como flexibilidade e agilidade para a tomada de decisões, empresas menores têm algumas limitações. Geralmente, elas possuem grandes limitações de recursos, humanos e físicos, exclusivos para a inovação, tais como equipes de Pesquisa e Desenvolvimento (P\&D) ou diretorias de inovação. Deste modo, eventuais decisões equivocadas quanto a compreender o mercado na qual está inserida e saber direcionar seus esforços de inovação podem resultar em consequências gravosas, até mesmo o fim de sua existência (CHRISTENSEN; 2012).

A justificativa da realização deste estudo pressupõe a abordagem de dois diferentes escopos. Em primeiro lugar, é preciso explanar a motivação principal da pesquisa: gestão da inovação em micro, pequenas e médias empresas. Conforme Tidd et al. (2008, p. 146), a discussão sobre empresas com porte reduzido (menos de 500 funcionários) é limitada, uma vez que há carência de pesquisas sobre empresas deste grupo que não se enquadram como sendo necessariamente inovadoras. Diante disso, espera-se que esta pesquisa possa contribuir com novo conhecimento sobre este campo de estudo (NEELY; HII, 1998). Ademais, espera-se possibilitar que empresas menores entendam a dinâmica do seu processo de inovação e, assim, alavanquem seu desempenho por meio da inovação.

Segundo, justifica-se a opção pelo recorte: indústria eletrônica no munícipio de Santa Rita do Sapucaí e o Vale da Eletrônica (MG). Apesar do grande debate sobre a questão da desindustrialização no Brasil, esta região no sul de Minas concentra empresas de eletrônicos, informática e telecomunicações. Projeções do sindicato local apontaram para um crescimento de 23\% no faturamento no ano de 2012 (TOMAZ, 2012), bastante superior ao do PIB nacional, que foi de $0,9 \%$ (IBGE, 2013). O setor eletroeletrônico é caracterizado como sendo de alto valor agregado e estratégico para o desenvolvimento do país, dado o seu caráter de transversalidade nas cadeias produtivas de praticamente todos os setores. A importância deste 
setor se reflete nas metas ambiciosas do país, que pretende estar entre os dez maiores produtores mundiais na indústria eletrônica, saltando de uma participação de 2,9\% no PIB de 2009 para 5\% até 2022 (BAMPI, 2009).

\subsection{Histórico do município de Santa Rita do Sapucaí MG}

A cidade de Santa Rita do Sapucaí está localizada no sul do estado de Minas Gerais, em uma posição estratégica entre os principais polos econômicos do país. O município está distante 416 km de Belo Horizonte, 220 km de São Paulo (SP) e 350 km do Rio de Janeiro. Sua população é de aproximadamente 38 mil habitantes e ocupa uma área de $353 \mathrm{~km}^{2}$ (IBGE CIDADES@, 2012). Está localizada em uma região onde se alternam montanhas e vales que formam a Bacia do Rio Sapucaí.

Em 2009, a cidade gerou um PIB de R 597 milhões (IBGE, 2011, p. 116) dos quais 31\% são provenientes da indústria. A média nacional da participação da indústria no PIB é de $21,8 \%$, o que demonstra que este munícipio é altamente industrializado. No ano seguinte, 2010, o valor do PIB per capita, indicador que relaciona o PIB ao número de habitantes, foi de $\mathrm{R} \$$ 21.512,28 para Santa Rita do Sapucaí (IBGE CIDADES@), enquanto que o PIB per capita nacional foi de R\$19.766,33 (IBGE, 2012, p.33).

Outro indicador social de grande importância é o Índice de Gini, uma medida comumente utilizada para calcular a desigualdade de distribuição de renda. Enquanto que o valor para o Brasil é de 0,524 (IBGE, 2012, p. 218), para Santa Rita do Sapucaí este valor cai para 0,44 (IBGE CIDADES@, 2013), salientando que quanto mais próximo de zero significa que a renda é mais uniformemente distribuída. Isto equivale a dizer que em Santa Rita do Sapucaí há uma menor distância entre os mais ricos e os mais pobres em comparação com o resto do Brasil.

Santa Rita do Sapucaí não é conhecida apenas pelas belas paisagens da Serra da Bocaina e por ser um importante centro produtor de café e laticínios. Sua economia também é fortemente baseada no setor industrial, nas áreas de eletrônica e tecnologia da informação. Até a década 
de 1950, era considerada uma cidade característica do interior de Minas Gerais, com uma economia predominantemente focada no setor primário (PMSRS, 2012).

A mudança começou a ocorrer no ano de 1959, quando a jovem Luzia Rennó Moreira, conhecida como Sinhá Moreira, ao retornar de uma viagem ao exterior fundou a primeira escola técnica de eletrônica da América Latina, a ETE, Escola Técnica de Eletrônica, Francisco Moreira da Costa. Pouco depois, seriam fundadas outras importantes instituições como o INATEL, Instituto Nacional de Telecomunicações, em 1964, e a FAI, Centro de Ensino Superior em Gestão, Tecnologia e Educação, em 1971. Estas foram as sementes do polo tecnológico que viria a ser batizado como "Vale da Eletrônica" (PMSRS, 2012).

\subsection{Vale da Eletrônica}

Até o início dos anos de 1970, havia uma elevada concentração de empresas na região metropolitana de São Paulo, gerando um desequilíbrio com o restante do Brasil em termos de desenvolvimento. A partir desta década, tem início um processo de reversão deste cenário, a polarização de São Paulo começava a dar lugar a uma desconcentração dos investimentos para outras regiões (PEROBELLI, 1996).

Este processo de espraiamento das empresas paulistas pode ser dividido em duas fases. Num primeiro momento, que tem inicio na década de 1970, esta nova configuração da geografia industrial foi consequência dos altos custos de aglomeração (deseconomias de urbanização) (DINIZ, 1993, p. 14) na região metropolitana de São Paulo e também de programas do governo federal que visavam diminuir as diferenças regionais. Exemplo disto é a queda da participação na produção industrial do país entre os anos de 1970 e 1980, quando cai de 58\% para 53\% (DINIZ, 1993, p. 20), e em 1990 cai novamente para 49\% (DINIZ, 1993, p. 3). Num segundo momento, que ocorreu na década de 1980, é possível perceber uma concentração de atividades industriais desta vez numa região mais ampla, localizada no eixo Belo Horizonte MG - Porto Alegre RS. Para ilustrar, no período compreendido entre as décadas de 1970 e 1990, a participação da produção industrial de Minas Gerais passa de 8\% para quase 13\% (PEROBELLI, 1996, p. 67). 
Neste contexto, o município de Santa Rita do Sapucaí se apresenta como uma região atraente para a instalação de novas empresas na área de tecnologia, como as de telecomunicações, eletrônica e informática. Alguns fatores ajudam a explicar a formação deste aglomerado. Dentre os fatores estruturais, podemos citar o avanço da rede de transportes e melhoria nos sistemas de comunicação (DINIZ, 1993, p. 14). Como fatores ambientais que a cidade apresenta, podemos elencar a presença de centros de ensino e pesquisa, presença de mão de obra especializada, facilidade de acesso e proximidade das grandes capitais (DINIZ, 1993, p. 54). Já nesta época começam as primeiras experiências em incubação de empresas, ainda que de maneira informal (DIAS, 2011, p. 79)

Assim, na década de 1980, foi institucionalizado o APL chamado de Vale da Eletrônica, em alusão ao Vale do Silício nos Estados Unidos (DINIZ; LEMOS, 1998 apud BOTELHO; KAMASAKI, 2004, p. 4). A implantação do parque tecnológico contou com o apoio da Prefeitura Municipal na forma de isenção de aluguel e incentivos fiscais, e as instituições de ensino e pesquisa ofereceram seus laboratórios e assessoria técnica e empresarial. Contribuindo para a consolidação do APL, em 1985 é oficialmente instituída a Incubadora de Empresas e Projetos do INATEL e mais tarde, em 1999, é criada a incubadora municipal PROINTEC (BOTELHO; KAMASAKI, 2004, p. 5).

O APL de eletroeletrônicos e telecomunicações em Santa Rita do Sapucaí é constituído por mais de 140 empresas que empregam cerca de dez mil pessoas e que, juntas, faturaram mais de R\$ 1,5 bilhão em 2009 (DIAS, 2011, p. 79-80). Segundo dados da Secretaria de Educação, a cidade possui cerca de seiscentos estudantes de nível técnico nas áreas de eletrônica e informática e dois mil estudantes de nível superior nas áreas de informática, telecomunicações, engenharia da computação e administração de empresas. Cabe salientar a vocação para a inovação dentro do polo tecnológico, onde $9 \%$ do faturamento é investido em pesquisa, desenvolvimento e inovação (GOVERNO DE MINAS, 2007, p. 6).

O Vale da Eletrônica tornou-se uma referência no Brasil como polo de tecnologia e é reconhecido pelo desenvolvimento e produção de eletroeletrônicos. Para sustentar o contínuo desenvolvimento deste polo, existem diversas instituições que oferecem apoio e contribuem para alavancar o sucesso da região. Estas instituições são: os centros educacionais de ensino técnico e superior como a FAI, o INATEL, a ETE e o SENAI, Serviço Nacional de Aprendizagem Industrial (fundado em 2002), responsáveis pela formação da mão de obra 
especializada na cidade; a incubadora municipal PROINTEC e a Incubadora de Empresas e Projetos do INATEL, as próprias empresas de tecnologia que se fortalecem e cooperam mutuamente, a Associação Industrial de Santa Rita do Sapucaí e o SINDVEL, Sindicato das Indústrias de Aparelhos Elétricos, Eletrônicos e Similares do Vale da Eletrônica.

\subsection{Governança no APL Eletroeletrônico de Santa Rita do Sapucaí}

O termo governança corporativa enseja um caráter de regulação e supervisão do modo como a empresa é administrada e de seu relacionamento com os diferentes grupos de interesse (stakeholders, shareholders) (IBGC, 2013; HITT et al., 2008, p. 276-277). Este tipo de governança ocorre no contexto da empresa enquanto unidade. Outro tipo de governança seria a chamada supra-empresas (ou também chamada de governança empresarial), que tem uma atuação similar. Seu propósito é o de promover a competitividade e o resultado do conjunto de empresas com as quais se relaciona. A diferença fundamental entre estas duas governanças reside na abrangência de atuação. Enquanto a primeira concentra esforços em uma empresa isoladamente, a segunda atua no conjunto das empresas. Estas últimas, apesar de independentes, estão ligadas de alguma maneira, seja por vínculos de localização geográfica, de relacionamentos transacionais, de processos competitivos ou de cooperação (ZACARELLI et al., 2008, p. 50-51).

Ainda segundo os mesmos autores, o termo governança supra-empresarial pode ser entendido como “[...] o exercício de influencia orientadora de caráter estratégico de entidades supraempresariais, voltado para a vitalidade do agrupamento, compondo competitividade e resultado agregado e afetando a totalidade das organizações componentes [...]” (ZACARELLI et al., 2008, p. 52).

Segundo Botelho et al. (2000, p. 6), a estrutura de governança do APL de Santa Rita do Sapucaí ocorre na forma de redes. A taxonomia adotada pelas autoras fora proposta pelos pesquisadores Cassiolato e Szapiro em 2003. Esta governança é característica de aglomerados de empresas de micro, pequeno e médio porte, onde não há grandes empresas que exerçam poder de coordenação das atividades econômicas e tecnológicas, ao contrário, persiste um alto relacionamento entre elas e nenhuma se destaca sobremaneira (IE/UFRJ, 2003, p. 15). Foi 
durante a década de 2000 que o SINDVEL se destacou como entidade supra-empresarial a frente da coordenação do APL, o que outrora fora executado de maneira difusa pelas ICTs e demais instituições locais (BOTELHO et al., 2000, p. 16).

O recente estudo de Santos (2013) vai ao encontro do declarado acima. Dados apurados em campo, através de entrevistas em profundidade, constataram que as empresas do Vale da Eletrônica reconhecem a liderança do SINDVEL. Sua atuação passa pela articulação política e representatividade nos níveis local, estadual e nacional, bem como promover a competitividade, divulgação e crescimento das empresas (SANTOS, 2013, p. 214-215). Cabe mencionar que a gestão do APL é compartilhada com outras instituições de apoio, são elas o SEBRAE, Serviço brasileiro de Apoio às Micro e Pequenas Empresas, a FIEMG, Federação das Indústrias do Estado de Minas Gerais, através do IEL, Instituto Euvaldo Lodi, e a SECTES, Secretaria Estadual de Ciência, Tecnologia e Ensino Superior de Minas Gerais (SANTOS et al., 2012, p. 13; SANTOS, 2013, p. 203-204).

\section{6 projeto NAGIVALE}

No sentido de promover e disseminar ainda mais a cultura da inovação nesta região, por iniciativa do BIDI-FAI e contando com a assessoria técnica do PGT-USP, o projeto Núcleo de Apoio à Gestão da Inovação no Vale da Eletrônica (NAGIVALE) foi elaborado. O objetivo principal do projeto é desenvolver e implantar um programa de gestão integrada da inovação em cada uma das empresas participantes e capacitar alunos de graduação para atuarem como Agentes de Inovação dentro delas.

O NAGIVALE é um dos projetos selecionados dentre mais de 110 propostas apresentadas à chamada pública lançada pela FINEP em novembro de 2010. A FINEP é uma empresa pública ligada ao Ministério de Ciência, Tecnologia e Inovação (MCTI), sua missão é promover o desenvolvimento nacional por meio do fomento público à ciência, tecnologia e inovação. Esta chamada pública faz parte do Programa Nacional de Sensibilização e Mobilização para a Inovação (PRÓ-INOVA) e tem como propósito criar núcleos para mobilizar, capacitar e apoiar empresas nas atividades de gestão da inovação, os chamados 
NAGIs. Foram oferecidos $\mathrm{R} \$ 50$ milhões em recursos do FNDCT/Fundos Setoriais para a criação destes núcleos. Ao todo, foram selecionados 24 projetos de todas as regiões do país.

Este projeto está sendo financiado também com recursos do CNPq e FAPEMIG e conta com a parceria do SINDVEL, Incubadora Municipal de Empresas de Santa Rita do Sapucaí, Incubadora de Empresas de Itajubá e Incubadora do INATEL. O período de execução do projeto NAGIVALE é de dois anos e inclui etapas como sensibilização e adesão, diagnóstico, capacitação, alinhamento estratégico, plano de gestão da inovação, implantação do plano, elaboração do Manual de Gestão da Inovação para empresas incubadas e, por fim, avaliação.

Ao final deste período, espera-se que as empresas participantes estejam capacitadas para estabelecer suas próprias estruturas de inovação, por meio do desenvolvimento e implantação de um Plano de Gestão da Inovação. É justamente no âmbito deste projeto que o presente estudo foi elaborado, a coleta de dados se deu nos meses iniciais do projeto.

\subsection{Organização geral da dissertação}

Este estudo foi estruturado em cinco capítulos. No Capítulo 1 foi delineado o problema de pesquisa e os motivos que levaram a estudá-lo, além da justificativa da relevância de sua abordagem e os objetivos, gerais e específicos. O panorama da indústria eletrônica no Brasil e do contexto onde o estudo se desenvolve foram aqui descritos.

O referencial teórico do estudo está no Capítulo 2. O foco de levantamento bibliográfico deste estudo refere-se a apresentação dos o entendimento do conceito de gestão da inovação e as diferentes dimensões que o compõe. Os modelos conceituais apresentados darão subsidio na construção dos questionários e na análise dos dados.

O Capítulo 3 trata de explicitar os procedimentos metodológicos adotados nesta pesquisa empírica. Foram detalhados o método, instrumentos de coleta, ferramentas de análise e recorte da pesquisa. 
O Capítulo 4 cuida da análise dos dados coletadas. A amostra é apresentada em termos de sua análise descritiva e, pelo uso da análise de regressão, os resultados da pesquisa são apresentados.

Por fim, no Capítulo 5, são apresentadas as conclusões desta dissertação. Também são apresentadas as contribuições alcançadas e as limitações que o estudo impõe. São sugeridas proposições de estudos futuros no campo da gestão da inovação em MPME. 


\section{REFERENCIAL TEÓRICO}

Este capítulo busca revisar a teoria acerca da Gestão da Inovação e assim dar condições para o delineamento dos constructos e a construção das variáveis que serão investigadas. Esta revisão bibliográfica pretende, ademais, dar subsídio quando da análise dos dados coletados. Primeiro, fazemos um resgate da evolução dos modelos de gestão ao longo do tempo. A seguir, daremos enfoque sobre alguns modelos teóricos da gestão da inovação.

\subsection{Inovação}

Em um mundo globalizado onde empresas, corporações e até mesmo países competem ferozmente por clientes e mercados, ser inovativo é questão de sobrevivência. O Decreto 5.798 de 07 de junho de 2006, que regulamenta a Lei 11.196 (mais conhecida como a Lei do Bem), define inovação tecnológica como sendo:

“A concepção de novo produto ou processo de fabricação, bem como a agregação de novas funcionalidades ou características ao produto ou processo que implique melhorias incrementais e efetivo ganho de qualidade ou produtividade, resultando maior competitividade no mercado (BRASIL, 2006).”

As inovações TPP, Tecnológicas em Produtos e Processos, de acordo com o Manual de Oslo, correspondem às implantações tecnologicamente novas ou às melhorias tecnológicas em produtos (bens e serviços) e processos (OECD, 2005). Tidd et al. (2008, p.30) definem inovação em produto como "mudança nas coisas (produtos/serviços) que uma empresa oferece" e inovação de processo como "mudanças na forma em que os produtos/serviços são criados e entregues".

A implantação ocorre somente quando estiver introduzida no mercado (inovação de produto) ou usada no processo de produção (inovação de processo), envolvendo uma série de atividades científicas, tecnológicas, organizacionais, financeiras e comerciais. Para ser considerada inovadora em TPP, é necessário que a empresa, durante o período de análise, 
tenha implantado produtos ou processos tecnologicamente novos ou com substancial melhoria tecnológica, sem a necessidade de que seja inédito no mundo (OECD, 2005).

A inovação não é realizada aleatoriamente e, por tratar-se de um processo de alta complexidade e alto risco e incerteza, faz-se necessário o emprego de procedimentos e metodologias adequados e um sistema eficiente para produzir os resultados objetivados pela empresa. Este processo deve ser gerenciado de maneira criteriosa de modo a produzir resultados, transformando invenções em produtos comercialmente viáveis no mercado (inovação).

A gestão da inovação é um processo organizacional que, segundo Tidd et al. (2008), envolvem três pilares básicos: conhecimento, informação e criatividade. Afirmam que a envolvem os seguintes processos considerados essenciais para alcançar resultados inovadores: planejamento; alocação; organização; e coordenação de fatores. Dessa maneira, significa gerir integradamente as alternativas lucrativas de (mais) valor (novas tecnologias) a partir de conhecimento, informação e criatividade.

Complementarmente, ao abordar o processo de inovação de uma maneira estruturada, é necessário que a empresa defina inicialmente um posicionamento estratégico, a partir do qual será lançada uma estratégia tecnológica com as principais metas a serem atingidas no escopo de lançar produtos inovadores para conseguir novos mercados, maior rentabilidade e satisfação dos stakeholders. O conceito moderno de gestão de inovação transcende os limites dos departamentos de pesquisa e desenvolvimento, envolvendo todas as interfaces da organização. É um processo cultural e contínuo, em que os pilares mencionados acima interagem sinergicamente.

\subsection{A evolução do processo de inovação}

A gestão da inovação é um fenômeno complexo que resulta da inter-relação de diversos fatores incertos, pouco previsíveis e, por vezes, caóticos. Uma das maneiras de se compreender fenômenos deste tipo é reduzi-los ou simplifica-los em modelos mentais e, a 
partir daí, irmos com o tempo adicionando ingredientes (fatores) de modo a aumentar nossa compreensão sobre o objeto estudado.

Para Tidd et al. (2008, p. 95), a importância de se compreender a inovação enquanto processo reside justamente no fato de que este conhecimento molda a forma como experimentamos e gerenciamos a inovação. Como processo, a inovação não se manteve imutável ao longo do tempo, ela evoluiu e acompanhou as mudanças pelas quais a sociedade passa.

Os modelos mentais que tentam traduzir o processo de inovação se reúnem em dois grupos. O primeiro entende este processo como sendo uma sequencia linear de atividades, onde a inovação pode partir de um desenvolvimento tecnológico e, por conseguinte, ser levada ao mercado, ou pode a inovação ser motivada por uma necessidade latente do mercado e ser por este direcionada. O segundo grupo de modelos, percebendo as limitações da abordagem linear, entende que a inovação é, na prática, um processo interativo e complexo que envolve outros fatores internos e externos à empresa. É permeado de idas e vindas ao longo do processo de inovação na forma de feedbacks e o grau de incerteza é elevado, chegando até mesmo a parecer caótico.

Os diferentes processos de inovação podem ser situados dentro de uma perspectiva histórica de sua evolução. Sobre este tema, o autor Rothwell (1994) soube enquadrar os diferentes processos em cinco diferentes gerações, em um processo que partiu de modelos lineares para modelos cada vez mais complexos e integrados da gestão da inovação. Para Tid (2006, p.3), a importância de entender a inovação enquanto processo reside em moldar a forma como a experimentamos e tentamos gerenciá-la.

\subsubsection{Primeira geração: tecnologia empurrada}

O que chamamos de primeira geração do processo de inovação teve início na década de 1950 e perdurou até meados da década seguinte. Este processo coincide com o período após a II Guerra Mundial, quando as economias de países desenvolvidos vivenciaram um período de crescimento econômico e rápida industrialização, gerando assim prosperidade e aumentando o poder de compra da população. Os governos e as empresas deram ênfase em programas de 
investimento relacionados à Pesquisa e Desenvolvimento (P\&D). Em um processo sequencial e linear, a pesquisa básica subsidiaria o conhecimento aplicado e o desenvolvimento tecnológico, para posteriormente serem absorvidas pelo mercado na forma de produtos, conforme a Ilustração 2. Em suma, o lançamento de novos produtos é uma função do investimento em $\mathrm{P} \& \mathrm{D}$, daí esta abordagem ter ficado conhecida como technology-push (ROTHWELL, 1994).

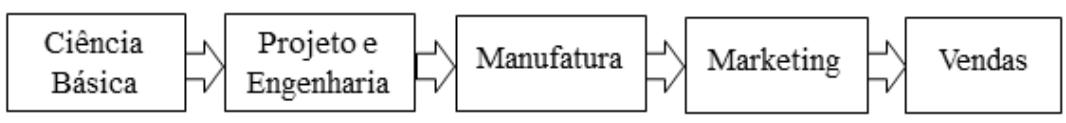

Ilustração 2 - Primeira geração: tecnologia empurrada Fonte: Fonte: ROTHWELL; 1994, p. 8

Entretanto, com o passar do tempo, este modelo revelou algumas deficiências. Segundo Neely e Hii (1998), a debilidade do modelo está na simplificação do processo de inovação. Em primeiro lugar, este processo é retratado como uma sequência estática, onde cada função é vista como sendo estanque dentro do processo. Além disto, é depositada muita ênfase em P\&D em detrimento de outros fatores que também contribuem para a inovação. Por fim, mas intimamente relacionado com estes dois apectos, o modelo falha em captar a interatividade do processo de inovação, na forma de feedbacks do mercado e de outras áreas dentro da empresa, bem como na possibilidade de o processo retroceder ou avançar.

\subsubsection{Segunda geração: puxada pelo mercado}

O segundo modelo que faz parte do grupo de processos lineares se situa entre meados da década de 1960 e início da década seguinte. Nesta fase, a competição entre as empresas começou a se intensificar, e logo o foco passou de produtos seguindo os paradigmas tecnológicos para um uso mais racional desta. Logo, a ênfase em investimentos de programas de P\&D foi desviada para uma maior preocupação com as atividades de Marketing. Segundo Rothwell (1994, p. 8), as percepções do processo de inovação começaram a mudar com uma preocupação maior em direção ao mercado, já que as empresas almejam aumentar seu marketshare. Na Ilustração 3, podemos ver que são as necessidades do mercado que orientam o papel de $\mathrm{P} \& \mathrm{D}$, que agora tem um papel secundário no processo, resultando no modelo chamado "demand pull". Em outras palavras, o fator chave no processo de inovar são as 
necessidades dos clientes, que servem como reservatório de ideias para orientar as atividades de P\&D (NEELY; HII, 1998, p.13).

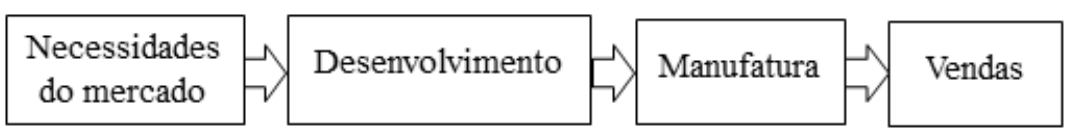

Ilustração 3 - Segunda geração: puxada pelo mercado

Fonte: ROTHWELL; 1994, p. 9

Este modelo compartilha de algumas fraquezas com a primeira geração, tais como a rigidez de um processo linear e sequencial da inovação. Ambos reduzem tratam da questão do progresso tecnológico como um equacionamento entre oferta e demanda, sem considerar outros fatores, como aprendizado, parcerias, características de cada setor.

\subsubsection{Terceira geração: modelo acoplado}

O modelo acoplado (coupling model) foi característico dos processos de inovação entre o começo da década de 1970 e meados da década de 1980. Esta foi uma época difícil na economia mundial, marcada por crises, inflação, saturação da demanda e altos índices de desemprego. Foi neste contexto que estudos empíricos sobre o processo da inovação começaram a proliferar, diversos eram os países e setores objetos de pesquisa. Os resultados dessas pesquisas apontavam que os primeiros modelos retratavam apenas parte do processo de inovação e propunham um novo, que integrava os dois anteriores. O modelo de terceira geração é um modelo de acoplamento, que reconhece tanto a influência de capacidades tecnológicas como das necessidades do mercado no contexto das empresas inovadoras, conforme observado na ilustração 4 (ROTHWELL, 1994, p. 9).

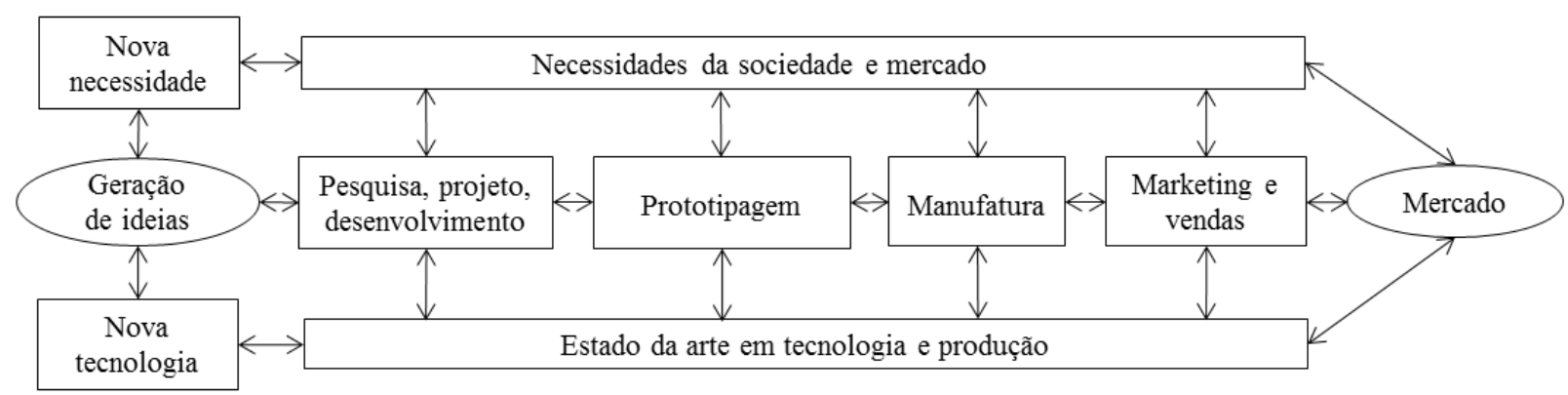

Ilustração 4 - Terceira geração: modelo acoplado Fonte: ROTHWELL; 1994, p. 9 
Esta abordagem contém vários pontos de interface entre as áreas da empresa e entre esta e os agentes externos, na forma de conhecimentos da comunidade científica e no mercado como fonte de informações. Ainda que o modelo apresente maior interação na forma de feedbacks constantes entre os diversos elos, ele é basicamente uma combinação dos modelos anteriores, porém com uma maior ligação entre as áreas de Marketing e P\&D. No entanto, a inovação aqui continua sendo retratada como um processo sequencial (NEELY; HII, 1998, p. 13).

\subsubsection{Quarta geração: modelo integrado}

Após o período de estagnação, no inicio da década de 1980 o mundo começa a dar sinais de recuperação. As empresas começam a dar maior ênfase na estratégia de seus negócios e no relacionamento com o ambiente externo, na forma de alianças estratégicas, formulação de estratégias globais, envolvimento de fornecedores no processo de fabricação e inovação, formação de redes de relacionamento e foco das empresas em seus core business e core technologies (ROTHWELL, 1994, p. 11).

Os modelos anteriores abordavam o processo de inovação como sendo essencialmente fluxos sequencias de informações. Para melhorar a falta de integração funcional nos modelos lineares, este abordagem veio retratar a inovação como um processo com maior complexidade, não linear e interativa (NEELY; HII, 1998, p. 14). A quarta geração, chamada de modelo integrado, é caracterizado pela integração e desenvolvimento paralelo de inovações. Participam simultaneamente deste processo, os diferentes departamentos da empresa e seus fornecedores. 


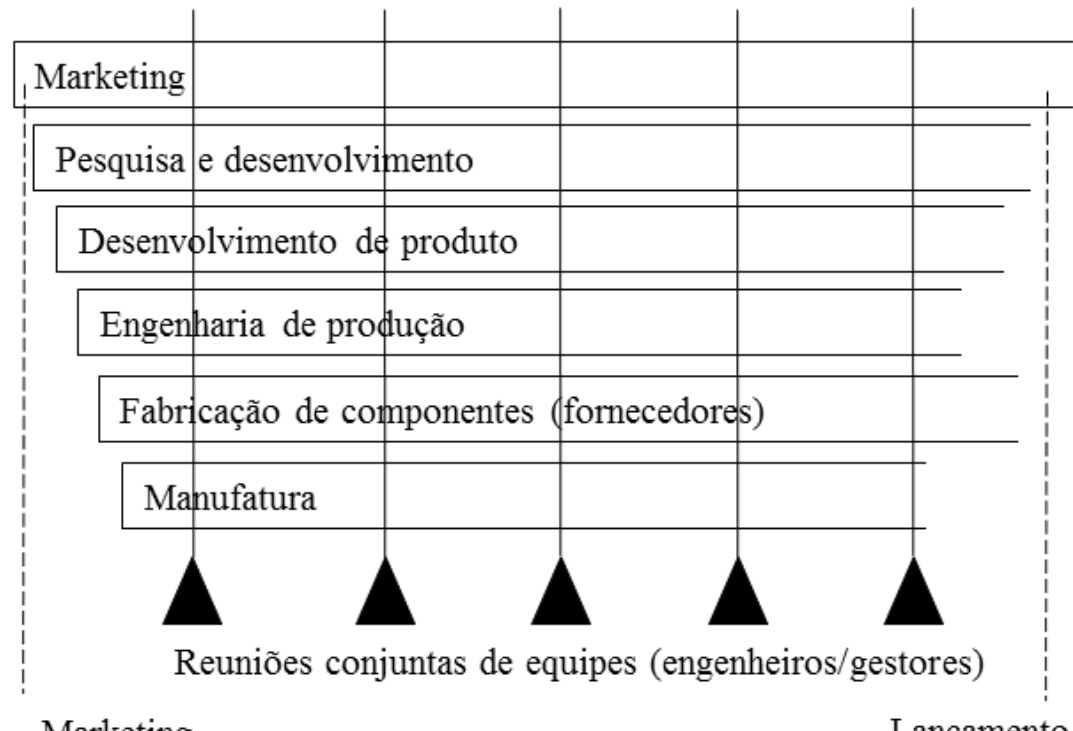

Marketing Lançamento

Ilustração 5 - Quarta geração: modelo integrado Fonte: Fonte: ROTHWELL; 1994, p. 9

Este modelo é bastante característico das empresas japonesas de manufatura. Segundo Rothwell (1994, p. 11), o sucesso das empresas japonesas era mais que a combinação de imitação de tecnologias, logística just-in-time de seus fornecedores e processos de produção eficientes. Eles se consolidaram porque envolviam seus fornecedores já nos estágios iniciais de desenvolvimento de novos produtos, bem como suas equipes internas trabalhavam paralelamente no projeto (ao invés de "em série"). Isto possibilitou que lançassem produtos mais rapidamente no mercado em comparação com seus concorrentes ocidentais, em um momento em que o time-to-market era um fator crucial para a competitividade (NEELY; HII, 1998, p. 14).

\subsubsection{Quinta geração: modelo de sistemas e redes}

A quinta geração do processo de inovação teve início na década de 1990. Neste período houve uma continuidade das tendências iniciadas na década anterior, tais como a preocupação das empresas com o acúmulo de tecnologias, relacionamentos estratégicos, tempo de lançamento de produtos (time-to-market), integração entre produto e produção (design for manufaturability), flexibilidade das organizações, maior regulamentação dos governos (ROTHWELL, 1994, p.12). Neely e Hii (1998, p. 15) acrescentam outras tendências como 
aumento das alianças estratégicas internacionais, do P\&D colaborativo, da preocupação com a gestão da cadeia de suprimento, das redes de relacionamento entre empresas.

Para Rothwell (1994, p. 13), dentre os diversos elementos mencionados anteriormente, talvez o mais importante seria o tempo de desenvolvimento e lançamento de produtos. Em um mercado mais acirrado, marcado por altas taxas de mudanças tecnológicas e menores ciclos de vida dos produtos, estar entre os primeiros aumentaria a competitividade da empresa. Para tanto, a empresa direcionou seu foco para a integração de sistemas e construção de redes com parceiros externos.

O conceito de modelo de quinta geração compreende a inovação como sendo um processo envolvendo muitos atores, que exige um nível de integração elevado tanto dentro da empresa como com o meio externo e que é facilitado pela infraestrutura de TI (TIDD, 2006, p.3). Segundo Tidd et al. (2008, p. 97), apesar do autor Rothwell não ter mencionado explicitamente a internet, os desafios impostos por ela se encaixam perfeitamente aqui.

Este modelo pode ser entendido como uma evolução da geração anterior. O próprio Rothwell (1994, p.15) confirma esta visão, quando afirma que “o processo de quinta geração é essencialmente um desenvolvimento do processo de quarta geração (paralelo, integrado) a tecnologia da mudança tecnológica, ela mesma está mudando”’3.

\subsection{Gestão da inovação: modelos teóricos}

$\mathrm{Na}$ literatura são apresentados diversos modelos que retratam o processo de gestão da inovação. Dentre estes modelos, muitos chegam se confundem com técnicas ou ferramentas que auxiliam fases específicas do processo de inovação.

Neste estudo, buscou-se fazer o resgate conceitual de modelos que retratam a gestão da inovação como um processo que envolve as dimensões da empresa de forma complementar, para assim possibilitarem a inovação. De maneira geral, as dimensões abordadas nos diferentes modelos são semelhantes, e independem de qual segmento a empresa pertença ou

\footnotetext{
3 "The process $5 \mathrm{G}$ is essentially a development of the $4 \mathrm{G}$ (parallel, integrated) process in which the technology of technological change is itself changing."
} 
do tipo de inovação que se pretende estudar. Os modelos usados neste estudo foram aqueles propostos pelos autores Jonash e Sommerlatte (2001), Tidd et al. (2001) e Hansen e Birkinshaw (2007).

\subsubsection{Modelo de Jonash e Sommerlatte, 2001}

Segundo Jonash e Sommerlatte (2001), a empresa deve focar diretamente na inovação para poder prosperar em uma concorrência cada vez mais feroz. Para isto, é preciso uma reorganização completa, que inclua estratégias, processos e recursos. Os autores analisam a inovação em um sentido mais amplo, envolvendo o que seja relacionado à criação de novos produtos, serviços e processos. Assim, a visão tradicional dos departamentos de $\mathrm{P} \& \mathrm{D}$, típica dos modelos de primeira geração, representa uma limitação para que a empresa inove dentro de um novo contexto.

Em contraponto a este modelo, os autores consideram que a gestão da inovação deve estar presente em toda a empresa. Neste momento, a empresa é entendida como um conceito ampliado, que contempla todos os colaboradores da cadeia de valor em seus processos de gestão, isto é, fornecedores, clientes e parceiros estratégicos. Este modelo de gestão da inovação é definido como geração mais avançada.

O modelo de geração mais avançada apresenta dois princípios fundamentais. O primeiro é "conduzir a inovação na companhia inteira para se criar valor"; o segundo é "alavancar tecnologia e competências para impulsionar a inovação sustentável e capturar vantagem competitiva" (JONASH; SOMMERLATTE, 2001, p. 2-3). A ideia principal do primeiro elemento é que grandes inovações não acontecem isoladamente, mas são frutos da mobilização tanto interna quanto de redes de empresas conectadas. Ademais, a questão do aprendizado é prioritária para perpetuar o ciclo de inovação. O segundo elemento é possível graças ao conceito de plataformas de tecnologia e competências.

Estes dois princípios fundamentais são possíveis desde que a empresa empregue seus esforços em cinco elementos fundamentais: estratégia, processos, recursos, organização e aprendizado. 
A Ilustração 6 representa a estrutura de inovação de geração mais avançada e de alto desempenho, proposta pelos autores.

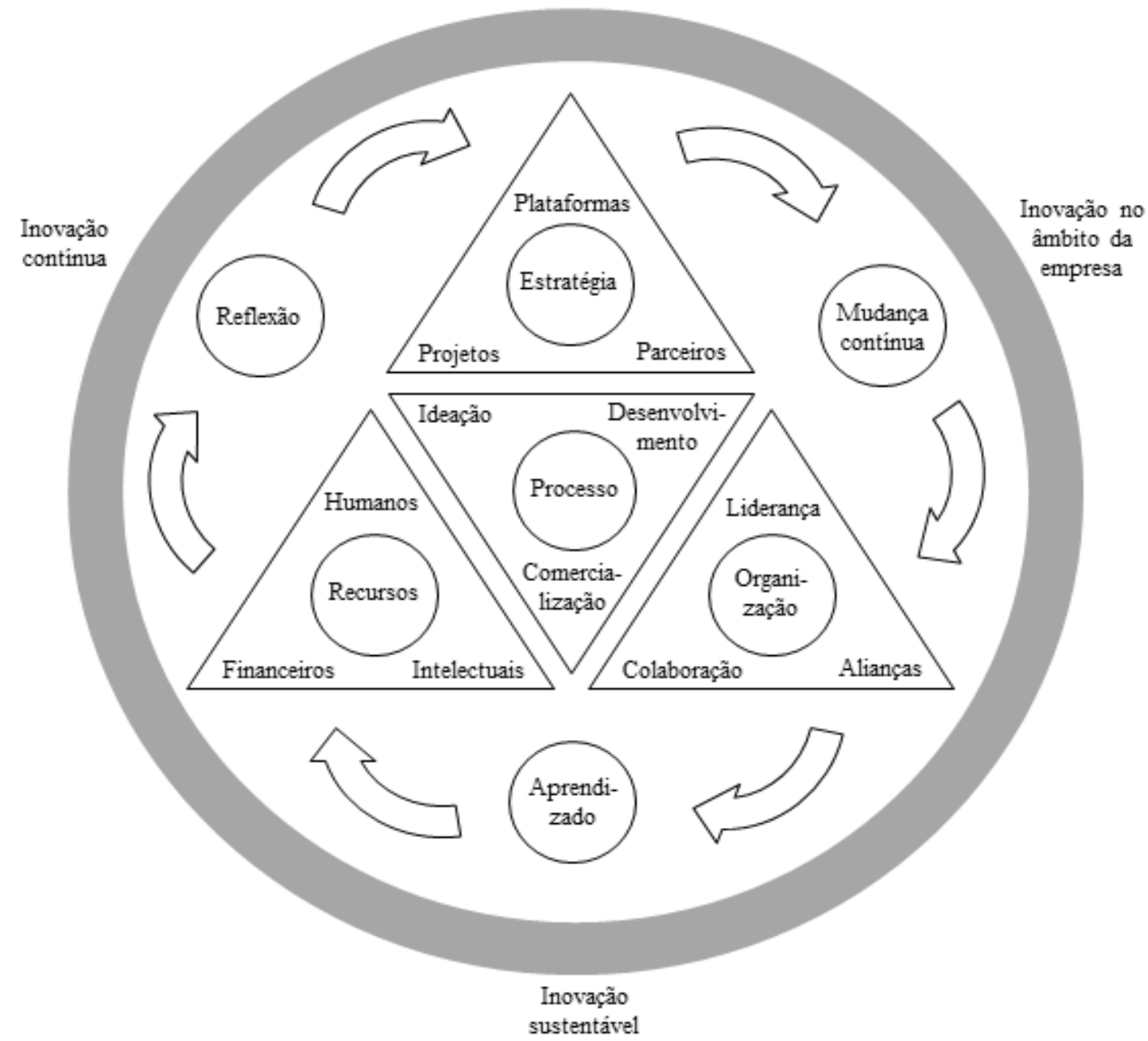

Ilustração 6 - Estrutura da inovação de geração mais avançada e de alto desempenho Fonte: adaptado de JONASH; SOMMERLATTE, 2001, p. 4

No vértice superior do modelo está representado o caminho da estratégia da inovação. A formulação da estratégia de inovação deve estar alinhada com a estratégia corporativa e é moldada pelas necessidades de inovação e tecnologia tanto da própria empresa, como da empresa ampliada, que inclui clientes, fornecedores e parceiros. Os autores recomendam fortemente o uso do conceito de plataformas. Originalmente este conceito fora empregado para definir estruturas comuns que serviam de base para o desenvolvimento de produtos afins, imprimindo maior eficiência e velocidade no lançamento para o mercado. Exemplo disto são os chassis de veículos que serviam de base para diferentes modelos.

Os autores extrapolaram este conceito de plataformas para abarcar tecnologias, competências ou aptidões chaves que fossem úteis no desenvolvimento de produtos e serviços. Quando 
plataformas não bastam para alavancar a inovação, a empresa deve recorrer às parcerias com especialistas (institutos de pesquisa, consultores e até concorrentes). Por fim, o portfólio de projetos da empresa deve explorar o potencial de longo prazo, mas também deve produzir resultados no curto prazo.

No centro da ilustração está representado o caminho do processo de inovação. Em contraposição ao modelo linear de primeira geração, no qual a inovação começava no departamento de P\&D e terminava com a saída do produto da linha de produção, os autores retrataram o processo como um complexo sistema de feedbacks envolvendo desde o nascimento da ideia, elaboração de protótipos, análise detalhada, até o lançamento para o mercado.

Os autores sugerem quatro indicações rumo à geração mais avançada. Em primeiro lugar, a empresa deve trocar informações continuamente com colaboradores (parceiros e aliados) bem como pesquisadores e acadêmicos em busca de novos horizontes tecnológicos, ela também deve acompanhar o movimento de seus concorrentes. A segunda indicação é quanto a integrar clientes e fornecedores ao processo. Em terceiro, deve-se ampliar a entrada de sistemas de inovação, dando maior ênfase nas fases iniciais como ideação e desenvolvimento de conceitos e sua triagem. Por fim, a adoção de plataformas e redes de inovação pode acelerar o ritmo das inovações.

O conceito de recursos de inovação não se refere apenas aos já tradicionais dados econômicofinanceiros, como despesas, projeções de orçamento ou inventário de instalações. Na geração mais avançada, o conceito de recursos é expandido para abranger também conhecimentos, tecnologias e competências existentes na empresa. $\mathrm{O}$ desafio dos gestores reside em aplicar o mesmo tratamento que dão à gestão de ativos tangíveis aos ativos intangíveis. Nestes últimos podem se revelar as maiores oportunidades para inovação dentro da empresa.

Para promover a inovação, as empresas devem estar organizadas de modo a serem altamente colaborativa e conectada em rede. A estrutura deve favorecer a comunicação em todas as direções. Ao conectar os colaboradores (internos e externos), são incentivadas as interações pessoais e o enriquecimento mútuo, fomentando as inovações. Três aspectos são considerados: liderança, integração das competências internas através de redes (colaboração interna), e estabelecimento de parcerias (cooperação externa). 
As empresas de geração mais avançada são um sistema de aprendizado dinâmico, baseado no conhecimento e comprometido com a inovação continua e sustentável. O sistema de gestão do conhecimento trabalha de forma a recolher, organizar e disponibilizar as informações de volta para todos.

\subsubsection{Modelo de Tidd; Bessant; Pavitt, 2001}

Tidd et al. (2008) propõe um processo de inovação que contempla três fases que, em maior ou menor grau, se manifesta em qualquer tipo de empresa. É de interesse de todas as empresas o crescimento, ou pelo menos, a sobrevivência. Por esse motivo, os autores entendem a inovação como uma atividade genérica. O processo de inovação compreende essencialmente as fases de busca, seleção e implementação, conforme a Ilustração 7. Ao longo deste ciclo, os autores apresentam a dimensão aprendizagem, que permite retroalimentar e melhorar a forma como este sistema ocorre.

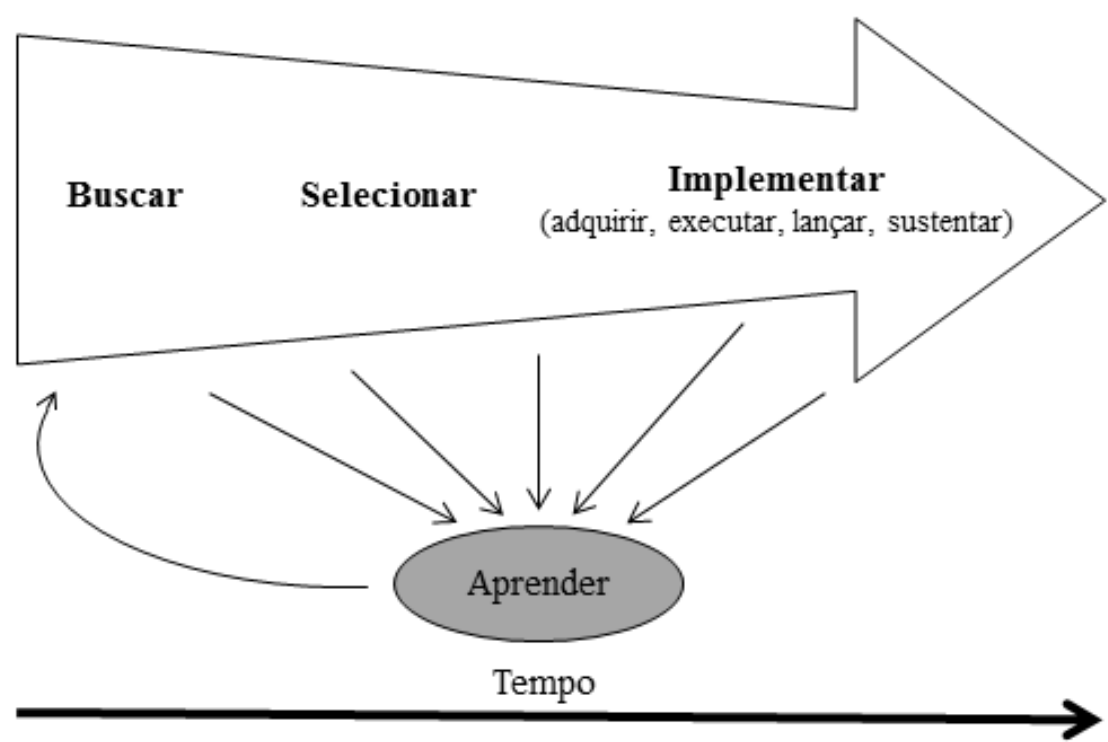

Ilustração 7 - Representação simplificada do processo de inovação Fonte: TID et al., 2008, p. 88

$\mathrm{Na}$ fase de busca, a empresa procede à análise do cenário, tanto interno como externo, procurando ameaças e oportunidades. A mudança pode surgir na forma de oportunidades tecnológicas, condições impostas pelo mercado, pressões de concorrentes, por exemplo. $\mathrm{Na}$ fase de seleção, a empresa deve decidir pelas oportunidades que serão priorizadas levando em 
conta a sua visão estratégica. A fase de implementação enseja a tradução do potencial da ideia inicial em um produto ou serviço que pode ser lançado ou processo que pode ser adotado. Esta fase do processo envolve aquisição de conhecimentos, habilidade para gerir e executar projetos em meio à incerteza, lançamento da inovação no mercado e como sustentar a adoção da inovação no longo prazo.

De modo análogo ao modelo apresentado anteriormente, a gestão da inovação para Tidd et al. posiciona o aprendizado ao longo do processo como aspecto fundamental. O estudo das organizações identifica receitas gerais ou um padrão geral do processo de inovação que contribui para o sucesso. Porém, cada empresa deve encontrar o seu próprio caminho e que deve ser coerente dentro de seu contexto.

Estas três fases (busca, seleção, implementação) que integram o processo de inovação são retroalimentadas pelo aprendizado obtido ao longo do caminho. Esse é traduzido em rotinas ou padrões de comportamento que, quando eficazes, ajudam a empresa a lidar com os desafios da inovação. Para que a gestão da inovação seja bem sucedida, não basta ser hábil em lidar apenas com "partes" do processo, a empresa deve ser boa em todas as dimensões. Os autores apresentam quatro grupos de comportamento: estratégia, relacionamentos externos eficazes, mecanismos de implementação e contexto organizacional apoiador; conforme pode ser observado na Ilustração 8.

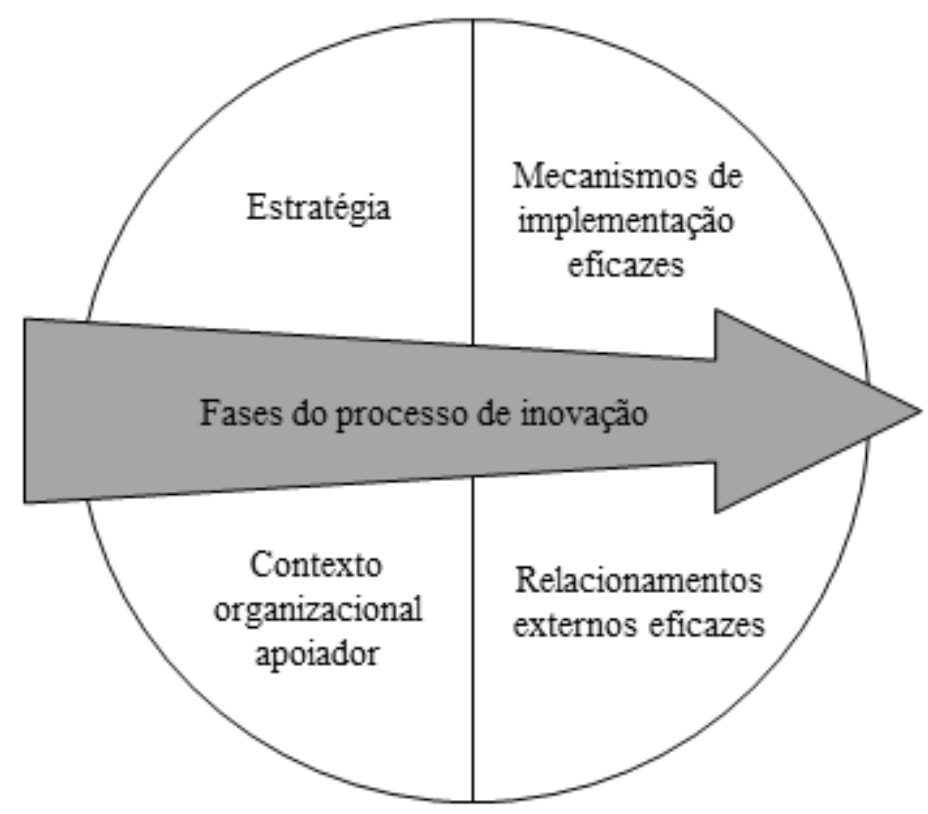

Ilustração 8 - Comportamentos ou rotinas para a inovação Fonte: TID et al., 2008, p. 578 
No âmbito da estratégia, os autores apontam para três ingredientes essenciais. O primeiro é o posicionamento da empresa por meio de seus produtos, processos, tecnologias e o contexto em que está inserida. O segundo ingrediente é quanto às trajetórias tecnológicas que a empresa pode seguir, dadas as competências acumuladas pela empresa. O ultimo é sobre os processos que integram a aprendizagem por todos os setores e níveis da empresa.

Os relacionamentos externos eficazes são fruto de uma aproximação com os atores envolvidos nas atividades da empresa. Estes podem ser o mercado, parceiros estratégicos, fornecedores, clientes e até concorrentes. A interação com o ambiente externo é uma oportunidade para a aprendizagem.

Através dos mecanismos de implementação eficazes é que as ideias ou oportunidades são transformadas em realidade. Em uma estrutura onde a tomada de decisões segue critérios claros, tais mecanismos são uteis para solucionar inevitáveis problemas que apareçam no decorrer dos projetos de inovação. Eles auxiliam a empresa quando é preciso centrar esforços no desenvolvimento de determinado produto ou processo, mas também são uteis para sinalizar quando é preciso frear.

Por fim, o contexto organizacional apoiador é o que permite às ideias surgirem e se transformarem efetivamente em inovações. É fundamental para a gestão da inovação que haja uma cultura voltada para o exercício da criatividade. As condições para que esta aconteça estão relacionadas com estruturas adequadas, organização do trabalho, treinamento e desenvolvimento, sistemas de reconhecimento e recompensa, comunicação interna.

\subsubsection{Modelo de Hansen e Birkinshaw, 2007}

Os autores Hansen e Birkinshaw (2007) propuseram um modelo que vê a inovação como uma cadeia de valor, compreendendo três fases principais: geração de ideias, conversão e difusão. Estas três fases abrange seis atividades críticas: colaboração interna, externa e entre unidades; seleção e desenvolvimento de ideias; e difusão pela empresa das ideias desenvolvidas. O modelo da cadeia de valor da inovação equivale a um fluxo integrado, onde ideias nascem e seguem em direção à implantação ou adoção pela empresa, conforme a Ilustração 9. Este 
modelo proporciona uma visão geral sobre onde os esforços de inovação estão sendo empregados. Assim, permite que os gargalos deste processo sejam corrigidos e, assim, a cadeia de valor da inovação é fortalecida.

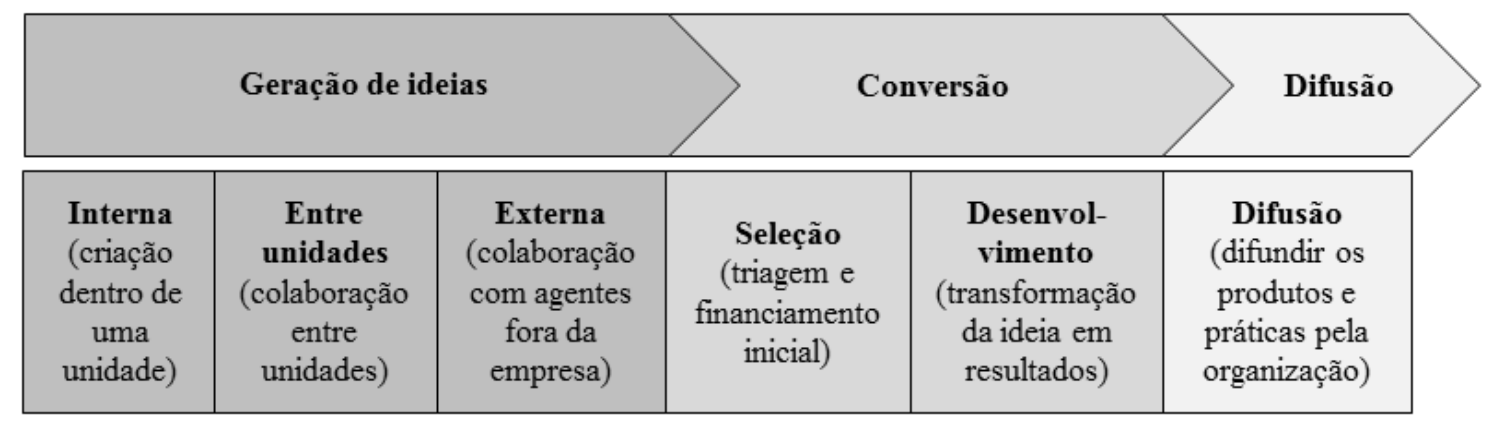

Ilustração 9 - Cadeia de valor da inovação

Fonte: adaptado de HANSEN; BIRKINSHAW, 2007, p. 4

A abordagem da inovação enquanto uma cadeia integrada permite que seus elos sejam avaliados como sendo fortes ou fracos. Segundo os autores, "sua capacidade de inovar é apenas tão boa quanto o elo mais fraco de sua cadeia de valor da inovação"4 (HANSEN; BIRKINSHAW, 2007, p. 1). Feita esta avaliação, as empresas devem prover as soluções mais adequadas a sua realidade, ao invés de importar soluções prontas de outras organizações. Neste caso, há o risco de as práticas de inovação genéricas então adotadas não serem as mais adequadas, prejudicando o desempenho através da cadeia de valor de inovação.

A fase de ideação é estruturada em torno de três atividades: geração interna, geração entre unidades e geração externa. Inicialmente, os gestores garimpam ideias dentro de seus departamentos, mas se deram conta de que ótimos conceitos podem surgir a partir da junção de fragmentos de ideias. Neste sentido, as atividades de geração de ideias entre unidades e a partir de fontes externas potencializam e enriquecem aquelas geradas internamente.

A segunda fase da cadeia de inovação compreende os processos de avaliação e seleção de ideias e mecanismos de financiamento dos projetos. Caso estes processos não sejam adequados, poderá tanto ocorrer interrupção ou excesso de ideias. No caso de interrupção, a consequência é a perda de oportunidades de criação de inovações, além da desmotivação das pessoas. O excesso, por outro lado, pode provocar desperdício de recursos, perda de foco e desalinhamento estratégico.

\footnotetext{
4 "Your capacity to innovate is only as good as the weakest link in your innovation value chain"
} 
Uma vez que as ideias foram desenvolvidas e resultaram em produtos ou novas práticas para a empresa, segue para a terceira fase, de difusão e propagação destas. Os autores ressaltam que, além do desafio da difusão de inovações junto aos canais e clientes, muitas vezes existem barreiras dentro das próprias organizações. Em empresas globais, por exemplo, a demora no lançamento de novos produtos ou serviços em um novo mercado pode abrir espaço para que concorrentes se antecipem e lancem produtos similares. Para empresas com problemas no processo de difusão, eles recomendam "evangelizadores". Seu papel seria o de aumentar a conscientização das pessoas a respeito da nova ideia e convencê-las a adotar o novo produto ou conceito de negócio.

A abordagem da pesquisa de Hansen e Birkinshaw (2007) é útil porque entende que a capacidade de uma empresa em inovar é apenas tão boa quanto o elo mais fraco na cadeia de valor da inovação. Uma vez identificado o gargalo do fluxo de inovações, a empresa deve empregar seus recursos e esforços para sanar os problemas deste elo. Feito isto, um novo gargalo irá emergir, e mais uma vez a empresa deverá voltar os olhos para o novo elo fraco identificado. De modo cumulativo, o processo de geração, conversão e difusão irá se tornar mais efetivo.

\subsubsection{Síntese teórica: gestão integrada da inovação}

As quarta e quinta gerações do processo de inovação retratada nos estudos de Rothweel (1994) tratam da gestão da inovação como sendo um modelo integrado, envolvendo as mais diversas dimensões de onde a inovação pode emergir. Foi a partir de meados dos anos 80, que a inovação deixa de ser retratada como um processo essencialmente linear e compartimentado. Este processo vem se consolidar na década seguinte, 1990, com a integração das organizações através de redes e destas com seus clientes. Os autores Neely e Hii (1998, p. 15) destacam a importância do trabalho em rede e da questão de localização geográfica para as atividades inovativas na empresa.

Também neste período são publicados estudos sobre modelos integrados da gestão da inovação. Os estudos de Jonash e Sommerlatte (2001) e Tidd et al. (2001), são referências no 
tocante a abordagem sistêmica do processo de inovação. O estudo de Hansen e Birkinshaw (2007) vem reforçar o caráter sistemático da inovação nas organizações. O Quadro 3, a seguir, sintetiza as principais características de cada um dos modelos, para então delinear quais serão as dimensões exploradas no levantamento de campo.

Quadro 3 - Características dos modelos de gestão da inovação

\begin{tabular}{|c|c|c|c|}
\hline Modelo & Autores & Características & $\begin{array}{c}\text { Dimensões, } \\
\text { processos, fases }\end{array}$ \\
\hline $\begin{array}{l}\text { "Geração } \\
\text { mais } \\
\text { avançada" }\end{array}$ & $\begin{array}{l}\text { Jonash; } \\
\text { Sommerlatte } \\
\quad(2001)\end{array}$ & $\begin{array}{l}\text { Modelo parte de dois princípios: a inovação } \\
\text { deve ser conduzida em toda a organização } \\
\text { (abordagem sistêmica); e alavancar } \\
\text { competências e tecnologias (através de } \\
\text { "plataformas"). Apresenta quatro dimensões } \\
\text { de onde pode emergir a inovação, permeadas } \\
\text { por uma quinta, a capacidade da organização } \\
\text { em aprender. }\end{array}$ & $\begin{array}{l}\text { - Estratégia de inovação } \\
\text { - Processo de inovação } \\
\text { - Recursos de inovação } \\
\text { - Organização da inovação } \\
\text { - Aprendizado }\end{array}$ \\
\hline $\begin{array}{l}\text { "Modelo } \\
\text { do } \\
\text { processo } \\
\text { de } \\
\text { inovação" }\end{array}$ & $\begin{array}{l}\text { Tidd; } \\
\text { Bessant; } \\
\text { Pavitt } \\
(2001)\end{array}$ & $\begin{array}{l}\text { A inovação como um processo genérico } \\
\text { (comum a qualquer empresa), associado a } \\
\text { sobrevivência e crescimento, composto por } \\
\text { três fases. A gestão da inovação eficaz } \\
\text { pressupõe um bom desempenho em quatro } \\
\text { comportamentos. }\end{array}$ & $\begin{array}{l}\text { - Processo de inovação: busca, } \\
\text { seleção e implementação } \\
\text { (permeadas pelo aprendizado) } \\
\text { - Estratégia } \\
\text { - Contexto organizacional } \\
\text { apoiador } \\
\text { - Mecanismos de implementação } \\
\text { - Relacionamento externo }\end{array}$ \\
\hline $\begin{array}{l}\text { "Cadeia } \\
\text { de valor } \\
\text { da } \\
\text { inovação" }\end{array}$ & $\begin{array}{l}\text { Hansen; } \\
\text { Birkinshaw } \\
\quad(2007)\end{array}$ & $\begin{array}{l}\text { Inovação como um fluxo integrado, que parte } \\
\text { da geração de ideias e segue rumo ao } \\
\text { mercado. Esta abordagem permite à empresa } \\
\text { identificar os gargalos do processo inovativo. }\end{array}$ & $\begin{array}{l}\text { - Processo de inovação: geração } \\
\text { de ideias, conversão e difusão }\end{array}$ \\
\hline
\end{tabular}

A partir do referencial teórico apresentado, se depreende que os modelos "Geração mais avançada" e "Modelo do processo de inovação" se assemelham porque descrevem o contexto no qual a gestão da inovação se manifesta. Em outras palavras, ambos os modelos retratam dimensões ("grupos de comportamentos" para Tidd et al., 2008, p. 577 ou "áreas fundamentais" para Jonash; Sommerlatte, 2001, p. 3) que devem estar envolvidas e ocorrendo de maneira harmônica para que a inovação aconteça. Apesar de cada modelo apresentar uma classificação própria das dimensões e seus limites não ser necessariamente iguais, de modo geral as dimensões em muito se sobrepõe ou se complementam: estratégia de inovação e estratégia; processo de inovação e mecanismos de implementação; recursos e organização da inovação com contexto organizacional apoiador e relacionamento externo; aprendizado e contexto organizacional apoiador. Em suma, estes dois modelos têm uma abordagem sistêmica da inovação. 
Já a similaridade entre o "Modelo do processo de inovação" e a "Cadeia de valor da inovação" reside no enfoque processual. Cada abordagem concorda que os desafio de inovar serão diferentes em cada empresa, ainda que atuem nos mesmos setores (HANSEN; BIRKINSHAW, 2007, p. 2; TIDD et al., 2008, p.89). No entanto, elas também concordam que há uma sequência subjacente a todas elas: busca ou geração de ideias; seleção ou conversão; implementação ou difusão. Em síntese, estes dois modelos entendem que a empresa deve praticar a inovação de maneira sistemática.

Ainda que haja inovações de sucesso como resultado do acaso (o que não seria sustentável ao longo do tempo), apenas pode-se dizer que a empresa está gerenciando a inovação quando os resultados alcançados forem decorrentes de um processo sistemático e sistêmico. Assim, o interesse deste estudo recai em avaliar o grau de maturidade da gestão e a relação com os resultados alcançados. Entendeu-se que deveriam ser analisadas cinco dimensões no contexto das empresas do APL Vale da Eletrônica, conforme Quadro 4.

Quadro 4 - Dimensões da gestão da inovação

\begin{tabular}{|c|l|}
\hline Dimensão & \multicolumn{1}{|c|}{ Características } \\
\hline Estratégia & $\begin{array}{l}\text { Analisa a empresa do ponto de vista de sua estratégia tecnológica e o alinhamento com a } \\
\text { estratégia do negócio em si. A inovação precisa estar alinhada à estratégia da empresa. }\end{array}$ \\
\hline $\begin{array}{c}\text { Processos } \\
\text { Internos }\end{array}$ & $\begin{array}{l}\text { Como as atividades empregadas na condução das operações internas à empresa estão } \\
\text { configuradas. A inovação pode ser alcançada através da revisão de suas rotinas, com o } \\
\text { objetivo de buscar maior eficiência, melhor produtividade, maior qualidade em seus } \\
\text { produtos e menor tempo de resposta ao ambiente. }\end{array}$ \\
\hline \multirow{2}{\text{Ambiente}}{$\begin{array}{l}\text { Eara lidar com um ambiente em contínua transformação, é imprescindível seu } \\
\text { monitoramento contínuo para que indícios de oportunidades e ameaças sejam } \\
\text { identificados. As empresas mais inovadoras adotam uma postura proativa em relação ao } \\
\text { ambiente onde operam, elas também operam em rede e possuem parcerias estabelecidas } \\
\text { com outros agentes. }\end{array}$} \\
\hline Organização \\
$\begin{array}{l}\text { Aqui se busca entender o modo como a empresa está organizada. Isto inclui sua estrutura } \\
\text { organizacional (representada pelo organograma da firma), mas também aborda aspectos } \\
\text { mais subjetivos como clima organizacional e comunicação interna. }\end{array}$ \\
\hline $\begin{array}{l}\text { A criação de uma cultura focada na inovação, em empresas menores, passa pelo papel do } \\
\text { líder, geralmente fundadores ou pessoas ligadas a ele. É analisada a questão da gestão do } \\
\text { conhecimento dentre da empresa, responsabilidade e autonomia dos funcionários, e } \\
\text { incentivos para a criatividade e inovação. }\end{array}$ \\
\hline
\end{tabular}




\section{METODOLOGIA DE PESQUISA}

Marconi e Lakatos (2006) concluem que "não há ciência sem o emprego de métodos científicos" (p. 83). Para as autoras, quando se fala em método na pesquisa científica, isto representa o conjunto de atividades sistemáticas e lógicas que permitem alcançar o objetivo proposto com uma maior segurança e economia.

Por vezes, o termo método se confunde com metodologia. Apesar desta discussão conceitual não resultar em maiores prejuízos, cabe aqui fazer esta distinção para darmos prosseguimento. Para Martins e Theóphilo (2009), utiliza-se a palavra metodologia para fazer referência a uma disciplina e ao seu objeto, que pode ser entendido como o estudo dos métodos. O seu objetivo é “[...] o aperfeiçoamento dos procedimentos e critérios utilizados na pesquisa." (2009, p. 37). Ao passo que, método, para os autores, pode ser entendido como os caminhos ou modos lógicos e racionais para se chegar a determinado objetivo. Nesta mesma linha, Vergara (2011) afirma que método é um caminho, uma lógica, uma forma de pensamento.

Basicamente, há três grandes métodos científicos de abordagem: a) hipotético-dedutivo; b) fenomenológico; e c) dialético (VERGARA, p. 3, 2011). De modo similar, para Martins e Theóphilo (2009) a classificação dos métodos científicos recaem basicamente em três categorias: a) abordagens empírico-positivistas; b) fenomenológica; e c) crítico-dialética (2009, p. 39). Ao dar prosseguimento em uma pesquisa científica, a escolha do método empregado irá depender do objeto de estudo, de sua natureza, de sua consolidação no campo do conhecimento e da amplitude e objetivos a serem perseguidos.

Se os métodos são procedimentos de raciocínio mais amplos, podemos entender que as técnicas são procedimentos mais restritos que se propõe a operacionalizar os métodos, mediante emprego de instrumentos adequados (SEVERINO, 2002). Compartilha desta visão o autor Silva (2003, p.39), que para evidenciar a diferença entre os termos relata que: "Podemos definir método como etapas dispostas ordenadamente para a investigação da verdade, no estudo de uma ciência para atingir determinada finalidade, e técnica como o modo de fazer de forma mais hábil, segura e perfeita alguma atividade, arte ou oficio." (SILVA, 2003, p. 39). Assim, podemos concluir que método é algo mais abrangente, ligado ao modo de se pensar, enquanto técnica é algo mais específico e está relacionada ao modo de execução. 
Antes de entrarmos na justificativa da escolha da técnica (ou estratégia), classificaremos o tipo de pesquisa. Segundo Vergara (2011, p. 41), há diversas taxonomias que têm o propósito de classificar o tipo de pesquisa. A autora apresenta dois critérios, classificação quanto aos fins e quantos aos meios.

Baseado no critério "quanto ao fim" adotado pela autora, este estudo pode ser classificado como essencialmente exploratório, mas também descritivo. Estudos exploratórios são realizados quando o conhecimento sobre determinado assunto é limitado, como é o caso de Gestão da Inovação em MPME atuantes em APLs. Já nos estudos descritivos, o foco recai em retratar características do fenômeno em estudo, podendo também estabelecer suas relações e, deste modo, servir de base para os estudos explicativos.

Na mesma linha, Sampieri et al. (2006, p. 103) inclui um novo tipo de pesquisa na taxonomia proposta por Vergara: a pesquisa correlacional. Este novo tipo estaria localizado entre a pesquisa descritiva e a explicativa: "Os estudos descritivos, em geral, fundamentam as pesquisas correlacionais, que, por sua vez, proporcionam informações para dar continuidade aos estudos explicativos [...]" (SAMPIERI et al., 2006, p. 98). Este estudo tem como objetivo identificar a relação entre duas ou mais variáveis ou conceitos, auxiliando portanto para explicar a estrutura de seu relacionamento em pesquisas futuras.

Segundo o critério "quanto ao meio" na taxonomia adotada por Vergara (2011), este estudo pode ser classificado como uma pesquisa bibliográfica e de campo. Bibliográfica porque o estudo será desenvolvido com base em material publicado em fontes acessíveis ao público em geral, como livros, artigos científicos e papers relativos ao campo de estudo. A partir desta pesquisa se construiu o Referencial Teórico (capítulo 2). Pesquisa de campo porque tratará de uma pesquisa empírica realizada diretamente onde ocorre o fenômeno, através da aplicação de questionários.

A definição de técnicas de pesquisa explicitada por Marconi e Lakatos (2006) coincide com a classificação "quanto aos meios" apresentada inicialmente. Para as autoras, "técnica é um conjunto de preceitos de que se serve uma ciência ou arte; é a habilidade para usar esses preceitos ou normas, a parte pratica.” (MARCONI; LAKATOS, 2006, p. 176). A técnica usada é pesquisa de campo, precedida por uma pesquisa bibliográfica sobre o tema em 
questão. Os autores Martins e Theóphilo (2009) dão o nome de "estratégias de pesquisa" o que fora classificado anteriormente como "técnicas de pesquisa" por Marconi e Lakatos (2006) e como "quanto aos meios" por Vergara (2011). Assim, a estratégia de pesquisa utilizada é pesquisa bibliográfica (MARTINS; THEÓPHILO, 2009, p. 54) seguida por levantamento (Ibid., p. 60).

Quanto ao enfoque, a pesquisa pode ser classificada como sendo qualitativa, quantitativa ou mista, que congrega as duas em um único estudo. A pesquisa qualitativa teve sua origem na Sociologia e Antropologia, onde objetivo final é compreender questões humanas e sociais complexas. A ênfase não repousa em fazer medições numéricas das variáveis envolvidas no fenômeno, mas sim em compreendê-lo sob uma perspectiva mais "holística", posto que considera o "todo" (SAMPIERI; COLLADO; LUCIO, 2006). É frequentemente recomendável em estudos exploratórios e que demandam a indução.

Pesquisas quantitativas têm sido muito utilizadas nas ciências chamadas "exatas", tais como física, química e biologia. A partir de coletas e medição de dados numéricos, procede-se a sua análise (usando técnicas estatísticas) para simplesmente descrever o fenômeno ou testar hipóteses elaboradas previamente. Está associada ao raciocínio dedutivo, onde parte-se de proposições gerais em direção às proposições mais particulares.

Para Sampieri, Collado e Lucio (2006, P. 05), não há um enfoque que seja intrinsecamente melhor que o outro, ambos são apenas diferentes em relação ao estudo do objeto. Os autores assumem que os enfoques são complementares, isto é, cada um exerce um papel especifico para entender o fenômeno e conduzir a solução da questão. A esta combinação dá-se o nome de triangulação.

Este estudo pretende responder uma questão de pesquisa proposta inicialmente e, assim, tentar verificar quais são as associações entre as dimensões da gestão da inovação com o desempenho inovativo das empresas, baseado nos dados obtidos no levantamento (survey). Assim, podemos defini-lo como uma pesquisa de caráter quantitativo. 


\subsection{Modelo conceitual}

Este estudo explora as relações supostamente existentes entre a gestão da inovação e o desempenho inovativo. No questionário apresentado às empresas, a estratégia adotada foi não perguntar diretamente se gerenciavam o processo de inovação. Em lugar disto, para cada dimensão da gestão da inovação abordada neste trabalho, foram feitas séries de perguntas a fim de se obter indiretamente uma resposta sobre práticas de gestão adotadas pela empresa respondente.

O referencial teórico acerca de gestão da inovação que fora levantado no Capítulo 2 serviu de subsídio para a construção do modelo conceitual desta pesquisa, que está representado graficamente abaixo.

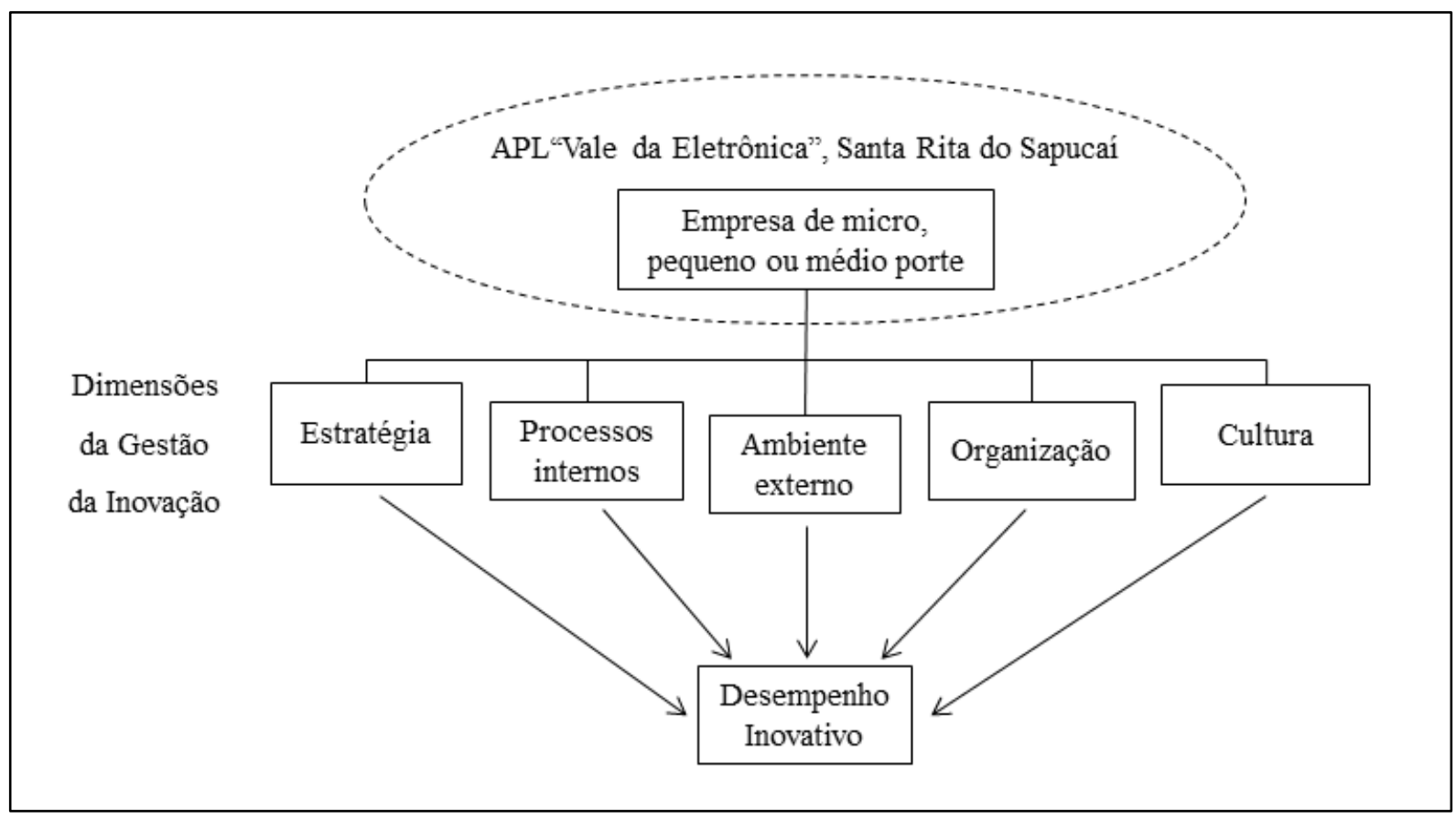

Ilustração 10 - Modelo conceitual da pesquisa 


\subsection{Universo e amostra}

Para tratarmos de amostra e universo, faz-se necessário definir qual é a unidade de análise $a$ priori. Feito isto, podemos partir para a delimitação da população ou universo (SAMPIERI et al., 2006). Neste estudo, a unidade de análise foi definida como a empresa industrial que opera no segmento de eletrônicos e TIC, pertencentes ao APL Vale da Eletrônica e que possuem ao menos um ano completo de existência.

O universo pode ser entendido como o conjunto de elementos (por exemplo: empresas, produtos, indivíduos) que possuem as características que serão objeto de estudo (VERGARA, 2011, p. 46). Segundo levantamento de 2010 conduzido pelo Instituto Euvaldo Lodi de Minas Gerais (IEL Minas), o universo desta pesquisa compreende 158 empresas do setor de eletrônicos localizadas no munícipio. A informação prestada pelo SINDVEL é de que 142 empresas constituem o APL Vale da Eletrônica.

A amostra é o subgrupo da população que se pretende estudar, e pressupõe-se que a amostra seja estatisticamente representativa. Nossa amostra segue um método de abordagem não probabilística, isto é, não depende da probabilidade aleatória para ser escolhida. Há um procedimento para que os indivíduos componham a amostra (SAMPIERI et al., 2006, p. 273). Especificamente, a amostra é do tipo por acessibilidade (VERGARA, 2011, p. 47), intencional (MARTINS; THEÓFILO, 2009, p. 123) ou por conveniência (HAIR; BABIN; MONEY; SAMOUEL, 2005, P.247). Sampieri et al. (2006) alerta que testes estatísticos em amostras deste tipo possuem um menor valor por serem generalizados para uma população que não foi considerada em seus parâmetros e nem em seus elementos (p. 271).

O tamanho final da amostra compreende 41 empresas. Esta totalidade representa as empresas que aderiram ao projeto NAGIVALE, explicado no primeiro capítulo. Não houve exclusão de questionários, uma vez que, durante a coleta de dados, aqueles que se mostravam anômalos ou duvidosos eram coletados novamente. Visto que foram encontradas duas informações divergentes, porém aproximadas, sobre o tamanho do universo $\left(\mathrm{N}_{\mathrm{SINDVEL}}=142\right.$ e $\left.\mathrm{N}_{\mathrm{IEL}}=158\right)$, a amostra válida $(n=41)$ representa cerca de $27,3 \%$ da população. 


\subsection{Questionários e procedimento de coletas de dados}

A coleta de dados para a pesquisa se deu através de aplicação de questionários (survey) assistidos pelos Agentes de Inovação do projeto NAGIVALE. Após coletados, os dados foram transcritos para um questionário online (www.surveygizmo.com), onde as respostas já tabuladas estariam disponíveis para uma análise preliminar e, eventualmente, poderia ser solicitado refazer a coleta. Às empresas assegurou-se que os dados apenas seriam expostos de forma agregada, sem qualquer menção feita de forma individual.

Antes de os questionários serem aplicados, foram realizadas duas diferentes fases de prétestes para se verificar e sanar possíveis falhas e inconsistências. A primeira fase consistiu em apresentar o questionário a dez professores universitários da FAI. O instrumento de coleta foi reformulado e, desta vez, apresentado a duas empresas com características semelhantes ao da população (HAIR; BABIN; MONEY; SAMOUEL, 2005, P.230). O intuito de submeter o instrumento de coleta a duas fases de pré-testes foi aumentar sua confiabilidade e validade, e assim garantir que o questionário medisse consistentemente aquilo que se deseja (MARTINS; THEÓPHILO, 2009, p. 94).

Neely e Hii (1998, p. 40) destacam que não há uma maneira ótima para se medir inovação e desempenho, as métricas para avaliar uma organização não necessariamente servirão para outra empresa. Por isso, o questionário deve ser orientado sob uma perspectiva prática e percorrer uma série de medições sob uma perspectiva balanceada. Junto com patentes, as surveys de inovação são os meios mais difundidos para se coletar informações sobre as atividades inovativas nas empresas. Ainda segundo os autores (1998, p. 41), as surveys sobre inovação podem ter duas abordagens: a primeira coleta informações analisando a inovação individualmente (object approach), a segunda analisa informações no nível da empresa (subject approach). Esta pesquisa adota a segunda abordagem.

A survey é indicada quando se almeja responder perguntas de pesquisa do tipo "o que?", "por que?”, “como?” e “quanto?” (FREITAS et al, 1999, p.105), isto é, quando o foco é descrever ou explicar aquilo que está acontecendo. Este é um procedimento usado para a coleta de dados primários e geralmente são usadas para se obter dados quantitativos de uma grande amostra de indivíduos (HAIR et al., 2005, p. 157). A coleta para esta pesquisa aconteceu em 
apenas um dado momento no tempo, daí ser considerada como transversal (HAIR et al., 2005, p. 87).

O questionário utilizado nesta pesquisa foi dividido em três seções. A primeira seção trata da caracterização da unidade de análise, neste caso, a empresa. Foram coletados dados que descrevem as empresas participantes do projeto, tais como faturamento, número de funcionários, idade, dentre outros. Para Hair et al (2005, p. 97), estes dados são objetivos, isto é, não envolvem opinião ou percepção dos respondentes.

A segunda seção chama-se Gestão Integrada da Inovação e visa medir as cinco dimensões (variáveis independentes) exploradas no referencial teórico (capítulo 2), além da caracterização das pessoas que a responderam. São elas as dimensões: estratégia, processos internos, ambiente externo, organização e cultura. De acordo com Hair et al, esta seção se caracteriza como dados subjetivos: "são a opinião de um funcionário a respeito desta característica.” (2005, p.98). Quando são agregados, estes dados tornam-se relativamente mais objetivos, pois não depende da opinião de uma única pessoa. Com vistas a reduzir a parcialidade das respostas e a limitação natural que cada pessoa sobre a empresa, foram coletados dados de respondentes de diferentes departamentos. O número de pessoas entrevistadas foi definido de acordo com o número de funcionários, respeitando as seguintes faixas:

Quadro 5 - Faixas de respondentes

\begin{tabular}{|l|l|}
\hline $\begin{array}{c}\text { Número de pessoas ocupadas } \\
\text { em tempo integral }\end{array}$ & $\begin{array}{c}\text { Quantidade de } \\
\text { respondentes }\end{array}$ \\
\hline Até 30 funcionários & 3 respondentes \\
\hline De 31 à 50 funcionários & 5 respondentes \\
\hline Acima de 50 funcionários & 7 respondentes \\
\hline
\end{tabular}

A terceira e última seção visa medir o constructo do desempenho da empresa em termos de inovações alcançadas, o chamado Desempenho Inovativo. Nas duas últimas seções, foram utilizadas questões do tipo Likert onde são apresentadas afirmações e os respondentes devem indicar seu nível de concordância (SAMPIERI, 2006, p. 306). Estas afirmações servem para medir conceitos como atitudes, percepções, sentimentos, opiniões e valores (HAIR et al.. 2005, p. 184). 
A princípio, esta escala de medida é considerada como uma variável ordinal (não métrica), o que por sua vez permitiria apenas que fossem feitas análises não paramétricas. Nesta escala, a princípio, não se poderia assumir que os intervalos entre os valores sejam iguais. Não obstante, no meio acadêmico é comum que sejam tratados como tal. Deste modo, as análises são facilitadas e medida Likert é assumida como sendo uma variável intervalar (VILHENA; RIBEIRO; MENDONÇA, 2008, p. 2), o que permitira a aplicação de técnicas paramétricas de análise, como as utilizadas neste estudo. Para Pell (2005 apud VILHENA; RIBEIRO; MENDONÇA, 2008, p. 2), basta que a amostra tenha distribuição normal e tamanho adequado para que se possa aplicar técnicas paramétricas a dados não-paramétricos. Compartilham desta visão Martins e Theóphilo (2009, p. 112) quando dizem que, apesar de escalas de atitudes não serem verdadeiramente intervalar, são tratadas como tal, possibilitando a aplicação de todas as estatísticas paramétricas comuns.

A escala Likert adotada varia de um a cinco pontos, onde o grau da variável é maior quanto maior a pontuação, isto é, o efeito observado do item em questão é mais intenso. O espectro de resposta parte da discordância total (um ponto) até a concordância total (cinco pontos).

Quando da transcrição das respostas pelos Agentes de Inovação para a internet, todas as respostas foram automaticamente codificadas pelo software. Assim, os dados foram transformados em símbolos (codificados e tabulados) para que pudessem ser manipulados de forma agregada (MARCONI; LAKATOS, 2006, p. 169).

\subsection{Análise descritiva da amostra}

A primeira análise a ser feita em cima da matriz de dados será a descritiva. Este tipo de análise serve como um primeiro guia ao pesquisador à medida que fornece informações sobre a qualidade dos dados e indicam, caso existam, algumas tendências (BOTTER et al., 1996, p. 11).

Algumas técnicas utilizadas nesta análise inicial foram distribuição de frequências, medidas de tendência central (ou de posição) e de dispersão (variabilidade). Também serão utilizadas a assimetria e curtose para visualizar quão próximo os dados chegam de uma distribuição 
normal (SAMPIERI et al., 2006, p. 433). Neste ponto, serão apresentadas as informações sobre as empresas, que são a unidade de análise desta pesquisa, quanto os respondentes, isto é, as pessoas que expressaram suas percepções quanto às variáveis pesquisadas.

Para melhor visualização e compreensão dos dados, os mesmos serão apresentados em gráficos e tabelas. Para isto, será utilizado o software Microsoft Excel 2010.

\subsection{Análise Multivariada}

A análise univariada estuda comportamentos e distribuições de uma única variável. Já à análise bivariada interessa estudar associações e correlações e elaborar análises de variância relativas a duas variáveis simultaneamente (FÁVERO et al., 2009, p. 5). Na prática da pesquisa quantitativa, muitas vezes o tema de estudo, por sua complexidade, envolve muitas variáveis de uma só vez. Segundo Sampieri, “os métodos de análise multivariada são aqueles em que se analisa a relação entre diversas variáveis independentes e pelos menos uma dependente.” (2006, p. 480). A diferença entre os três tipos de análise pode ser observada na ilustração 11.

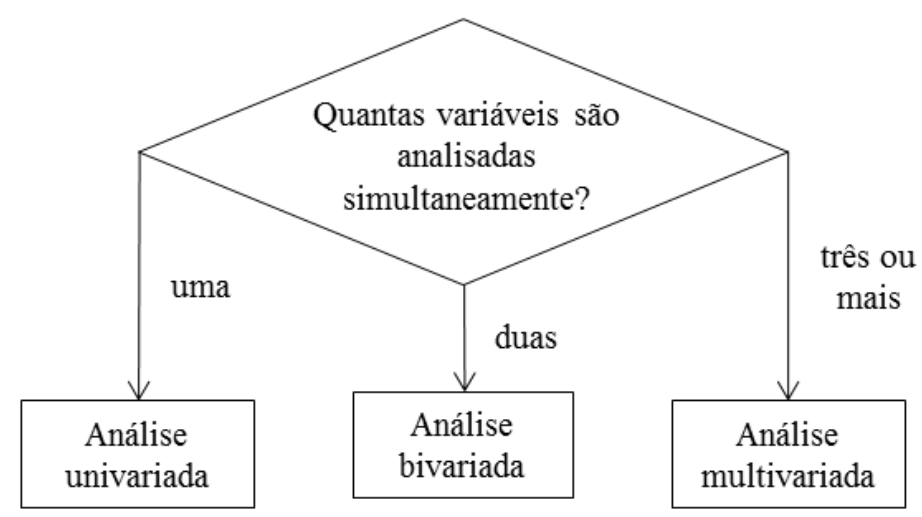

Ilustração 11 - Tipos de análise de dados em função do número de variáveis Fonte: FÁVERO et al., 2009, p. 5

No presente estudo, além das técnicas estatísticas descritivas, também será utilizada a análise multivariada. O seu uso se justifica pelo próprio objetivo do problema de pesquisa ser mais complexo, à medida que envolve uma quantidade maior de variáveis. A escolha de qual técnica é mais adequada irá depender do tipo de relação examinada, da quantidade de variáveis dependentes e do tipo de escala utilizada (HAIR et al., 2006, p. 35). 
O tipo de relação que se dá entre as variáveis pode ser classificado em dois grupos: técnicas de dependência e técnica de interdependência. A primeira refere-se às relações onde uma ou mais variáveis (dependentes) são explicadas ou preditas em função do comportamento de outras (independentes) (FÁVERO et al., 2009, p. 7). A segunda é assim chamada quando não há uma única variável definida como sendo dependente, isto é, todas as variáveis no contexto são analisadas em conjunto (HAIR et al., 2005, p. 319 e 388).

A técnica de análise multivariada utilizada é análise de regressão múltipla (HAIR et. al., 2005, p.435). O uso desta justifica-se pois a teoria aponta que há associação entre Desempenho Inovativo e Gestão da Inovação. Ademais, há apenas uma variável dependente em questão. Por fim, os dados coletados que comporão o input da análise apresentam comportamento de variável intervalar, ou seja, são dados paramétricos. A justificativa pela escolha pode ser acompanhada na Ilustração 12.

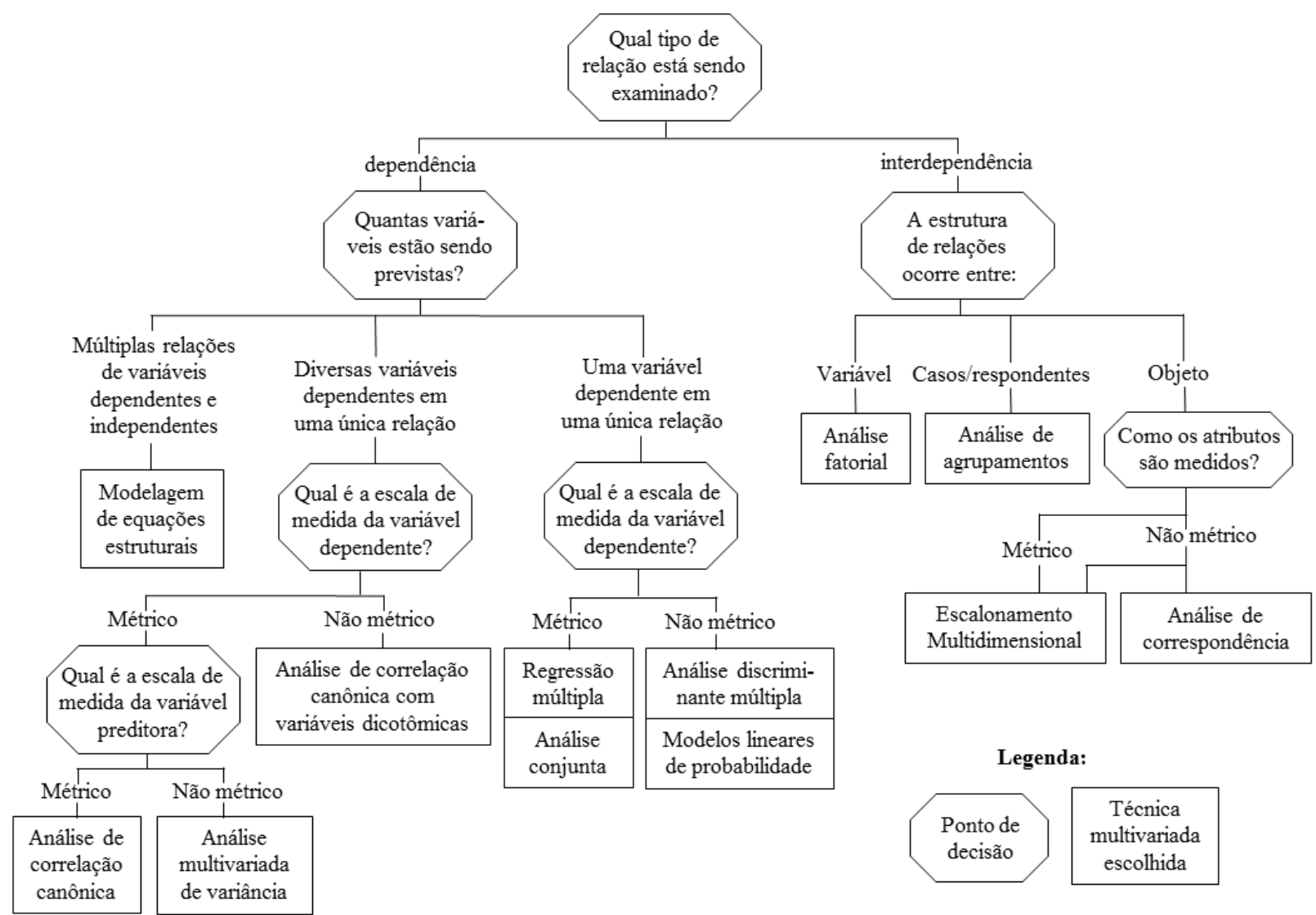

Ilustração 12 - Seleção de uma técnica multivariada Fonte: HAIR et al., 2005, p. 36-37 
A análise de regressão múltipla pode ser usada quando se deseja a criação de modelos que expliquem o impacto produzido por um grupo de variáveis sobre o comportamento de outra variável (FÁVERO, 2009, p. 7). Isto pode ser observado de modo esquemático na Ilustração 13.

$$
\begin{array}{cc}
\text { Variáveis } & \begin{array}{c}
\text { Variável } \\
\text { dependente }
\end{array}
\end{array}
$$

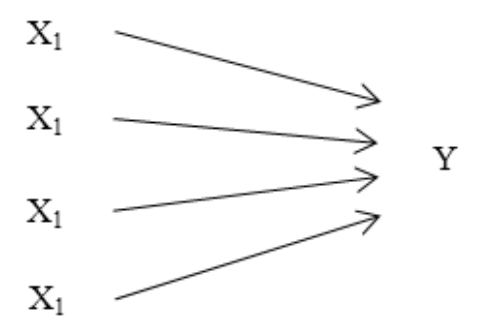

Ilustração 13 - Esquema de regressão múltipla Fonte: SAMPIERI et al., 2006, p. 480

Dada sua maior complexidade, a análise multivariada requer o uso de computadores e pacotes estatísticos para realizar os cálculos necessários. No tratamento e análise dos dados nesta pesquisa será utilizado o software estatístico IBM SPSS Statistics (Statistical Package for the Social Sciences) em sua versão PASW Statistics 17.0.

\subsubsection{Análise de regressão múltipla}

As técnicas estatísticas de análise multivariada têm pressupostos intrínsecos que devem ser atendidos. No caso de essas premissas não serem atendidas, os resultados da pesquisa podem ser afetados de forma negativa. Em última instância, o pesquisador pode ser induzido a defender um modelo que não condiz com a realidade (HAIR et al, 2005).

Os pressupostos subjacentes à técnica de análise de regressão múltipla deverão ser testados em dois momentos distintos. $\mathrm{O}$ primeiro condiz com a fase imediatamente posterior à coleta de dados, quando cada variável será examinada individualmente. O próprio software estatístico oferece ferramentas para identificar problemas, tais como testes, gráficos e diagramas. Caso alguma premissa não seja atendida, o pesquisador pode proceder à 
transformação dos dados. Nesta fase, as suposições que deveram ser atendidas são (HAIR et al., 2005, p. 76):

a) Normalidade;

b) Homocedasticidade;

c) Ausência de erros correlacionados; e

d) Linearidade.

O segundo momento em que se deve verificar o atendimento às premissas ocorrerá quando o modelo de regressão já estiver sido estimado. Uma vez determinada a variável estatística, através do cálculo de coeficientes de regressão, ela atuará coletivamente para predizer o comportamento da variável independente. As suposições a serem atendidas são (HAIR et al., 2005, p. 153):

a) Linearidade do fenômeno medido;

b) Variância constante dos termos de erro;

c) Independência dos termos de erro; e

d) Normalidade da distribuição dos termos de erro.

\subsection{Construção das variáveis}

Segundo Martins e Theóphilo (2009, p. 17 e 35), um constructo é a operacionalização de abstrações usadas pelos cientistas sociais em suas teorias. O constructo é a ponte que liga o plano das ideias e teorias com o mundo real, e para tal conta com a observação e mensuração de variáveis e fenômenos. Em outras palavras, constructo pode ser entendido como uma variável (ou ainda uma combinação delas) que representam empiricamente um conceito, obtido de determinado marco teórico.

A operacionalização desta pesquisa passa por medir seis constructos (ou variáveis). Para medir cada constructo, foram utilizadas escalas de itens múltiplos. Segundo Hair et al.(2005, p. 195), "uma escala de itens múltiplos consiste de uma série de afirmações (itens ou indicadores) individuais estritamente relacionadas cujas respostas são combinadas em escore composto [...] usado para medir um conceito". Cada dimensão da gestão integrada da inovação e mais o desempenho inovativo será composto por, no mínimo, oito itens para poder 
mensurar o constructo. A escala utilizada em todos eles será a escala Likert de cinco pontos e o questionário completo referente às variáveis se encontra no Apêndice 1 .

Elaborar novas escalas para medir conceitos ou constructos demanda muito tempo e esforço dos pesquisadores, à medida que é preciso garantir confiabilidade e validade. Por isso, é comum adotar escalas já utilizadas previamente, que podem ser replicadas exatamente como foram elaboradas, ou com algumas pequenas modificações no instrumento original, desde que não alterem sua essência (HAIR et al, 2005, p. 205). Aqui, foram utilizadas escalas extraídas de questionários já existentes, mas com algumas modificações para adequação à realidade das empresas.

Para Sampieri et al. (2006, p. 287), todo instrumento de coleta deve reunir dois requisitos, confiabilidade e validade. A confiabilidade é a medida onde a repetição da aplicação do instrumento de coleta ao mesmo indivíduo ou objeto, gera resultados similares. A confiabilidade pode ser medida através do cálculo do Alpha de Cronbach. Este é um modelo de consistência interna e se baseia na correlação média entre os itens. O valor deste índice oscila entre 0 e 1 , sendo que quanto mais perto de 1 maior a confiabilidade do instrumento. A validade refere-se ao grau em que um instrumento de coleta consegue medir aquilo à que se propõe medir inicialmente. Neste estudo, procurou-se atingir a validade do instrumento de coleta a partir de uma revisão da literatura e da utilização de questões presentes em estudos anteriores. 


\subsubsection{Variáveis independentes}

As variáveis independentes, na quantidade de cinco, foram construídas com base na revisão teórica, conforme consta no Capítulo 2.

Estratégia: Analisa a empresa do ponto de vista de sua estratégia tecnológica e o alinhamento com a estratégia do negócio em si. A inovação precisa estar alinhada à estratégia da empresa.

Quadro 6 - Variáveis para medir o constructo Estratégia
\begin{tabular}{|l|c|}
\hline \multicolumn{1}{|c|}{ Item } & Tipo de Escala \\
\hline ES13. As pessoas tem uma ideia clara de como a inovação pode nos ajudar a competir. & Likert de 5 pontos \\
\hline $\begin{array}{l}\text { ES14. Nossa estratégia de inovação é expressa de maneira clara; assim, todos } \\
\text { conhecem as metas de melhoria. }\end{array}$ & Likert de 5 pontos \\
\hline $\begin{array}{l}\text { ES15. As pessoas sabem qual é a nossa competência característica, isto é, aquilo que } \\
\text { nos proporciona uma vantagem competitiva. }\end{array}$ & Likert de 5 pontos \\
\hline $\begin{array}{l}\text { ES18. Nossa equipe tem uma visão clara e disseminada sobre como a empresa se } \\
\text { desenvolverá por meio da inovação. }\end{array}$ & Likert de 5 pontos \\
\hline ES19. Existem comprometimento e suporte da alta gestão para promover inovação. & Likert de 5 pontos \\
\hline $\begin{array}{l}\text { ES21. Existe uma ligação clara entre os projetos de inovação que realizamos e a } \\
\text { estratégia geral do negócio. }\end{array}$ & Likert de 5 pontos \\
\hline
\end{tabular}

Processos Internos: Como as atividades empregadas na condução das operações internas à empresa estão configuradas. A inovação pode ser alcançada através da revisão de suas rotinas, com o objetivo de buscar maior eficiência, melhor produtividade, maior qualidade em seus produtos e menor tempo de resposta ao ambiente.

Quadro 7 - Variáveis para medir o constructo Processos Internos

\begin{tabular}{|l|c|}
\hline \multicolumn{1}{|c|}{ Item } & Tipo de Escala \\
\hline $\begin{array}{l}\text { PI22. Há processos apropriados que nos ajudam a gerenciar o desenvolvimento de um } \\
\text { novo produto, de maneira eficaz, desde a ideia ate o lançamento. }\end{array}$ & Likert de 5 pontos \\
\hline $\begin{array}{l}\text { PI23. Nossos projetos de inovação geralmente são realizados no prazo e dentro do } \\
\text { orçamento. }\end{array}$ & Likert de 5 pontos \\
\hline $\begin{array}{l}\text { PI24. Possuímos mecanismos eficazes para nos assegurar de que todos (e não apenas o } \\
\text { setor de marketing) compreendam as necessidades do cliente. }\end{array}$ & Likert de 5 pontos \\
\hline $\begin{array}{l}\text { PI26. Pesquisamos sistematicamente ideias de novos produtos (por exemplo, através } \\
\text { de: feiras, missões, revistas especializadas, congressos, etc). }\end{array}$ & Likert de 5 pontos \\
\hline PI28. Temos um sistema claro para escolha de projetos de inovação. & Likert de 5 pontos \\
\hline $\begin{array}{l}\text { PI42. As pessoas estão envolvidas com sugestão de ideias para melhorias dos produtos } \\
\text { ou processos. }\end{array}$ & Likert de 5 pontos \\
\hline
\end{tabular}


Ambiente Externo: para lidar com um ambiente em contínua transformação, é imprescindível seu monitoramento contínuo para que indícios de oportunidades e ameaças sejam identificados. As empresas mais inovadoras adotam uma postura proativa em relação ao ambiente onde operam, elas também operam em rede e possuem parcerias estabelecidas com outros agentes.

Quadro 8 - Variáveis para medir o constructo Ambiente Externo

\begin{tabular}{|l|l|}
\hline \multicolumn{1}{|c|}{ Item } & Tipo de Escala \\
\hline $\begin{array}{l}\text { AE54. Há uma grande flexibilidade da organização para responder às ações dos } \\
\text { concorrentes. }\end{array}$ & Likert de 5 pontos \\
\hline $\begin{array}{l}\text { AE55. Há uma grande flexibilidade da organização para responder às ações dos } \\
\text { fornecedores. }\end{array}$ & Likert de 5 pontos \\
\hline $\begin{array}{l}\text { AE56. Há uma grande habilidade da organização para captar e compreender } \\
\text { comportamentos, tendências e atitudes dos clientes. }\end{array}$ & Likert de 5 pontos \\
\hline $\begin{array}{l}\text { AE57. Há uma grande capacidade da organização em acompanhar e entender as ações } \\
\text { das demais instituições (exemplos de outras instituições: agências regulatórias, de } \\
\text { fomento, de exportação/importação etc, sindicatos, associações de classe, dentre } \\
\text { outras). }\end{array}$ & Likert de 5 pontos \\
\hline
\end{tabular}

Organização: aqui se busca entender o modo como a empresa está organizada. Isto inclui sua estrutura organizacional (representada pelo organograma da firma), mas também aborda aspectos mais subjetivos como clima organizacional e comunicação interna.

Quadro 9 - Variáveis para medir o constructo Organização

\begin{tabular}{|l|c|}
\hline \multicolumn{1}{|c|}{ Item } & \multicolumn{1}{|c|}{ Tipo de Escala } \\
\hline O41. As pessoas trabalham bem em conjunto além dos limites departamentais. & Likert de 5 pontos \\
\hline $\begin{array}{l}\text { O45. Possuímos equipes/áreas com claras responsabilidades e que se dedicam para a } \\
\text { condução de diversos tipos de inovação. }\end{array}$ & Likert de 5 pontos \\
\hline $\begin{array}{l}\text { O46. O modo pelo qual a empresa está estruturada permite que decisões sejam } \\
\text { tomadas rapidamente. }\end{array}$ & Likert de 5 pontos \\
\hline $\begin{array}{l}\text { O47. A comunicação é eficaz e funciona bem em todas as direções da organização, isto } \\
\text { é, de cima para baixo, de baixo para cima e diagonalmente entre as áreas. }\end{array}$ & Likert de 5 pontos \\
\hline $\begin{array}{l}\text { O52. A estrutura organizacional é flexível e adequada para encaminhar projetos } \\
\text { inovadores. }\end{array}$ & Likert de 5 pontos \\
\hline O53. Há uma forte integração entre as diversas áreas da empresa. & Likert de 5 pontos \\
\hline
\end{tabular}

Cultura: a criação de uma cultura focada na inovação, em empresas menores, passa pelo papel do líder, geralmente fundadores ou pessoas ligadas a ele. É analisada a questão da gestão do conhecimento dentre da empresa, responsabilidade e autonomia dos funcionários, e incentivos para a criatividade e inovação. 
Quadro 10 - Variáveis para medir o constructo Cultura

\begin{tabular}{|l|c|}
\hline \multicolumn{1}{|c|}{ Item } & Tipo de Escala \\
\hline C49. Nosso sistema de reconhecimento/recompensa favorece a ocorrência da inovação. & Likert de 5 pontos \\
\hline $\begin{array}{l}\text { C58. Existe um clima de apoio para novas ideias. Em outras palavras, nossos } \\
\text { funcionários sentem que a alta administração apoia a criatividade e permitem que as } \\
\text { novas ideias sejam transformadas em realidade. }\end{array}$ & Likert de 5 pontos \\
\hline C59. Há um forte comprometimento com treinamento e desenvolvimento de pessoas. & Likert de 5 pontos \\
\hline C72. Aqui, as pessoas são estimuladas a aprender de forma contínua. & Likert de 5 pontos \\
\hline $\begin{array}{l}\text { C73. Pequenos erros e falhas são tratados como parte integrante do processo de } \\
\text { aprendizado. }\end{array}$ & Likert de 5 pontos \\
\hline $\begin{array}{l}\text { C74. A empresa oferece aos funcionários uma parte do tempo e recursos para que } \\
\text { dediquem a atividades de pesquisa, geração de ideias e de conceitos e inovação de um } \\
\text { modo geral. }\end{array}$ & Likert de 5 pontos \\
\hline
\end{tabular}

\subsubsection{Variável dependente}

O estudo conta com apenas uma variável dependente, chamada Desempenho Inovativo. Esta variável seria é o reflexo ou resultado de como as outras cinco dimensões que compõe a gestão da inovação estão integradas. O questionário coletou dados referentes aos três anos anteriores (2009 a 2011) ao momento da aplicação do mesmo.

Quadro 11 - Variáveis para medir o constructo Desempenho Inovativo

\begin{tabular}{|l|c|}
\hline \multicolumn{1}{|c|}{ Item } & Tipo de Escala \\
\hline $\begin{array}{l}\text { DI17. Nos últimos três anos (2009-2011), produzimos inovações que melhoraram a } \\
\text { qualidade dos bens ou serviços. }\end{array}$ & Likert de 5 pontos \\
\hline $\begin{array}{l}\text { DI18. Nos últimos três anos (2009-2011), realizamos inovações que ampliaram a gama } \\
\text { de bens ou serviços ofertados. }\end{array}$ & Likert de 5 pontos \\
\hline $\begin{array}{l}\text { DI20. Nos últimos três anos (2009-2011), criamos inovações que ampliaram a } \\
\text { participação da empresa no mercado. }\end{array}$ & Likert de 5 pontos \\
\hline $\begin{array}{l}\text { DI21. Nos últimos três anos (2009-2011), as inovações que realizamos permitiram } \\
\text { abrir novos mercados. }\end{array}$ & Likert de 5 pontos \\
\hline $\begin{array}{l}\text { DI24. Nos últimos três anos (2009-2011), as inovações de nossa empresa permitiu } \\
\text { reduzir os custos de produção/serviços prestados. }\end{array}$ & Likert de 5 pontos \\
\hline
\end{tabular}




\section{ANÁLISE E DISCUSSÃO DOS RESULTADOS OBSERVADOS}

\subsection{Análise descritiva da amostra}

Devido ao compromisso de confidencialidade dos dados fornecidos pelos entrevistados, serão apenas apresentadas de maneira agregada as caracterizações de respondentes e de empresas pertencentes à amostra.

\subsubsection{Caracterização dos respondentes}

Ao final de cerca de três meses de coleta, foram reunidos questionários relativos a 160 pessoas que expuseram suas percepções sobre a gestão da inovação de 41 empresas. A maioria dos respondentes pertence ao gênero masculino $(64,4 \%)$, a outra parte $(35,6 \%)$ pertence ao gênero feminino, conforme Gráfico 2.

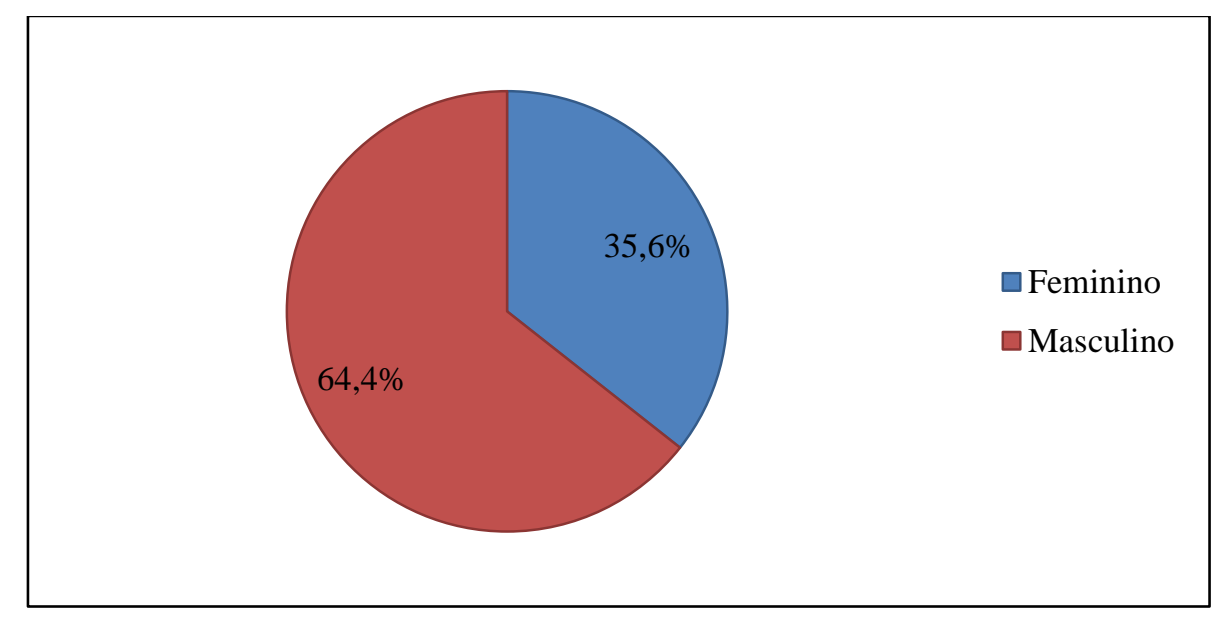

Gráfico 2 - Distribuição dos respondentes por gênero 
Com relação às áreas ou departamentos funcionais que estas pessoas ocupam na empresa, a maioria atua na área de Pesquisa, Desenvolvimento e Engenharia $(28,75 \%)$, seguido por departamentos ligados à Administração (23,75\%), conforme Gráfico 3.

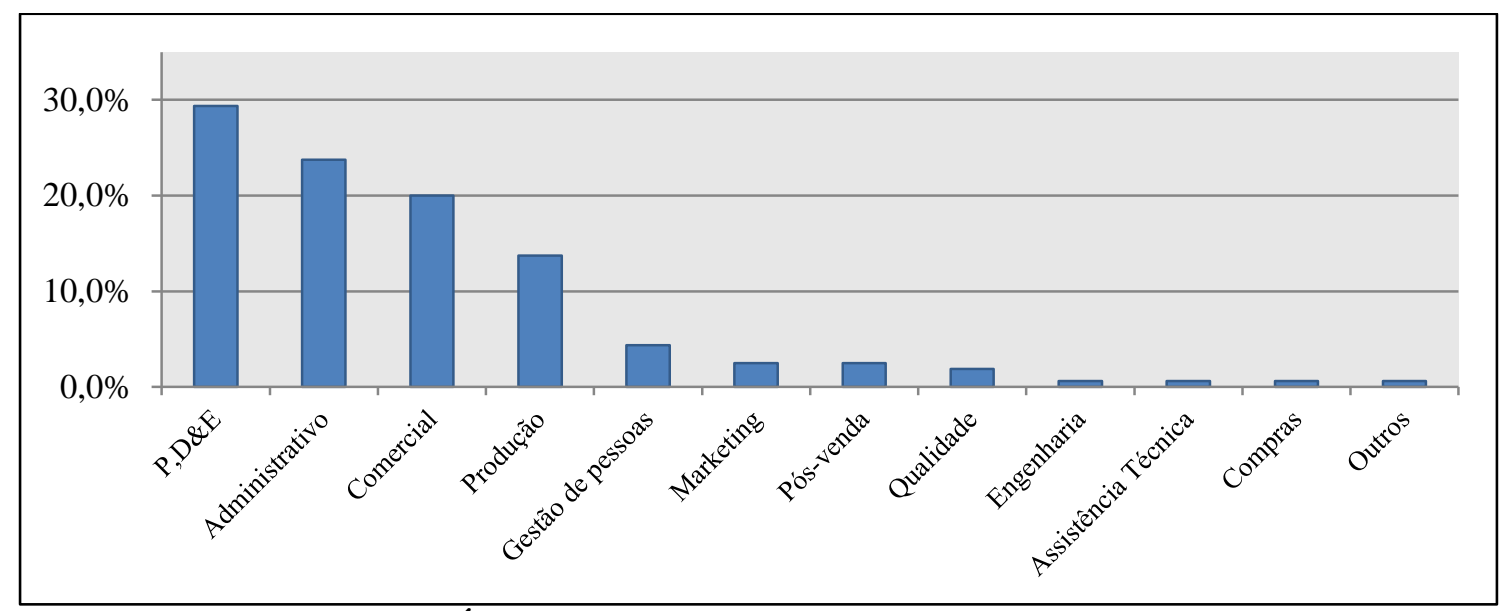

Gráfico 3 - Áreas ou departamentos onde os respondentes atuam

Observa-se uma diferença quanto ao padrão de ocupação de pessoas dos gêneros masculinos e femininos com relação às áreas e departamentos que ocupam. Dentre o gênero masculino, há uma maior ocupação por parte destes nas áreas de P,D\&E (41,75\%) que tradicionalmente se encarregam da gestão e geração de inovações nas empresas, seguido pelas áreas comercial e administrativa (cada uma com 19,42\%), conforme Gráfico 4.

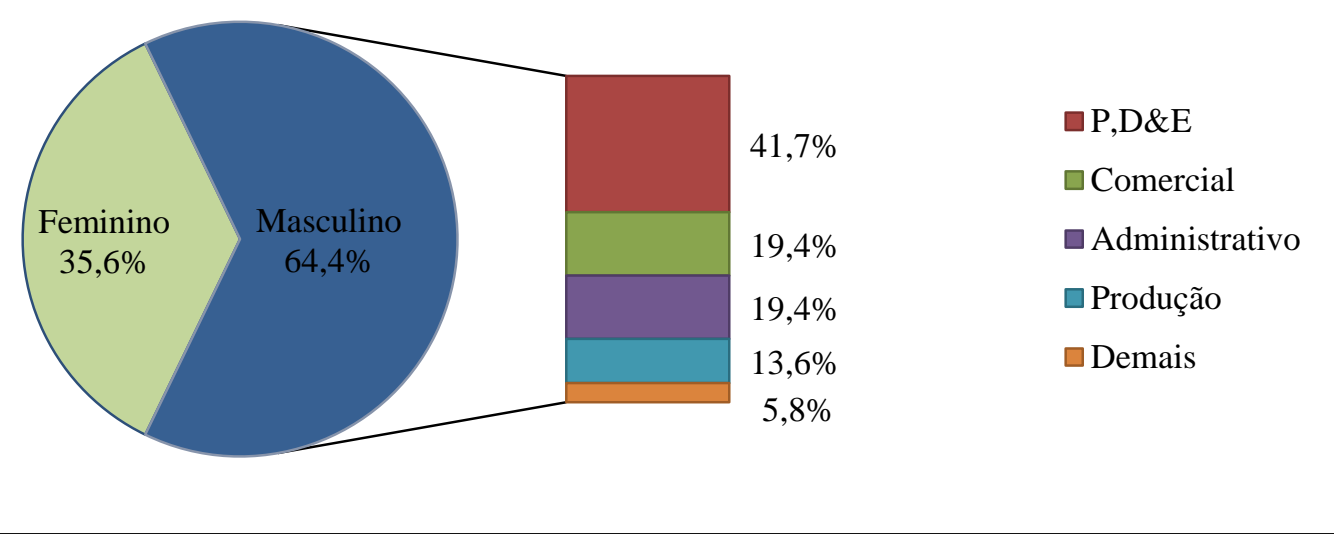

Gráfico 4 - Áreas ou departamentos ocupados por pessoas do gênero masculino 
Já dentre as pessoas de gênero feminino, a maior taxa de ocupação estão nas áreas administrativas $(31,58 \%)$, comercial $(21,05 \%)$ e produção $(14,04 \%)$. A ocupação de pessoas do gênero feminino em Pesquisa, Desenvolvimento e Engenharia está apenas em quinto lugar, com $7,02 \%$ (ante $41,75 \%$ daqueles do gênero masculino), como pode-se observar no conforme Gráfico 5.

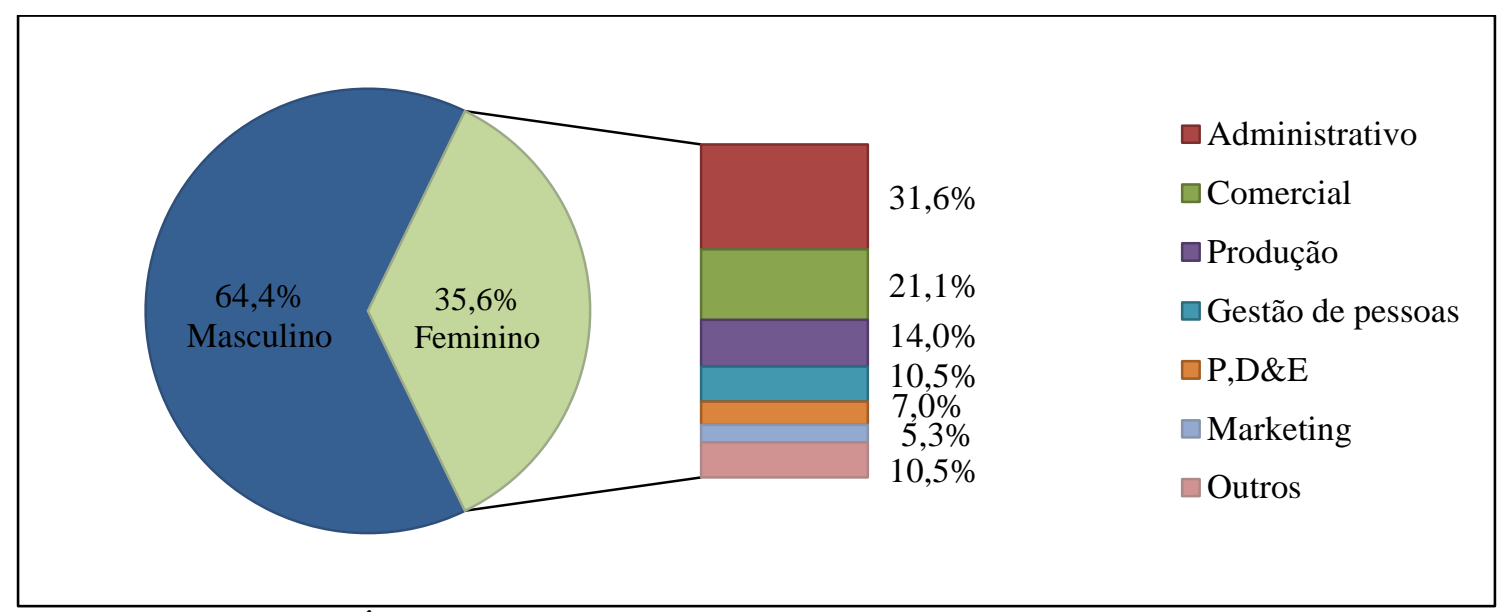

Gráfico 5 - Áreas ou departamentos ocupados por pessoas do gênero feminino

Com relação aos cargos ou posições ocupados pelos respondentes da amostra, $40 \%$ são operadores/analistas, 37,5\% são gerentes/superintendentes de áreas, $20 \%$ foram os próprios empresários (compreendendo sócios, com 16,88\%, e donos exclusivos do empreendimento, com $3,13 \%$ ). Por fim, $2,5 \%$ da amostra era composta por pessoas da diretoria ou pertencentes ao chamado C-level. O Gráfico 6 representa esta distribuição.

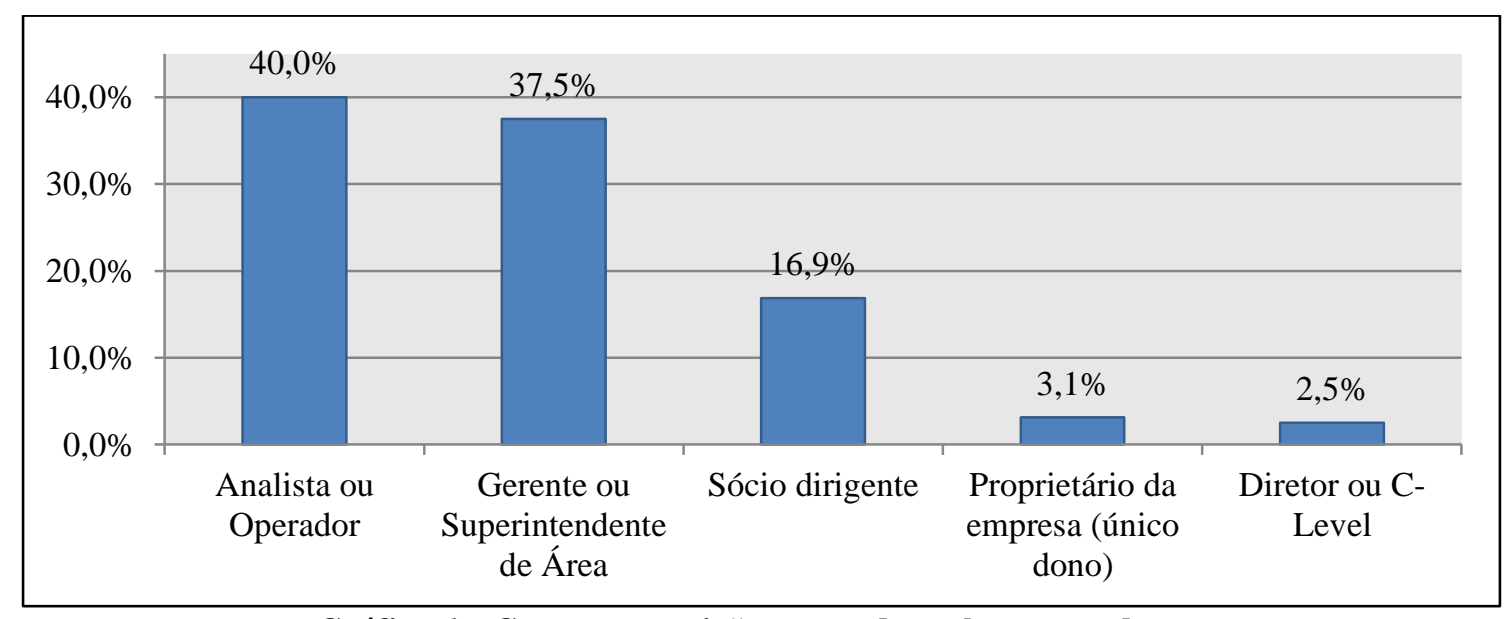

Gráfico 6 - Cargos ou posições ocupados pelos respondentes 
Assim como na análise das áreas e departamentos das empresas, há também uma diferença nos padrões na distribuição de gêneros quando confrontados com os cargos ou posições. Pelo Gráfico 7, é possível perceber que a proporção de pessoas do gênero feminino tende a diminuir em cargos ou posições mais altas.

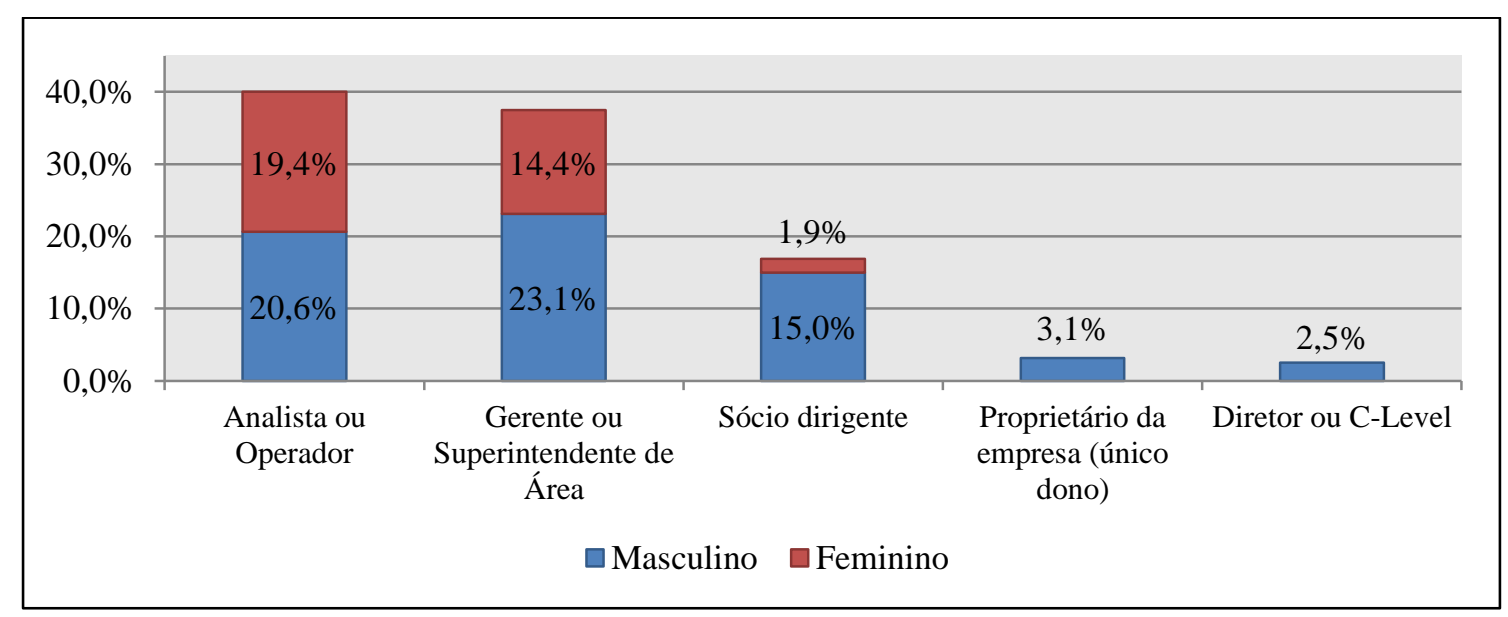

Gráfico 7 - Cargos ou posições ocupados pelos respondentes, segundo o gênero

Do total, 32 respondentes eram sócios ou proprietários (único dono) das empresas pesquisadas, perfazendo uma proporção de $20 \%$ da amostra (onde 16,88\% são sócios dirigentes e 3,13\% são proprietários da empresa, conforme Gráfico 6). A maioria dos sócios e proprietários entrevistados se ocupa de atividades ligadas a Pesquisa, Desenvolvimento e Engenharia, com 40,63\%, seguida por atividades administrativas, com 31,25\%, conforme Gráfico 8.

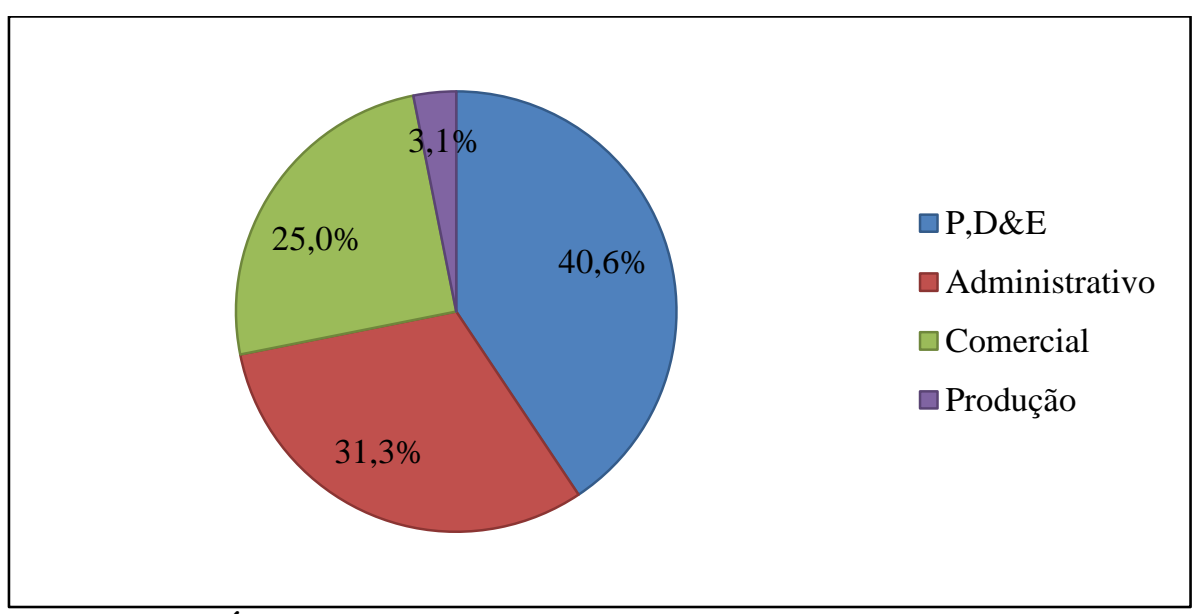

Gráfico 8 - Áreas ou departamentos nos quais sócios e proprietários atuam 
A maioria dos respondentes possui curso de nível superior, são $61,25 \%$ do total. Cerca de 18\% deles possuem alguma pós-graduação, sejam elas do tipo Lato Sensu (15\%) ou do tipo Stricto Sensu $(3,13 \%)$ da amostra. Apesar de a maioria ter curso de nível superior, há um contingente considerável que possui menos tempo de educação formal, são 38,75\%. Porém, a maioria das pessoas deste último grupo provavelmente obterá o diploma nos anos que virão. Conforme depreendemos do Gráfico 9, o nível de qualificação educacional dos respondentes é bom, o que irá refletir na qualidade das respostas obtidas.

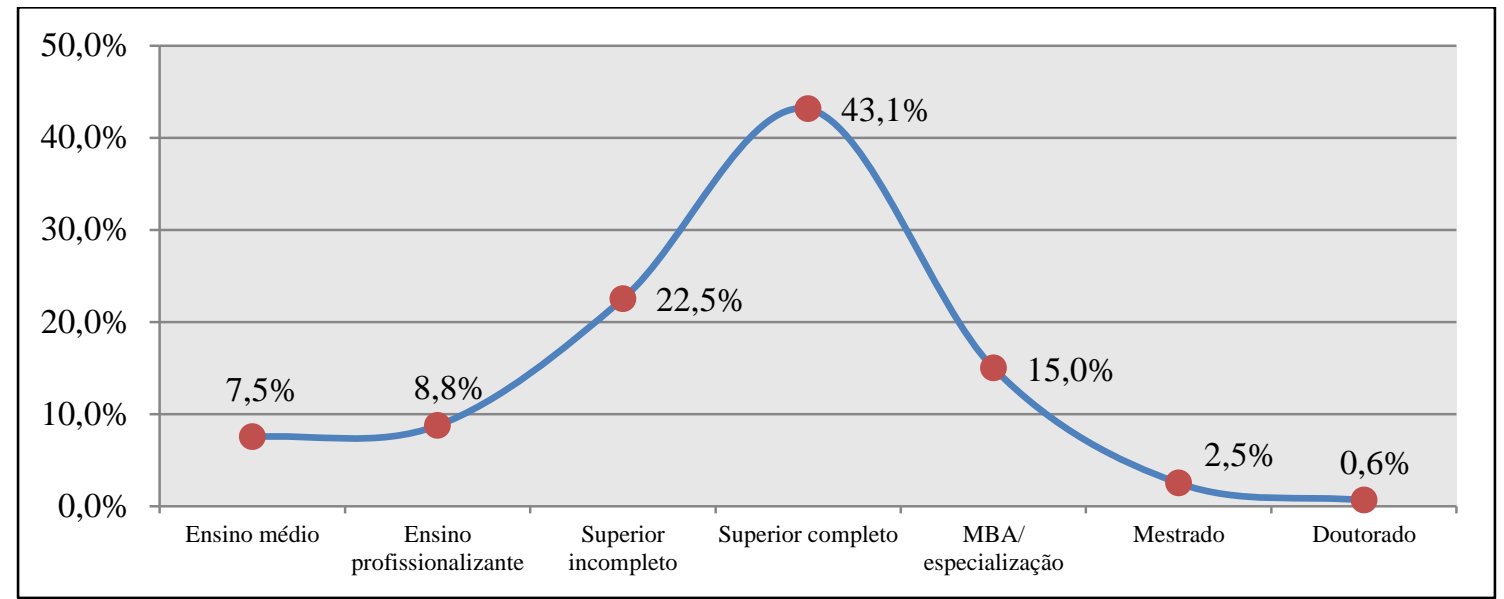

Gráfico 9 - Grau de instrução dos respondentes

Daqueles $61,3 \%$ de respondentes que possuem curso de nível superior (98 pessoas em termos absolutos), 43,9\% são formados em Engenharia, seguidos por Administração com 36,7\%. Os demais respondentes (que são 19,4\%) vieram de cursos tais como Sistemas, Publicidade, Propaganda e Marketing, Ciências da Computação, Economia, dentre outros, conforme pode ser visto no Gráfico 10.

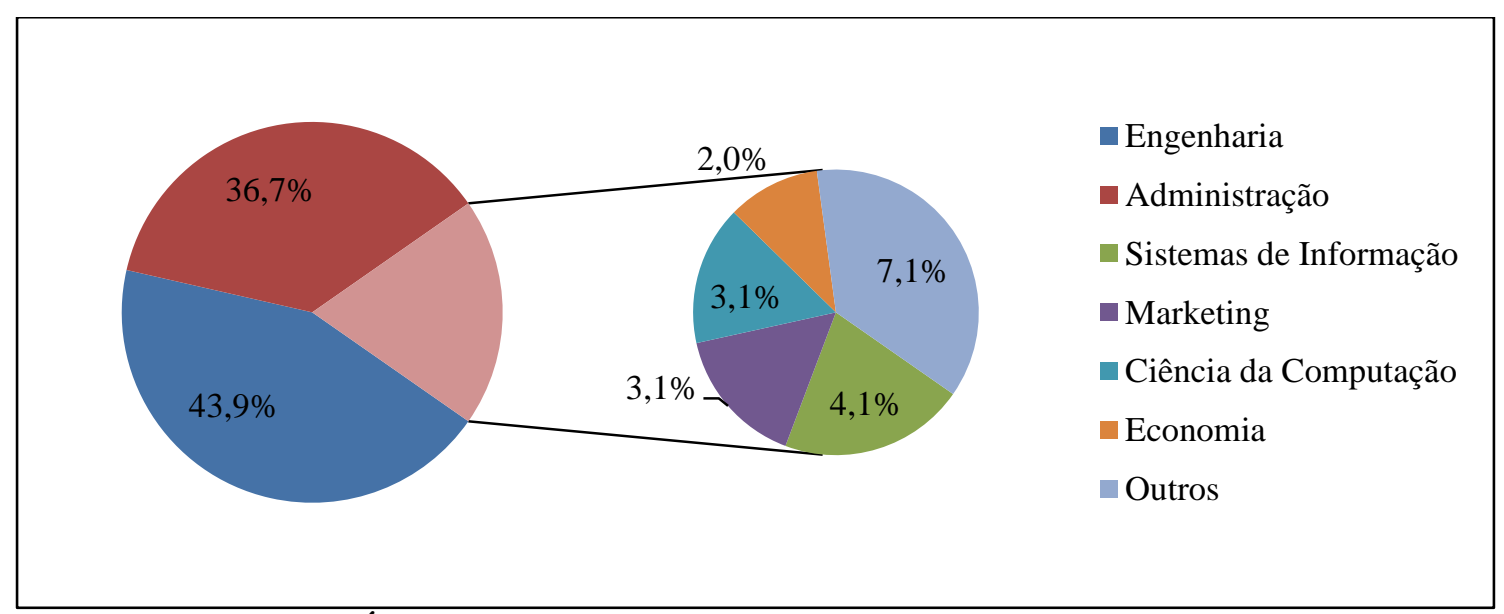

Gráfico 10 - Áreas de formação dos respondentes com ensino superior completo 
O tempo médio de experiência profissional total (desde que iniciou a trabalhar até o momento da pesquisa) é de 12,64 anos com um desvio padrão amostral de 9,41 anos (medida de dispersão) e mediana em 10 anos (medida de posição). Deduz-se que a distribuição da amostra é muito heterogênea quanto à experiência profissional, assemelhando-se a uma distribuição normal. Isto é mais facilmente observado no histograma a seguir (Gráfico 11).

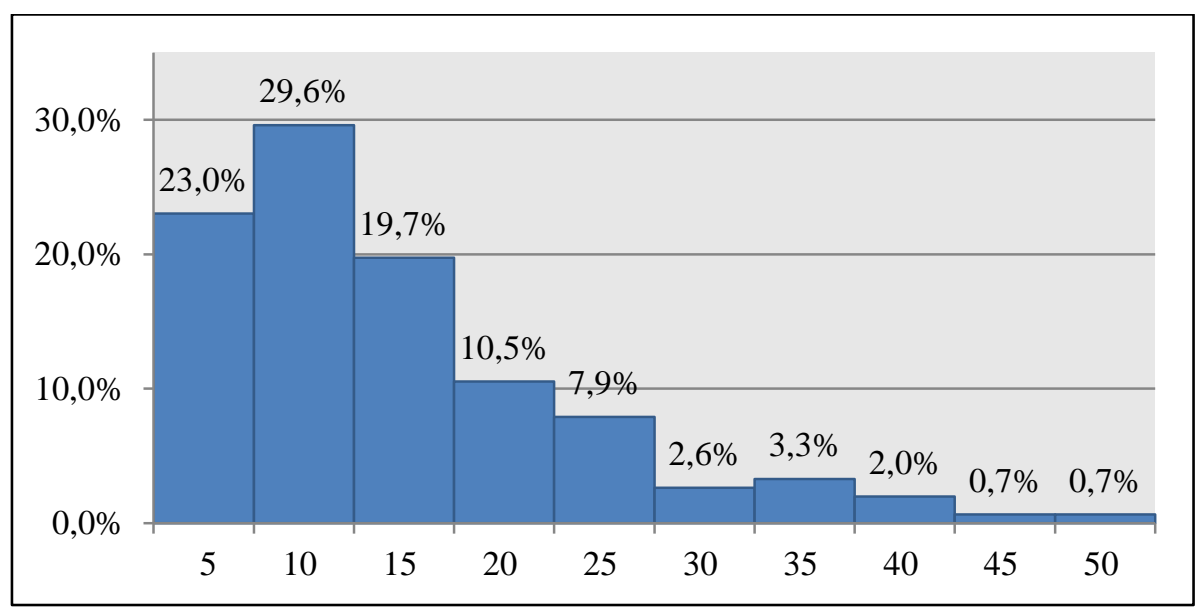

Gráfico 11 - Distribuição da experiência profissional dos respondentes (eixo x em anos)

Os respondentes estão em média há 6,5 anos trabalhando na mesma empresa. $\mathrm{O}$ desvio padrão amostral é de 6,2 anos (medida de dispersão) e a mediana recai em 5 anos (medida de posição). Novamente verifica-se uma distribuição assimétrica. O histograma do Gráfico 12 mostra esta distribuição.

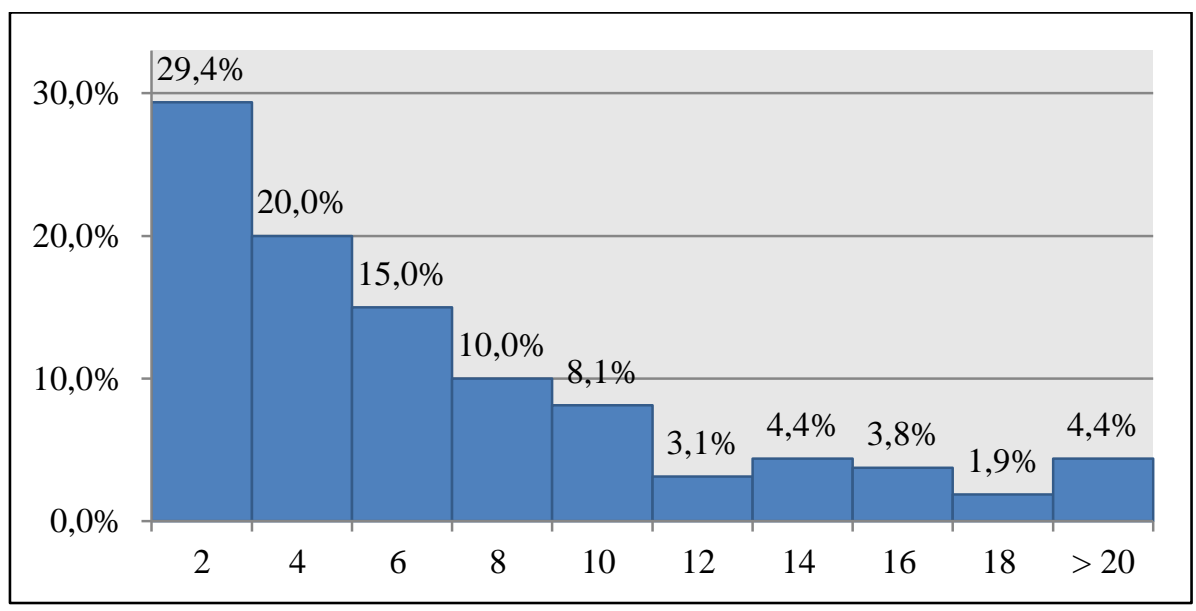

Gráfico 12 - Distribuição do tempo de atuação na empresa (eixo x em anos) 


\subsubsection{Caracterização das empresas}

Como já fora dito, nossa amostra é composta por 41 empresas. Segundo o critério de porte de empresa adotada pelo BNDES e aplicável a todos os setores conforme Tabela 1, a maioria das empresas $(70,7 \%)$ são microempresas, seguidas por de pequeno porte $(17,1 \%)$ e de médio porte (12,2\%), conforme Gráfico 13. O faturamento médio para o ano de 2011 foi de $\mathrm{R} \$ 5,11$ milhões, no entanto esta média não é a medida mais adequada uma vez que há uma grande concentração de empresas com faturamento muito menor. A mediana está em R\$ 1,24 milhão.

Tabela 1 - Classificação de porte de empresa segundo a receita operacional bruta anual

\begin{tabular}{|l|l|}
\hline \multicolumn{1}{|c|}{ Classificação } & \multicolumn{1}{c|}{ Receita operacional bruta anual } \\
\hline Microempresa & Menor ou igual a R\$2,4 milhões \\
\hline Pequena empresa & Maior que R\$ 2,4 milhões e menor ou igual a R\$ 16 milhões \\
\hline Média empresa & Maior que R\$ 16 milhões e menor ou igual a R\$ 90 milhões \\
\hline Média-grande empresa & Maior que R\$ 90 milhões e menor ou igual a R\$ 300 milhões \\
\hline Grande empresa & Maior que R\$ 300 milhões \\
\hline & Fonte: BNDES, Porte de Empresa
\end{tabular}

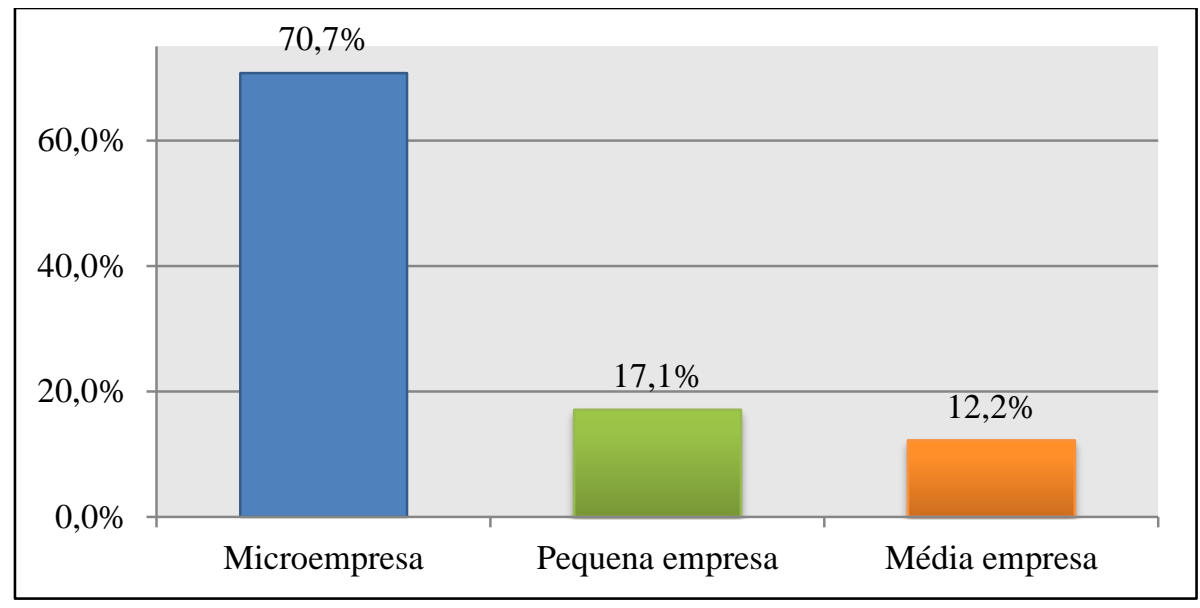

Gráfico 13 - Porte das empresas 
Sobre o tempo de operação, as empresas têm em média 10,9 anos de existência. Há uma concentração na amostra de empresas mais jovens, com menos de 10 anos desde sua fundação (63,4\% do total), observada no Gráfico 14.

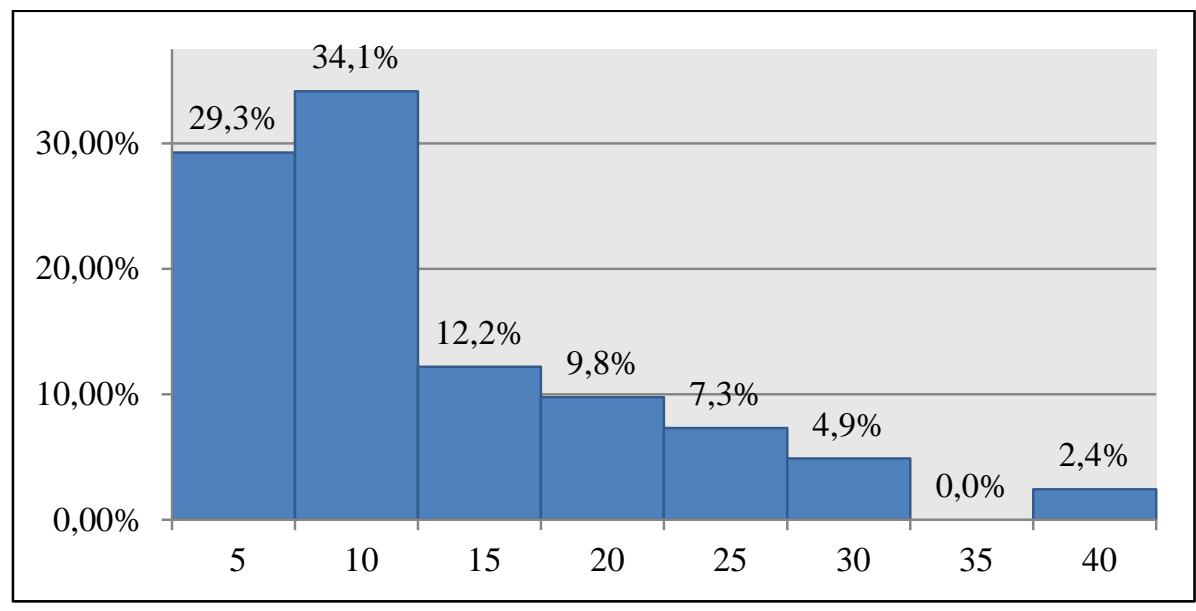

Gráfico 14 - Distribuição da idade das empresas (eixo x em anos)

Ao todo, as 41 empresas da amostra empregavam quase 1,6 mil pessoas em tempo integral dentro das empresas ao final de 2011, considerando sócios, funcionários e prestadores de serviços. Isto dá uma média de 38,6 de pessoas por empresa. Também esta distribuição é deveras desigual. Pouco mais da metade das empresas $(51,2 \%)$ ocupam até 19 pessoas, outros 41,5\% são de empresas com um quadro de 20 até 99 pessoas ocupadas e apenas 7,3\% possuem um quadro acima de 100 pessoas, conforme Gráfico 15. Os maiores quadros funcionais chegavam a cerca de 250 pessoas ocupadas em uma mesma empresa.

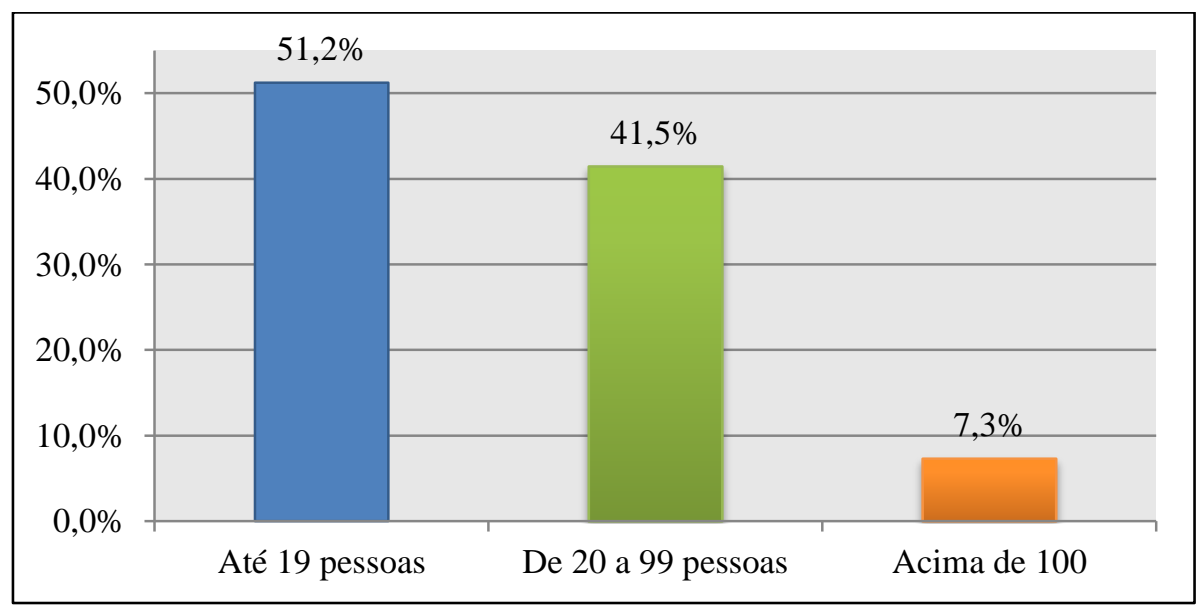

Gráfico 15 - Número de pessoas ocupadas 
As informações apresentadas acima, tais como porte da empresa, tempo de existência, faturamento e número de pessoas ocupadas foram reunidas na Tabela 2. Depreende-se disto que, em média, empresas instituídas mais recentemente são as que possuem menor faturamento e ocupam menos pessoas.

Tabela 2 - Faturamento, idade e pessoas ocupadas segundo o porte de empresa

\begin{tabular}{|l|c|c|c|}
\hline \multicolumn{1}{|c|}{ Porte } & Idade & $\begin{array}{c}\text { Faturamento bruto } \\
\text { em 2011 }\end{array}$ & $\begin{array}{c}\text { Pessoas ocupadas } \\
\text { em 2011 }\end{array}$ \\
\hline Microempresa & 8,8 anos & $\mathrm{R} \$ 817,46$ mil & 15,1 pessoas \\
\hline Pequena empresa & 13,1 anos & $\mathrm{R} \$ 5,93$ milhões & 47,4 pessoas \\
\hline Média empresa & 20,2 anos & $\mathrm{R} \$ 28,88$ milhões & 162,2 pessoas \\
\hline Média total & 10,9 anos & $\mathrm{R} \$ 5,11$ milhões & 38,6 pessoas \\
\hline
\end{tabular}

As empresas foram classificadas de acordo com os segmentos de atuação. A classificação de segmentos utilizada é do SINDVEL. O principal setor de atuação é o de Eletroeletrônicos, com 14 empresas, seguido pelos setores de Segurança (cinco empresas) e Automação Industrial e Telecomunicações, com três empresas cada (gráfico 16). A maioria das áreas de atuação representam setores cujos produtos possuem alto valor agregado devido à inovação e tecnologias empregadas. Outras áreas de atuação presentes representam aquelas que dão suporte ou fornecem à cadeia de valor de eletrônicos e assemelhados, e possuem papel fundamental para o desempenho e competitividade do Arranjo Produtivo Local (APL) do Vale da Eletrônica, como no caso de empresas de Embalagens ou Partes e Peças. A abrangência do principal mercado geográfico é, para 92,7\% da amostra, é no nível nacional. Ainda há uma minoria (7,3\%) que atua em nível regional e nenhuma das empresas respondeu que tem como principal mercado o exterior.

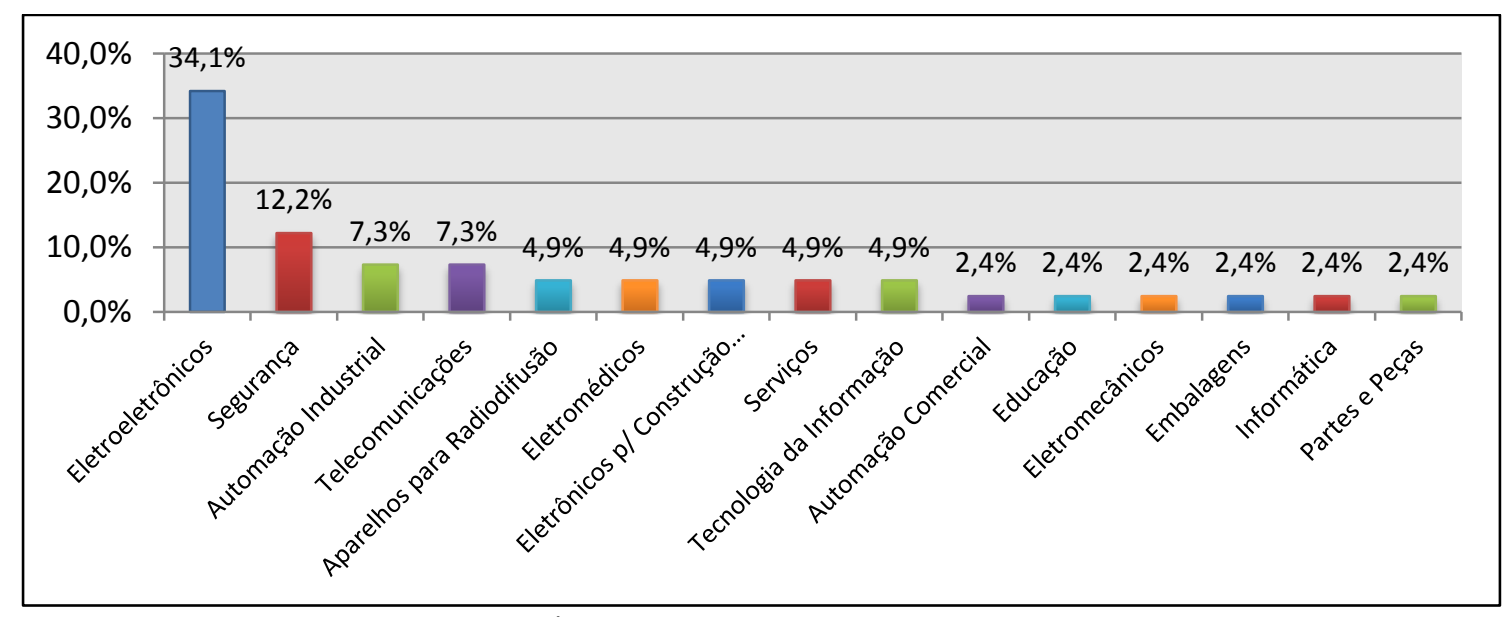

Gráfico 16 - Segmentos de atuação 
O município de Santa Rita do Sapucaí conta atualmente com duas incubadoras de empresas: o PROINTEC e a incubadora do INATEL. A importância das incubadoras pode ser constatada na significativa parcela de empresas da amostra que nasceram ou que estão ligadas a alguma incubadora, conforme o Gráfico 17.

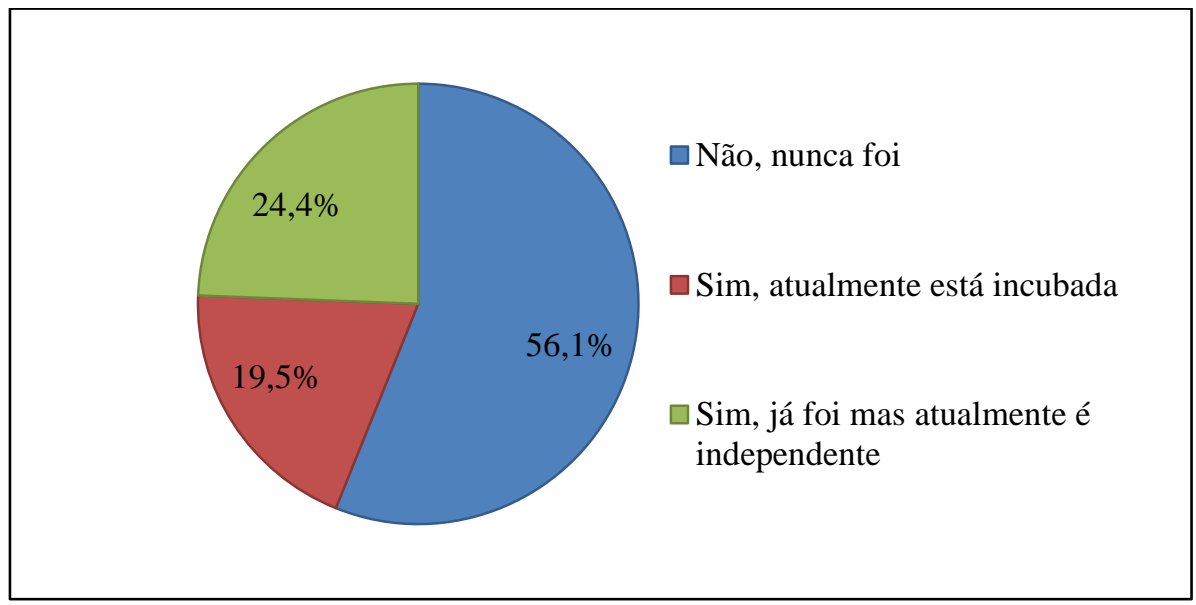

Gráfico 17 - Processo de incubação

Com relação ao tipo de administração levada a cabo na empresa, 63,4\% das empresas são geridas por profissionais enquanto que o restante, $36,6 \%$, possui uma administração familiar. Em micro e pequenas empresas, a proporção entre os dois tipos de administração é mais equilibrada. Porém, dentre as empresas de médio porte, $80 \%$ delas são gerenciadas por profissionais.

Sobre a origem do capital controlador, apenas uma empresa $(2,4 \%)$ da amostra tem participação de capital estrangeiro (proveniente da China), o restante são exclusivamente capital nacional. Próximo de $20 \%$ são as empresas que possuem mais de uma unidade, sejam elas uma filial, sede, escritório de representação comercial ou ainda uma unidade que faz parte do mesmo grupo, mas que possui outro CNPJ.

Sobre inovação, quando indagadas sobre o principal produto novo ou substancialmente aperfeiçoado lançado nos três anos anteriores à pesquisa (de 2009 a 2011), pouco mais da metade $(51,2 \%)$ dos respondentes informou que lançaram produtos novos para o mercado nacional, mas já existente no mercado mundial (ver Gráfico 18). Isto demonstra uma estratégia de inspiração em mercados estrangeiros para no lançamento no mercado doméstico. 


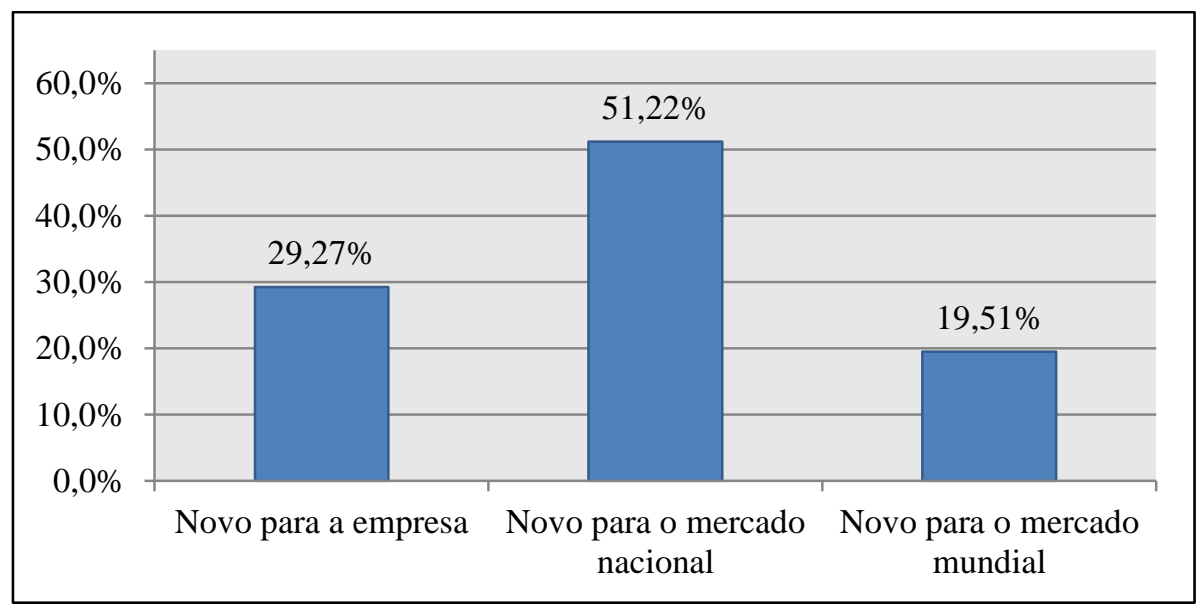

Gráfico 18 - Grau de novidade da inovação

Não são muitas as empresas do Vale da Eletrônica que se preocupam com a questão da propriedade intelectual. No período compreendido entre 2009 e 2011, apenas 53,7\% das empresas utilizaram algum meio (marcas, patente de invenção e de modelo utilizado, desenho industrial ou direitos de autor, no caso de softwares). Caso sejam excluídos da contagem os registros de marcas, este número cai para $38,1 \%$ das empresas que se preocuparam em utilizar pelo menos um dos meios para se resguardar em possíveis contendas. O Gráfico 19 mostra melhor a incidência de registros segundo cada meio de proteção.

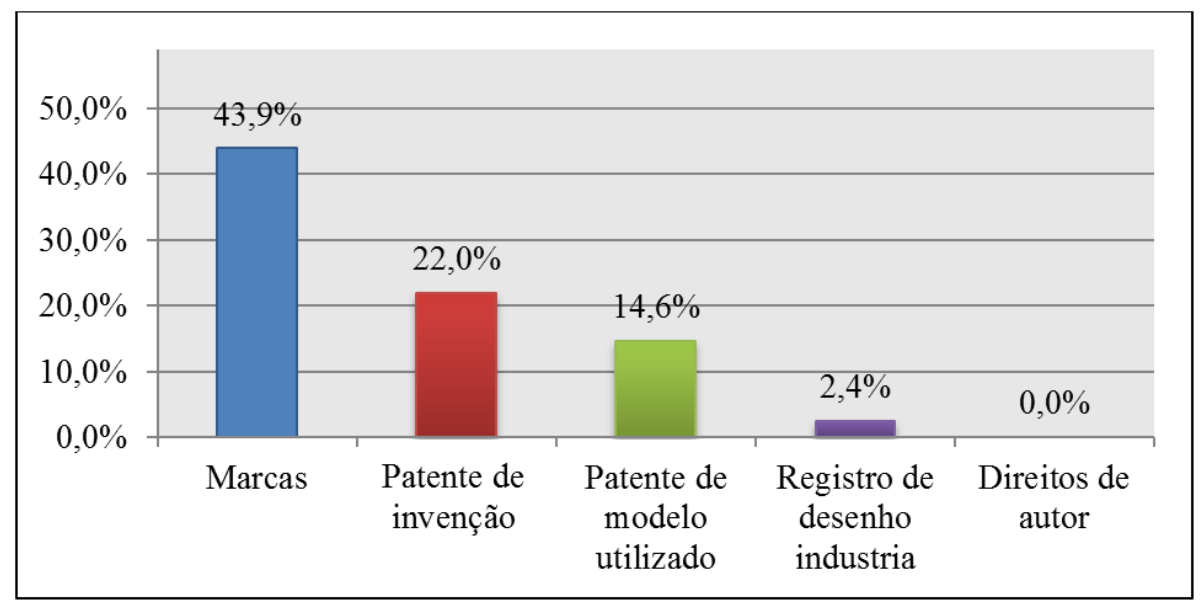

Gráfico 19 - Meios empregados como proteção da propriedade intelectual 


\subsection{Confiabilidade das variáveis}

Para analisar a confiabilidade dos constructos, foi utilizada a técnica conhecida como Coeficiente Alfa de Cronbach. Os resultados desta análise são obtidos calculando a média dos coeficientes de todas as combinações possíveis dos itens, sempre dois a dois. Este coeficiente varia de 0 a 1 , sendo que um alto valor para este índice significa que os respondentes estão dando respostas de um modo coerente (HAIR et al., 2005, p. 200). A seguir (Tabela 3) é mostrada a intensidade da associação entre os itens por faixas.

Tabela 3 - Regras práticas sobre a dimensão do coeficiente Alfa de Cronbach

\begin{tabular}{|c|c|}
\hline Alpha de Cronbach & Intensidade da associação \\
\hline$<0,6$ & Baixa \\
\hline $0,6 \mathrm{a}<0,7$ & Moderada \\
\hline $0,7 \mathrm{a}<0,8$ & Boa \\
\hline $0,8 \mathrm{a}<0,9$ & Muito boa \\
\hline 0,9 & Excelente \\
\hline
\end{tabular}

Fonte: HAIR et al., 2005, p. 200

Para cada uma das dimensões da gestão da inovação, bem como para a variável resultado, foram executados os comandos para a obtenção dos coeficientes de confiabilidade estatística usando o software SPSS.

A primeira dimensão aborda aspectos ligados à Estratégia de Inovação. Este constructo é medido através de seis itens, que são: estratégia de inovação clara; compreensão do significado desta pelas pessoas da organização; conhecimento de qual é principal competência da empresa; compreensão de como a inovação ajudará a empresa se desenvolver; apoio da alta gestão; e ligação clara entre projetos inovação e estratégia corporativa. Tais variáveis apresentaram um coeficiente de 0,835 (Tabela 4), que é considerado como um nível muito bom, indicando que as respostas são coerentes.

A dimensão Processos Internos foi medida através de seis itens, que são elas: geração de ideias internas; pesquisa de ideias a partir do ambiente externo; sistema claro de seleção de projetos; existência de um gerenciamento apropriado para o processo inovativo (desde a ideia até o lançamento); compreensão das necessidades dos clientes; e projetos realizados conforme o previsto (em termos de prazo e orçamento). O Alfa de Cronbach foi 0,777 (Tabela 4), considerado como bom. 
A dimensão Ambiente Externo busca explorar o relacionamento das empresas com os atores com quem elas estão envolvidas. Há quatro itens que compõe esta dimensão, que medem: flexibilidade em responder as ações de concorrentes e fornecedores; habilidade em compreender o mercado; e capacidade de entender as ações de organismos institucionais. $\mathrm{O}$ Alfa de Cronbach calculado foi 0,827 (Tabela 6), considerado como muito bom.

O constructo Organizacão é composto por seis itens. Esta dimensão foi construída a partir das seguintes variáveis: integração entre pessoas de diferentes áreas; equipes dedicadas para a inovação; tempestividade das decisões; comunicação eficaz; estrutura flexível para desenvolver projetos; e integração entre departamentos. $\mathrm{O}$ índice de confiabilidade para este constructo foi de 0,842 (Tabela 6), considerado como muito bom.

A última variável independente foi chamada de Cultura. Esta dimensão, composta por seis itens, investiga: efetividade do sistema de reconhecimento/recompensa; clima propício para expor ideias; comprometimento com treinamento/desenvolvimento das pessoas; tolerância a pequenos erros/falhas; e tempo/recursos para que pessoas se dediquem a geração de ideias. $\mathrm{O}$ valor do Alfa de Cronbach medido foi de 0,810 (Tabela 4), considerado como muito bom.

Tabela 4 - Estatística de Confiabilidade para as dimensões da Gestão da Inovação

\begin{tabular}{|c|c|c|c|c|c|}
\hline & Estratégia & $\begin{array}{c}\text { Processos } \\
\text { internos }\end{array}$ & $\begin{array}{c}\text { Ambiente } \\
\text { Externo }\end{array}$ & Organização & Cultura \\
\hline Cronbach's Alpha & 0,835 & 0,777 & 0,827 & 0,842 & 0,810 \\
\hline N of Items & 6 & 6 & 4 & 6 & 6 \\
\hline
\end{tabular}

Este estudo tem apenas uma variável dependente. Esta se refere ao desempenho alcançado pelas empresas derivado de suas inovações nos três anos anteriores à coleta de dados, referente ao período compreendido entre 2009 e 2011. O constructo Desempenho Inovativo foi medida através de cinco itens, que são: lançamento de novos bens/serviços; aumento da qualidade daqueles existentes; abertura de novos mercados; aumento da participação em mercados já existentes; e redução dos custos de produção/prestação. O Alfa de Cronbach medido foi de 0,768 (Tabela 5), considerado como bom.

Tabela 5 - Estatísticas de Confiabilidade para o Desempenho Inovativo

\begin{tabular}{|c|c|}
\hline & $\begin{array}{c}\text { Desempenho } \\
\text { Inovativo }\end{array}$ \\
\hline Cronbach's Alpha & 0,768 \\
\hline N of Items & 5 \\
\hline
\end{tabular}


De modo geral, todos os constructos que compõe esta pesquisa apresentaram índices de confiabilidade satisfatórios para compor a análise. Definidas as cinco variáveis independentes e a única variável dependente, será inicialmente feita uma análise descritiva de cada uma delas para então prosseguir para as análises inferenciais, que serão correlação e regressão linear.

\subsection{Análise descritiva dos resultados por dimensão}

Neste subitem estão apresentados os resultados descritivos das variáveis que compõe cada constructo do modelo. A escala métrica utilizada foi a Likert, com variação de 1 a 5 pontos, onde quanto mais próximo de 5 indica que a empresa adota práticas características da gestão da inovação. Cada empresa analisada teve de três a sete respondentes, a resposta para cada item foi calculada pela média simples das respostas. Para facilitar a visualização dos dados em tabela, as respostas foram separadas em três categorias conforme o grau de concordância com relação às afirmações apresentadas no questionário. As categorias podem ser conferidas na Tabela 6, sendo que a letra " $x$ " que aparece nesta tabela é o resultado da média das respostas apresentadas.

Tabela 6 - Agrupamento por nível de concordância da escala Likert

\begin{tabular}{|c|c|}
\hline Opções de Resposta & Categoria \\
\hline$x \leq 2,5$ & Baixa concordância \\
\hline $2,5<x \leq 3,5$ & Concordância moderada \\
\hline$x>3,5$ & Alta concordância \\
\hline
\end{tabular}

Os resultados que compõe a dimensão Estratégia podem ser verificados na Tabela 7. Analisando o constructo como um todo, é alta a quantidade de respondentes $(74,4 \%)$ que estão atentos para a inovação no contexto da Estratégia da empresa. Esta preocupação pode ser verificada principalmente pelo alto índice de concordância para algumas das variáveis levantadas.

Dentre as variáveis que compõe esta dimensão, destaca-se positivamente o item ES19, que indica que há "comprometimento e suporte da alta gestão para promover inovação", com $87,8 \%$ de respondentes na faixa de alta concordância. Do outro lado, o item ES14 foi aquele 
que teve uma maior incidência de respostas nas faixas inferiores de concordância $(7,3 \%$ em baixa concordância, 39,0\% em concordância moderada), comparativamente aos demais que compõe o constructo. O item afirma que a "estratégia de inovação é expressa de maneira clara", logo, apenas para pouco mais da metade dos respondentes esta afirmação é plenamente reconhecível.

Tabela 7 - Resultados da dimensão Estratégia

\begin{tabular}{|c|c|c|c|c|c|c|c|}
\hline & E13 & E14 & E15 & E18 & E19 & E21 & \multirow[b]{2}{*}{ Estratégia } \\
\hline & $\begin{array}{c}\text { Inovação } \\
\text { ajuda a } \\
\text { competir }\end{array}$ & $\begin{array}{l}\text { Estratégia } \\
\text { de inova- } \\
\text { ção clara }\end{array}$ & $\begin{array}{l}\text { Competência } \\
\text { característica }\end{array}$ & $\begin{array}{c}\text { Visão } \\
\text { disseminada }\end{array}$ & $\begin{array}{l}\text { Compromisso } \\
\text { da alta gestão }\end{array}$ & $\begin{array}{c}\text { Alinhamento } \\
\text { projetos e } \\
\text { estratégia }\end{array}$ & \\
\hline $\begin{array}{c}\text { Baixa } \\
\text { concordância }\end{array}$ & $0,0 \%$ & $7,3 \%$ & $2,4 \%$ & $7,3 \%$ & $0,0 \%$ & $2,4 \%$ & $3,3 \%$ \\
\hline \begin{tabular}{|c|} 
Concordância \\
moderada
\end{tabular} & $17,1 \%$ & $39,0 \%$ & $19,5 \%$ & $29,3 \%$ & $12,2 \%$ & $17,1 \%$ & $22,4 \%$ \\
\hline $\begin{array}{c}\text { Alta } \\
\text { concordância }\end{array}$ & $82,9 \%$ & $53,7 \%$ & $78,0 \%$ & $63,4 \%$ & $87,8 \%$ & $80,5 \%$ & $74,4 \%$ \\
\hline Média & 4,21 & 3,61 & 3,93 & 3,69 & 4,20 & 4,04 & 3,95 \\
\hline Desvio padrão & 0,68 & 0,74 & 0,65 & 0,78 & 0,60 & 0,63 & 0,71 \\
\hline
\end{tabular}

Na dimensão Processos Internos, os resultados estão apresentados na Tabela 8. De todas as cinco dimensões da Gestão da Inovação analisadas descritivamente, esta foi aquela que apresentou a menor incidência de respostas na faixa "alta concordância" ( $x>3,5)$, com 54,5\% dos respondentes.

Dos seis itens que compõe a dimensão, o destaque negativo fica por conta do item PI23, que trata do cumprimento dos projetos de inovação aos prazos e orçamentos estipulados. Apenas uma minoria $(29,3 \%)$ concorda que seus projetos geralmente são executados dentro do previsto. Para contrapor esta variável, destaca-se positivamente o item PI42 que indaga sobre a geração de ideias internamente às empresas. A maioria dos respondentes $(80,5 \%)$ concorda que as pessoas dentro de suas organizações estão envolvidas com sugestão de ideias para melhorias de produtos ou processos. Logo na sequência, apresenta-se favoravelmente a variável PI26, que investiga se a empresa pesquisa ideias externamente, com $78,0 \%$ de resposta no nível de "alta concordância". 
Tabela 8 - Resultados da dimensão Processos Internos

\begin{tabular}{|c|c|c|c|c|c|c|c|}
\hline & PI22 & PI23 & PI24 & PI26 & PI28 & PI42 & \\
\cline { 2 - 7 } & $\begin{array}{c}\text { Gerenciamento } \\
\text { do processo } \\
\text { inovativo }\end{array}$ & $\begin{array}{c}\text { Adequação } \\
\text { a prazos/ } \\
\text { orçamento }\end{array}$ & $\begin{array}{c}\text { Compreensão } \\
\text { das } \\
\text { necessidades } \\
\text { do cliente }\end{array}$ & $\begin{array}{c}\text { Pesquisa de } \\
\text { ideias no } \\
\text { ambiente } \\
\text { externo }\end{array}$ & $\begin{array}{c}\text { Critérios para } \\
\text { seleção de } \\
\text { projetos }\end{array}$ & $\begin{array}{c}\text { Geração } \\
\text { de ideias } \\
\text { internas }\end{array}$ & $\begin{array}{c}\text { Processos } \\
\text { Internos }\end{array}$ \\
\hline $\begin{array}{c}\text { Baixa } \\
\text { concordância }\end{array}$ & $22,0 \%$ & $29,3 \%$ & $9,8 \%$ & $2,4 \%$ & $19,5 \%$ & $2,4 \%$ & $14,2 \%$ \\
\hline $\begin{array}{c}\text { Concordância } \\
\text { moderada }\end{array}$ & $31,7 \%$ & $41,5 \%$ & $39,0 \%$ & $19,5 \%$ & $39,0 \%$ & $17,1 \%$ & $31,3 \%$ \\
\hline $\begin{array}{c}\text { Alta } \\
\text { concordância }\end{array}$ & $46,3 \%$ & $29,3 \%$ & $51,2 \%$ & $78,0 \%$ & $41,5 \%$ & $80,5 \%$ & $54,5 \%$ \\
\hline Média & 3,42 & 2,97 & 3,55 & 4,19 & 3,29 & 4,09 & 3,58 \\
\hline Desvio padrão & 0,87 & 0,94 & 0,86 & 0,78 & 0,85 & 0,71 & 0,93 \\
\hline
\end{tabular}

As próximas três dimensões que compõe o modelo de Gestão Integrada da Inovação, Ambiente Externo, Organização e Cultura, apresentam resultados bastante similares entre si. Analisados aos resultados agregados de cada dimensão, estes se revelam em um patamar intermediário, isto é, não tão altos como a dimensão Estratégia (74,4\% na faixa "alta concordância") e nem tão baixos como a dimensão Cultura $(54,5 \%$ na faixa "alta concordância").

Os resultados da dimensão Ambiente Externo estão apresentados na Tabela 9. Todas as quatro variáveis possuem valores bastante homogêneos. A variável AE56 que indaga sobre a habilidade da organização em captar e compreender comportamentos, tendências e atitudes de seus clientes, foi a que teve a maior incidência de respostas na faixa de "alta concordância", com $78,0 \%$. Isto equivale a dizer que as empresas da amostra estão atentas para as necessidades de seus clientes. Já as variáveis AE54 e AE55 tiveram cerca de um terço $(34,1 \%)$ de respostas nos níveis de baixa ou moderada concordância, ambas indagam sobre a capacidade da organização em responder às ações de concorrentes e fornecedores. 
Tabela 9 - Resultados da dimensão Ambiente Externo

\begin{tabular}{|c|c|c|c|c|c|}
\hline & AE54 & AE55 & AE56 & AE57 & \multirow[b]{2}{*}{$\begin{array}{l}\text { Ambiente } \\
\text { Externo }\end{array}$} \\
\hline & $\begin{array}{l}\text { Resposta aos } \\
\text { concorrentes }\end{array}$ & $\begin{array}{l}\text { Resposta aos } \\
\text { fornecedores }\end{array}$ & $\begin{array}{c}\text { Compreensão } \\
\text { do mercado }\end{array}$ & $\begin{array}{c}\text { Compreensão de } \\
\text { organismos } \\
\text { institucionais }\end{array}$ & \\
\hline $\begin{array}{c}\text { Baixa } \\
\text { concordância }\end{array}$ & $4,9 \%$ & $2,4 \%$ & $4,9 \%$ & $0,0 \%$ & $3,0 \%$ \\
\hline $\begin{array}{c}\text { Concordância } \\
\text { moderada }\end{array}$ & $29,2 \%$ & $31,7 \%$ & $17,1 \%$ & $31,7 \%$ & $27,4 \%$ \\
\hline $\begin{array}{c}\text { Alta } \\
\text { concordância }\end{array}$ & $65,9 \%$ & $65,9 \%$ & $78,0 \%$ & $68,3 \%$ & $69,5 \%$ \\
\hline Média & 3,77 & 3,88 & 3,96 & 3,94 & 3,89 \\
\hline Desvio Padrão & 0,65 & 0,71 & 0,67 & 0,59 & 0,66 \\
\hline
\end{tabular}

A penúltima dimensão do modelo apresentado no referencial teórica trata da Organização, e seus os resultados constam da Tabela 10. Para definir este constructo, foram utilizadas seis variáveis. A variável O41 apresentou a maior média, 4,23, e frequência de respostas com alta concordância, 85,4\%, quando comparada com as demais variáveis desta dimensão. Isto quer dizer que nas empresas pesquisadas predomina uma alta integração entre as pessoas além dos limites departamentais.

No extremo oposto está a variável O47, com média 3,58, que trata da eficácia da comunicação dentro da organização, seja ela em qualquer direção e sentido. Apesar de haver uma distribuição equilibrada entre as empresas que tem uma concordância moderada e alta, pela tabela pode-se notar que a comunicação é um tópico que se destaca dos demais.

Tabela 10 - Resultados da dimensão Organização

\begin{tabular}{|c|c|c|c|c|c|c|c|}
\hline & O41 & $\mathrm{O} 45$ & $\mathrm{O} 46$ & O47 & O52 & O53 & \multirow[b]{2}{*}{$\begin{array}{c}\text { Organi- } \\
\text { zação }\end{array}$} \\
\hline & $\begin{array}{c}\text { Integração } \\
\text { entre pessoas }\end{array}$ & $\begin{array}{c}\text { Equipes } \\
\text { dedicadas } \\
\text { para a } \\
\text { inovação }\end{array}$ & $\begin{array}{c}\text { Tempestividade } \\
\text { das decisões }\end{array}$ & $\begin{array}{c}\text { Comunicação } \\
\text { eficaz }\end{array}$ & $\begin{array}{c}\text { Estrutura } \\
\text { flexível para } \\
\text { desenvolver } \\
\text { projetos }\end{array}$ & $\begin{array}{l}\text { Integração } \\
\text { entre áreas }\end{array}$ & \\
\hline $\begin{array}{c}\text { Baixa } \\
\text { concordância }\end{array}$ & $2,4 \%$ & $7,3 \%$ & $9,8 \%$ & $9,8 \%$ & $0,0 \%$ & $0,0 \%$ & $4,9 \%$ \\
\hline $\begin{array}{c}\text { Concordância } \\
\text { moderada }\end{array}$ & $12,2 \%$ & $26,8 \%$ & $24,4 \%$ & $43,9 \%$ & $17,1 \%$ & $26,8 \%$ & $25,2 \%$ \\
\hline \begin{tabular}{|c|} 
Alta \\
concordância \\
\end{tabular} & $85,4 \%$ & $65,9 \%$ & $65,9 \%$ & $46,3 \%$ & $82,9 \%$ & $73,2 \%$ & $69,9 \%$ \\
\hline Média & 4,23 & 3,70 & 3,86 & 3,58 & 4,09 & 4,07 & 3,92 \\
\hline Desvio padrão & 0,66 & 0,77 & 0,97 & 0,87 & 0,60 & 0,65 & 0,79 \\
\hline
\end{tabular}


Na dimensão Cultura, os resultados podem ser vistos na Tabela 11. Há nesta dimensão a maior diferença entre dois itens que a compõe, são eles o C73 (maior média 4,33) e o C74 (menor média 3,02).

A maioria das empresas afirma que consideram pequenos erros e falhas cometidos como parte intrínseca do processo de aprendizagem, conforme C73. Dos 28 itens que compõe as cinco dimensões do modelo de gestão integrada da inovação, foi exatamente esta questão que obteve a maior concordância, com 90,2\%. Ao passo que o item C74, foi o segundo item de todos (atrás apenas de PI23, adequação a prazos e orçamentos) que teve maior frequência de respostas com baixa concordância, 26,8\%. Este item investiga se as empresas oferecem tempo e recursos para que funcionários se dediquem a atividades ligadas à inovação de modo geral.

Tabela 11 - Resultados da dimensão Cultura

\begin{tabular}{|c|c|c|c|c|c|c|c|}
\hline & C49 & C58 & C59 & C72 & C73 & C74 & \multirow[b]{2}{*}{ Cultura } \\
\hline & $\begin{array}{l}\text { Efetividade } \\
\text { do reconhe- } \\
\text { cimeno/ } \\
\text { recompensa }\end{array}$ & $\begin{array}{c}\text { Clima } \\
\text { propício } \\
\text { para expor } \\
\text { ideias }\end{array}$ & $\begin{array}{c}\text { Comprometi- } \\
\text { mento com } \\
\text { treinamento/ } \\
\text { desenvolvimento }\end{array}$ & $\begin{array}{c}\text { Aprendizado } \\
\text { Contínuo }\end{array}$ & $\begin{array}{c}\text { Tolerância } \\
\text { a pequenos } \\
\text { erros/falhas }\end{array}$ & $\begin{array}{c}\text { Tempo/recursos } \\
\text { para dedicar } \\
\text { à geração } \\
\text { de ideias }\end{array}$ & \\
\hline $\begin{array}{c}\text { Baixa } \\
\text { concordância }\end{array}$ & $17,1 \%$ & $4,9 \%$ & $7,3 \%$ & $0,0 \%$ & $0,0 \%$ & $26,8 \%$ & $9,3 \%$ \\
\hline $\begin{array}{l}\text { Concordância } \\
\text { moderada }\end{array}$ & $36,6 \%$ & $7,3 \%$ & $26,8 \%$ & $19,5 \%$ & $9,8 \%$ & $41,5 \%$ & $23,6 \%$ \\
\hline $\begin{array}{c}\text { Alta } \\
\text { concordância }\end{array}$ & $46,3 \%$ & $87,8 \%$ & $65,9 \%$ & $80,5 \%$ & $90,2 \%$ & $31,7 \%$ & $67,1 \%$ \\
\hline Média & 3,39 & 4,14 & 3,79 & 4,22 & 4,33 & 3,02 & 3,82 \\
\hline Desvio Padrão & 1,00 & 0,66 & 0,77 & 0,62 & 0,61 & 0,90 & 0,90 \\
\hline
\end{tabular}

Quanto à única variável dependente, Desempenho Inovativo, os resultados podem ser vistos na Tabela 12. Os resultados desta dimensão se diferenciam bastante daqueles das dimensões anteriores (todas independentes) devido aos altos percentuais na faixa "alta concordância", isto poderá ser mais bem observado na Seção seguinte, através dos histogramas.

O Desempenho Inovativo, de modo agregado, apresenta uma incidência de 84,9\% na faixa de respostas acima de 3,5 (vide Tabela 6). Foi o item DI18 que apresentou maior contribuição, 92,7\% das empresas da amostra aumentaram o portfólio de produtos ofertados nos três anos anteriores à coleta, através de inovações de produto. Na sequência, a variável DI17 com 90,2\% de respostas afirma que as inovações deste período permitiram melhorar a qualidade dos produtos, através de inovação de processo. Com $87,8 \%$ de empresas respondentes estão as 
variáveis DI20 e DI21 cada uma, ambas tratam do quesito mercado. As inovações tanto permitiram tanto aumentar a participação das empresas nos mercados em que já atuavam quanto abrir outros novos. Por último, o item DI24 retrata que há menos empresas que conseguiram reduzir seus custos de produção ou prestação de serviços, o que seria possível através de inovações de processos.

Tabela 12 - Resultados da variável independente Desempenho Inovativo

\begin{tabular}{|c|c|c|c|c|c|c|}
\hline & $\begin{array}{c}\text { DI17 } \\
\text { Melhoria da } \\
\text { qualidade de } \\
\text { bens/serviços } \\
\text { existente }\end{array}$ & $\begin{array}{c}\text { Lançamento } \\
\text { de novos } \\
\text { bens/serviços }\end{array}$ & $\begin{array}{c}\text { Aumento da } \\
\text { participação } \\
\text { em mercados } \\
\text { existentes }\end{array}$ & $\begin{array}{c}\text { Abertura } \\
\text { de novos } \\
\text { mercados }\end{array}$ & $\begin{array}{c}\text { Redução dos } \\
\text { custos de } \\
\text { produção/ } \\
\text { prestação }\end{array}$ & $\begin{array}{c}\text { Desempenho } \\
\text { Inovativo }\end{array}$ \\
\hline $\begin{array}{c}\text { Baixa } \\
\text { concordância }\end{array}$ & $4,9 \%$ & $2,4 \%$ & $7,3 \%$ & $4,9 \%$ & $19,5 \%$ & $7,8 \%$ \\
\hline $\begin{array}{c}\text { Concordância } \\
\text { moderada }\end{array}$ & $4,9 \%$ & $4,9 \%$ & $4,9 \%$ & $7,3 \%$ & $14,6 \%$ & $7,3 \%$ \\
\hline $\begin{array}{c}\text { Alta } \\
\text { concordância }\end{array}$ & $90,2 \%$ & $92,7 \%$ & $87,8 \%$ & $87,8 \%$ & $65,9 \%$ & $84,9 \%$ \\
\hline Média & 4,54 & 4,49 & 4,42 & 4,49 & 3,75 & 4,34 \\
\hline
\end{tabular}

\subsection{Análise descritiva das dimensões}

Na subseção anterior, foram analisadas internamente cada uma das cinco dimensões da gestão da inovação e mais a sexta dimensão, representada pela variável independente. O propósito foi investigar cada um dos itens que compunham determinada dimensão. Já nesta seção, o intuito é analisar comparativamente as dimensões. Para isso, foram elaborados histogramas (Gráficos 20 a 25), onde a base representa as possíveis opções de resposta (de 1 a 5) e a altura, a frequência com que cada opção de resposta aparecia. Porém, diferentemente da análise interna de cada dimensão, na análise comparativa entre as dimensões os extremos superiores e inferiores de respostas não foram agrupados.

O histograma serve para demonstrar graficamente a distribuição de determinada característica de uma amostra. Uma de suas vantagens é permitir analisar tendência central, dispersão e frequências relativas de diferentes valores a partir de um simples exame visual.

As dimensões que compõe a gestão integrada da inovação estão representadas nos Gráficos 20 a 24, a seguir. A partir da inspeção destes gráficos, percebe-se que todas as distribuições 
são negativamente assimétricas, isto é, as extremidades se alongam para a esquerda. A medida de assimetria em todas as dimensões é baixa, todas apresentaram valor em módulo inferior a 1,0 (HAIR, 2005, p. 274). A curtose é uma medida do achatamento da distribuição, valores próximos de zero indicam que a curva se aproxima de uma curva normal. As distribuições das cinco dimensões que compõe o modelo de gestão da inovação (variáveis independentes) se aproximam de uma distribuição normal.

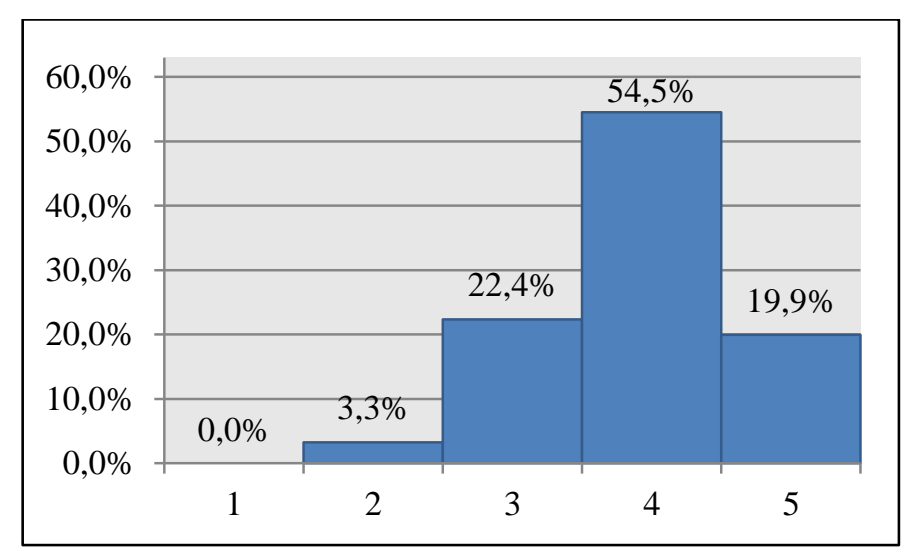

Gráfico 20 - Frequência de respostas da dimensão Estratégia.

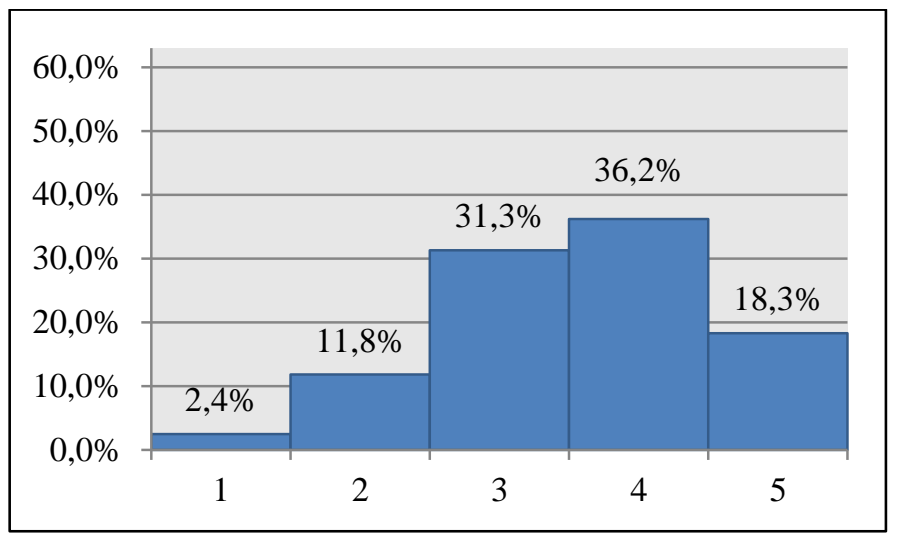

Gráfico 21 - Frequência de respostas da dimensão Processos Internos.

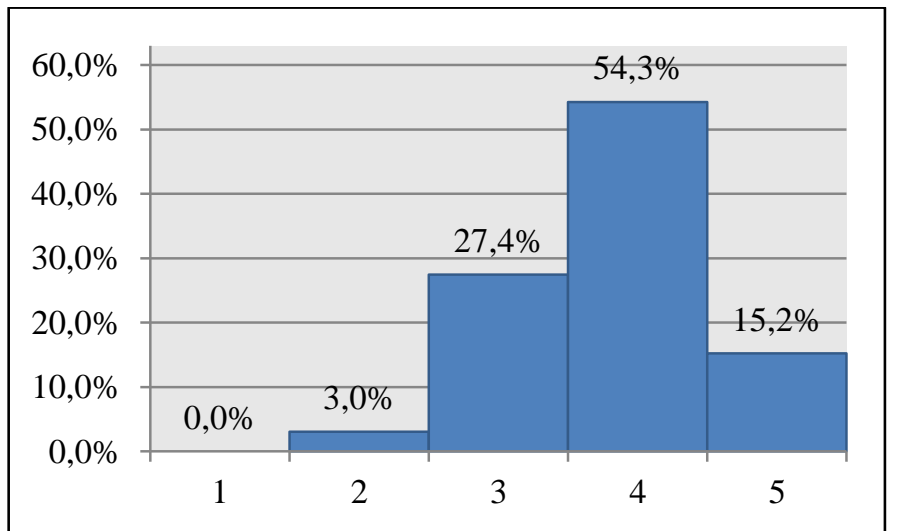

Gráfico 22 - Frequência de respostas da dimensão Ambiente Externo. 


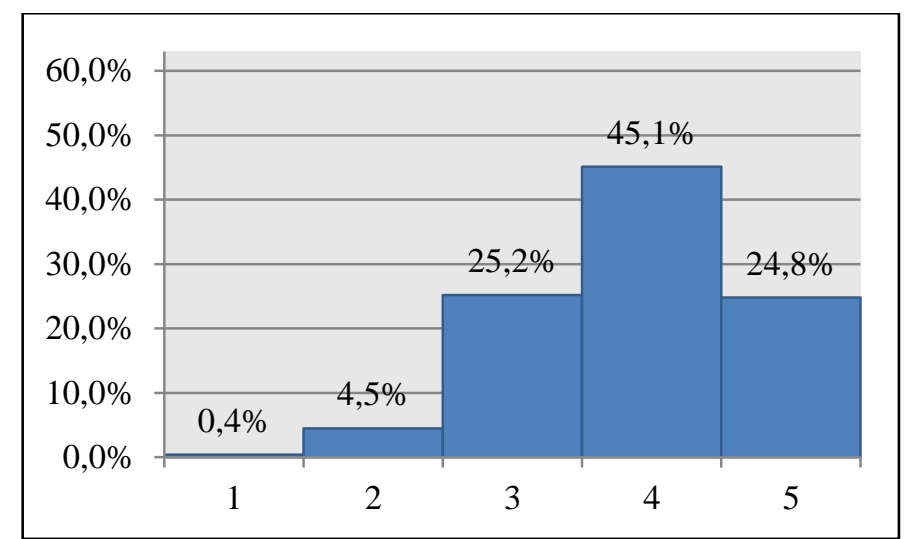

Gráfico 23 - Frequência de respostas da dimensão Organização.

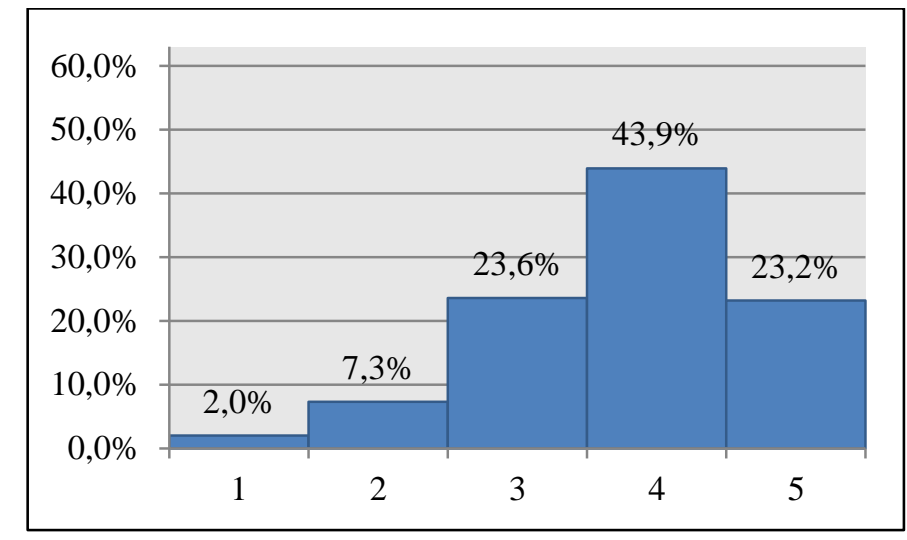

Gráfico 24 - Frequência de respostas da dimensão Cultura.

A variável dependente, Desempenho Inovativo, apresenta outro comportamento. Como se observa no Gráfico 25, a maior parte dos respondentes encontra-se na faixa de "alta concordância" com as afirmações apresentadas no questionário. Equivale a dizer que as inovações feitas pelas empresas nos três anos (2009-2011) tiveram resultados bastante positivos. Enquanto as demais dimensões (variáveis independentes) apresentavam um formato de sino, a distribuição da variável dependente é do tipo declive à esquerda (ou também chamada de despenhadeiro). O Desempenho Inovativo não acompanha o padrão de distribuição das variáveis que em tese o viabilizam, a partir da análise visual e comparando-se as médias constata-se que ele está acima. 


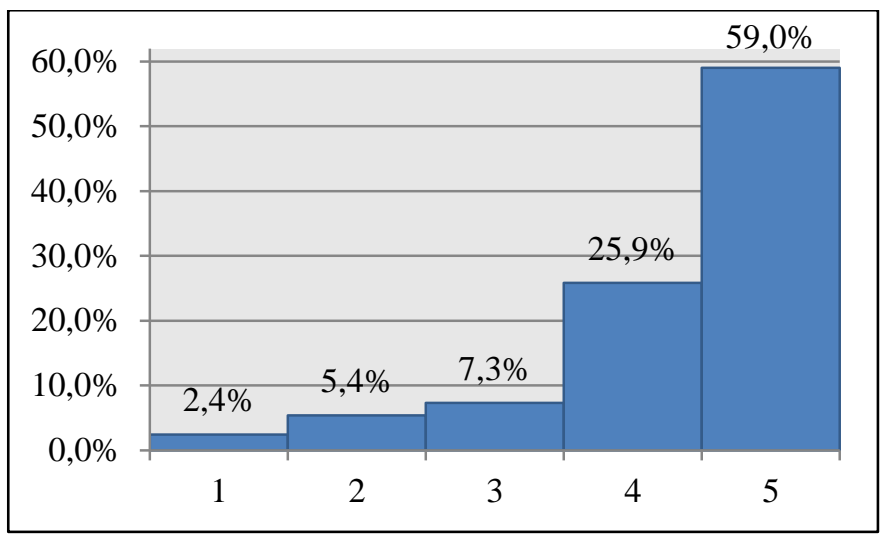

Gráfico 25 - Frequência de respostas da variável resultado Desempenho Inovativo.

A Tabela 13 apresenta diversas estatísticas descritivas obtidas com o software Microsoft Excel 2010. Nesta tabela, constam valores de curtose e assimetria, medidas para avaliar a distribuição dos dados, bem como outras medidas que vêm confirmar a diferença do comportamento das variáveis independentes em contraste com a dependente.

Tabela 13 - Estatísticas descritivas das variáveis independentes e dependente.

\begin{tabular}{|c|c|c|c|c|c|c|}
\hline & Estratégia & $\begin{array}{c}\text { Processos } \\
\text { Internos }\end{array}$ & $\begin{array}{c}\text { Ambiente } \\
\text { Externo }\end{array}$ & Organização & Cultura & $\begin{array}{c}\text { Desempenho } \\
\text { Inovativo }\end{array}$ \\
\hline Média & 3,95 & 3,58 & 3,89 & 3,92 & 3,82 & 4,34 \\
\hline Mediana & 4,00 & 3,67 & 4,00 & 4,00 & 4,00 & 5,00 \\
\hline Moda & 4,00 & 4,00 & 4,00 & 4,00 & 4,00 & 5,00 \\
\hline $\begin{array}{c}\text { Desvio } \\
\text { padrão }\end{array}$ & 0,71 & 0,93 & 0,66 & 0,79 & 0,90 & 0,99 \\
\hline $\begin{array}{c}\text { Variância da } \\
\text { amostra }\end{array}$ & 0,51 & 0,87 & 0,43 & 0,63 & 0,81 & 0,99 \\
\hline Curtose & $-0,19$ & $-0,68$ & $-0,43$ & $-0,10$ & 0,05 & 2,24 \\
\hline Assimetria & $-0,66$ & $-0,33$ & $-0,36$ & $-0,63$ & $-0,74$ & $-1,66$ \\
\hline Intervalo & 3,20 & 4,00 & 2,80 & 3,60 & 4,00 & 4,00 \\
\hline Mínimo & 1,80 & 1,00 & 2,20 & 1,40 & 1,00 & 1,00 \\
\hline Máximo & 5,00 & 5,00 & 5,00 & 5,00 & 5,00 & 5,00 \\
\hline
\end{tabular}

Nas seções seguintes, a análise estatística será realizada através de técnicas inferenciais. Tais técnicas são úteis quando o propósito da pesquisa consiste em extrapolar os resultados da amostra para a população. Visto que o intuito é poder extrapolar os achados para , alguns respondentes os quais o tempo de existência (empresas fundadas após 2009) não se adequava ao período solicitado nas questões da variável dependente Dimensão Inovativo (correspondente a 2009-2011), foram excluídos que correspondiam aos últimos três anos anteriores à coleta. Deste modo, o tamanho de observações consideradas foi reduzido em seis respondentes, passando de 41 para 35 . 


\subsection{Análise das correlações}

O uso da análise de correlações serve para identificar possíveis relações de associação linear entre variáveis. Com esta técnica, permite-se aprofundar nas análises, conclusões e achados da pesquisa (MARTINS; THEÓPHILO, 2009, p. 130).

Uma das maneiras de avaliar a intensidade da associação linear entre as variáveis é através do coeficiente de Pearson, expresso pela letra $r$. Este coeficiente de correlação varia de uma escala de $-1 \mathrm{a}+1$. Nesta escala, quanto mais próximo ao módulo de 1 melhor é a qualidade do ajuste, em outras palavras os pontos em um diagrama de dispersão se aproximarão de uma reta. Pode a associação ser positiva (relação direta, ambas variam no mesmo sentido) ou negativa (relação inversa, uma aumenta e a outra diminui). No caso de valores próximos a zero, significa que não há associação linear.

Além do coeficiente de Pearson, é preciso estar atento para saber se este é estatisticamente significativo. É comum em estudos um nível de significância (Sig. ou p-value) de até 5\%, isto significa que valores encontrados até este limite representam uma relação linear significante. Dependendo da aceitação do nível de risco, é possível encontrar estudos com nível de significância de até $10 \%$. Fixado o limite, caso o valor encontrado de Sig. seja superior, então não haverá mais evidência de que a relação linear seja significante.

Para a análise de regressão múltipla, é importante que as variáveis independentes sejam estatisticamente independentes e não covariem. Caso ocorra de as variáveis independentes apresentarem correlações altas umas com as outras, haverá o problema da multicolinearidade (HAIR, 2005, p. 327). A matriz apresentada na Tabela 14, na página seguinte, serve para identificar tais correlações. 
Tabela 14 - Correlação das variáveis da gestão da inovação.

\begin{tabular}{|ll|c|c|c|c|c|}
\hline & $\mathrm{E}$ & $\mathrm{PI}$ & $\mathrm{AE}$ & $\mathrm{O}$ & $\mathrm{C}$ \\
\hline E & Pearson Correlation & 1 & 0,766 & 0,789 & 0,754 & 0,751 \\
& Sig. (2-tailed) & & 0,000 & 0,000 & 0,000 & 0,000 \\
& $\mathrm{~N}$ & 35 & 35 & 35 & 35 & 35 \\
\hline PI & Pearson Correlation & 0,766 & 1 & 0,738 & 0,813 & 0,674 \\
& Sig. (2-tailed) & 0,000 & & 0,000 & 0,000 & 0,000 \\
& N & 35 & 35 & 35 & 35 & 35 \\
\hline AE & Pearson Correlation & 0,789 & 0,738 & 1 & 0,708 & 0,652 \\
& Sig. (2-tailed) & 0,000 & 0,000 & & 0,000 & 0,000 \\
& N & 35 & 35 & 35 & 35 & 35 \\
\hline O & Pearson Correlation & 0,754 & 0,813 & 0,708 & 1 & 0,695 \\
& Sig. (2-tailed) & 0,000 & 0,000 & 0,000 & & 0,000 \\
& N & 35 & 35 & 35 & 35 & 35 \\
\hline C & Pearson Correlation & 0,751 & 0,674 & 0,652 & 0,695 & 1 \\
& Sig. (2-tailed) & 0,000 & 0,000 & 0,000 & 0,000 & \\
& N & 35 & 35 & 35 & 35 & 35 \\
\hline
\end{tabular}

Pela tabela acima, o que se nota é que há uma correlação positiva de força moderada e alta (HAIR, 2005, p.312) entre todas as variáveis independentes que compõe o modelo. Ademais, todas apresentam nível de significância de 1\%. Isto provavelmente acarretará em um problema de multicolinearidade no momento da análise de regressão múltipla.

Quando o intuito da análise de regressão múltipla é entender o relacionamento entre as variáveis independentes, o pesquisador tem duas opções para tratar do problema da multicolinearidade. A primeira seria aumentar o número de observações, de modo a poder distinguir com maior nitidez o efeito direto de cada variável independente sobre a dependente. A segunda seria remover variáveis independentes do modelo. Neste estudo, a amostra é formada pelas empresas que aderiram ao projeto NAGIVALE, inviabilizando o aumento da amostra. Portanto, modelos diferentes em termos das dimensões que o compõe serão testados e, se preciso for, variáveis independentes serão excluídas.

\subsection{Análise de regressão linear}

Neste estudo, busca-se estabelecer as relações da gestão da inovação com o desempenho inovativo. Nas análises estatísticas inferenciais, considerou-se que a relação linear tem 
intercepto igual a 0, isto é, o coeficiente linear é nulo. Parte-se do pressuposto que, se a empresa não adotar nenhuma prática relacionada à inovação, então seu desempenho em termos de inovação será inexistente (no-intecept model no SPSS). Ademais, visto que as dimensões foram construídas com quantidades diferentes de variáveis, todas elas foram normalizadas pelo método max-min.

Outro ponto que cabe mencionar diz respeito à análise de subgrupos desta amostra. Executar esta análise isoladamente para cada segmento de empresas, ou seja, para cada grupo de empresas de micro, de pequeno e de médio portes separadamente, seria bastante enriquecedor para este trabalho. No entanto, o tamanho destes subgrupos não garante o poder estatístico da análise de regressão múltipla. Mesmo para análise de regressão bivariada, apenas relações fortes poderiam ser detectadas com alguma certeza (HAIR et al., 2009, p. 167).

\subsubsection{Análise de regressão bivariada}

A análise de regressão bivariada é utilizada para estabelecer a relação entre duas variáveis, uma independente e outra dependente. Apesar de ser relativamente simples, esta análise fornece informações valiosas, tais como a presença e o tipo desta relação, sua força e sua direção (HAIR, 2005, p. 310), bem como o poder explanatório do modelo.

A presença avalia se a relação entre duas variáveis é sistemática. É indicada pelo nível de significância estatística, indicado no software SPSS como Sig. É usual em Ciências Sociais adotar um nível de significância de 5\% (SAMPIERI et al., 2006, p. 442), valor este adotado no presente estudo. O nível de significância (Sig. ou p-value) é a probabilidade de se rejeitar a hipótese nula $\left(\mathrm{H}_{0}\right.$ : coeficiente angular $\beta$ é igual a zero), quando esta é verdadeira (erro do tipo I). Em outras palavras, para Sig. menores que 5\% assume-se que há relação linear.

O tipo de relação entre duas variáveis pode ser linear ou não. É possível identificar o tipo de relação e sua força através do coeficiente de correlação, indicado pela letra $\mathrm{R}$ no pacote estatístico SPSS. Quanto mais próximo de 1, mais a distribuição das observações se assemelha a uma reta e maior a sua força de associação. Outra análise sobre a linearidade é 
possível através do gráfico de resíduos. Se houver de fato uma relação linear, então este gráfico apresentará uma distribuição aleatória (fenômeno da homocedasticidade).

Uma vez identificado que há relação linear, esta poderá ser positiva ou negativa. A primeira se dará quando um aumento nos valores da variável independente causar um aumento na variável dependente, a segunda se dará quando ocorrer o inverso. No SPSS, a direção da relação bivariada é indicada pela letra $B$, que representa o coeficiente angular da reta.

Por fim, a medida no SPSS indicada como $R$ Square fornece a capacidade preditiva ou explicativa da regressão linear. Neste estudo, esta medida expressará o quão bem o comportamento da variável independente explica o comportamento da variável dependente.

Apesar de a análise de regressão bivariada ser executada separadamente no software utilizado, os resultados foram apresentados consolidados nas Tabelas 15 e 16. A variável independente referente a cada análise consta na coluna Model.

Tabela 15 - Resumo do modelo de cada análise de regressão bivariada

\begin{tabular}{|c|c|c|c|c|}
\hline Model & R & R Square & $\begin{array}{c}\text { Adjusted } \\
\text { R Square }\end{array}$ & $\begin{array}{c}\text { Std. Error of } \\
\text { the Estimate }\end{array}$ \\
\hline E_norm & 0,973 & 0,947 & 0,945 & 3,988337 \\
PI_norm & 0,969 & 0,939 & 0,937 & 4,259065 \\
\hline AE_norm & 0,970 & 0,942 & 0,940 & 4,175529 \\
\hline O_norm & 0,973 & 0,946 & 0,945 & 4,008711 \\
\hline C_norm & 0,974 & 0,948 & 0,947 & 3,932274 \\
\hline
\end{tabular}

Tabela 16 - Coeficientes de cada análise de regressão bivariada

\begin{tabular}{|c|c|c|c|c|c|}
\hline \multirow{2}{*}{ Model } & \multicolumn{2}{|c|}{ Unstandardized Coefficients } & $\begin{array}{c}\text { Standardized } \\
\text { Coefficients }\end{array}$ & \multirow{2}{*}{$\mathrm{t}$} & \multirow{2}{*}{ Sig. } \\
\cline { 2 - 4 } & $\mathrm{B}$ & Std. Error & Beta & & \\
\hline E_norm & 1,113 & 0,045 & 0,973 & 24,582 & 0,000 \\
\hline PI_norm & 1,266 & 0,055 & 0,969 & 22,928 & 0,000 \\
\hline AE_norm & 1,128 & 0,048 & 0,970 & 23,416 & 0,000 \\
\hline O_norm & 1,115 & 0,046 & 0,973 & 24,450 & 0,000 \\
\hline C_norm & 1,184 & 0,047 & 0,974 & 24,952 & 0,000 \\
\hline
\end{tabular}

Uma vez que os recursos que o software oferece foram explicados, é possível interpretar as tabelas acima. Em se tratando de análise de regressão bivariada, os resultados indicam que as cinco dimensões que compõe o modelo de Gestão Integrada da Inovação (Estratégia, 
Processos Internos, Ambiente Externo, Organização e Cultura), isoladamente, guardam relação linear e positiva com o Desempenho Inovativo.

O intuito de realizar a análise de regressão bivariada previamente à múltipla, deve-se ao problema da multicolinearidade, identificado na Seção 4.5. Percebeu-se que as variáveis do modelo covariavam, isto é, funcionavam basicamente como proxy umas das outras. Por este motivo, na presente seção foram apresentadas as estruturas do relacionamento bivariado. $\mathrm{Na}$ seção subsequente, será analisado como o modelo se comporta quando todas as variáveis independentes estiverem presentes.

\subsubsection{Análise de regressão múltipla}

A análise de regressão múltipla é uma extensão da técnica vista anteriormente. A maioria dos problemas envolve uma quantidade maior de fatores, neste sentido a análise de regressão múltipla se apresenta como um modelo mais próximo da realidade (HAIR, 2005, p. 326).

Além dos conceitos já apresentados, é preciso introduzir outro: a tolerância. Esta medida, indicada como tolerance no SPSS, serve para indicar o efeito da multicolinearidade. É calculada através de um processo que transforma cada variável independente em uma dependente prevista pelas demais, para então calcular $R$ square e subtraí-lo de 1. Quanto menor o valor da tolerância, melhor a variável em questão é prevista pelas demais, resultando no efeito da multicolinearidade e a tornando dispensável para o modelo.

Na análise de regressão linear múltipla, foi utilizado como critério de seleção o método Forward. Este método parte de um modelo sem nenhuma variável predecessora, no qual são adicionadas as variáveis independentes, uma a uma, a começar por aquela que guarda maior correlação com a variável resultado. Os índices calculados estão expressos nas Tabelas 17 e 18.

\begin{tabular}{|} 
Tabela 17 - Resumo do modelo da análise de regressão múltipla \\
\begin{tabular}{|c|c|c|c|c|} 
Model & R & R Square & $\begin{array}{c}\text { Adjusted } \\
\text { R Square }\end{array}$ & $\begin{array}{c}\text { Std. Error of } \\
\text { the Estimate }\end{array}$ \\
\hline C_norm & 0,974 & 0,948 & 0,947 & 3,932274 \\
\hline
\end{tabular}
\end{tabular}


Tabela 18 - Coeficientes da análise de regressão múltipla

\begin{tabular}{|c|c|c|c|c|c|}
\hline \multirow{2}{*}{ Model } & \multicolumn{2}{|c|}{ Unstandardized Coefficients } & $\begin{array}{c}\text { Standardized } \\
\text { Coefficients }\end{array}$ & \multirow{2}{*}{$\mathrm{t}$} & \multirow{2}{*}{ Sig. } \\
\cline { 2 - 4 } & $\mathrm{B}$ & Std. Error & Beta & & \\
\hline C_norm & 1,184 & 0,047 & 0,974 & 24,952 & 0,000 \\
\hline
\end{tabular}

Tabela 19 - Variáveis excluídas da análise de regressão múltipla

\begin{tabular}{|c|c|c|c|c|c|}
\multirow{2}{*}{ Model } & Beta In & $\mathrm{t}$ & Sig. & $\begin{array}{c}\text { Partial } \\
\text { Correlation }\end{array}$ & Collinearity Statistics \\
\cline { 6 - 6 } & & & & Tolerance \\
\hline E_norm & 0,441 & 1,458 & 0,154 & 0,246 & 0,016 \\
\hline PI_norm & 0,314 & 1,314 & 0,198 & 0,223 & 0,026 \\
\hline AE_norm & 0,344 & 1,362 & 0,182 & 0,231 & 0,023 \\
\hline O_norm & 0,440 & 1,682 & 0,102 & 0,281 & 0,021 \\
\hline
\end{tabular}

Conforme fora declarado na Seção 4.5, era de se esperar que, devido à alta correlação entre as variáveis independentes, apenas uma quantidade reduzida destas bastaria para explicar o modelo. Desta forma, os resultados indicam que somente a dimensão Cultura contribui significativamente para explicar o modelo integrado de Gestão da Inovação. 


\section{CONCLUSÕES}

\section{$5.1 \quad$ Conclusões}

O objetivo deste trabalho foi analisar como empresas de micro, pequeno e médio porte (MPMEs) gerenciam o seu processo de inovação e qual a associação desta gestão com o desempenho alcançado pelas inovações. Este estudo, amparado pela fundamentação teórica e pelo conjunto de dados primários analisados, permitiu chegar a algumas conclusões.

Primeiramente, cabe fazer aqui uma observação. As empresas pesquisadas fazem parte do Projeto NAGIVALE, financiado pela FINEP e que tem como objetivo promover e disseminar o tema da inovação. Posto que as empresas aderiram ao projeto por interesse próprio, percebese com isto que as empresas, de uma maneira ou de outra, estão atentas para a questão da inovação e o impacto causado em seus negócios. Conforme explicitado na Seção 3.2 (Capítulo Metodologia), esta pesquisa teve como objeto de estudo uma amostra por conveniência. Sendo assim, não é demais frisar que a extrapolação dos resultados para contextos que não guardam semelhança com o cenário desta pesquisa (MPMEs de setores com alto valor agregado pertencentes a APLs) deve ser feito com ressalvas.

O objetivo geral desta dissertação foi "identificar como os fatores da Gestão da Inovação abordados (Estratégia, processos Internos, Ambiente Externo, Organização e Cultura) se associam para refletir no Desempenho Inovativo e quais são os preponderantes no contexto das MPMEs pesquisadas" (Quadro 1). Com relação ao objetivo geral do trabalho, pode-se dizer que foi parcialmente alcançado. Diz-se que foi alcançado parcialmente porque se esperava que a análise estatística identificasse talvez dois ou mais fatores que, quando combinados, fossem capazes de explicar a estrutura de relacionamento entre a Gestão da Inovação e o reflexo no Desempenho Inovativo das empresas.

Quando do planejamento deste estudo, a expectativa era de que as diferentes dimensões que compunham o modelo integrado de Gestão da Inovação tivessem comportamentos distintos. Em outras palavras, supunha-se que algumas dimensões se apresentassem como sendo mais praticadas, outras como sendo menos preponderantes. Ao contrário, o que se observou por meio dos dados coletados foi que todas apresentavam comportamento bastante homogêneo, 
conforme constatado nos Gráficos 20 a 24. Devido a este fato, surgiu-se o problema da multicolinearidade das dimensões. Ao final da análise, constatou-se que bastava uma única dimensão para explicar a Gestão da Inovação: a dimensão Cultura.

As análises estatísticas descritivas das dimensões, vistas nas Tabelas 9 a 13, indicam que os escores (obtidos pelo cálculo da média) de cada dimensão giram em torno de 3,8 (o escore 4 significa "concordo parcialmente" na escala Likert utilizada). Como as empresas da amostra pertencem a setores de maior valor agregado; principalmente eletroeletrônicos, equipamentos para sistemas de segurança, automação, telecomunicações; elas enfrentam forte concorrência. Para manterem-se competitivas, é imprescindível que estejam constantemente lançando novos produtos e aprimorando suas práticas em gerenciamento. Assim, os altos escores para as dimensões da gestão da inovação vêm corroborar sua motivação para a inovação.

Apesar da semelhança guardada entre as dimensões, há algumas nuances que merecem ser comentadas. A dimensão Processos Internos se destaca porque apresenta a média dos escores mais baixo, 3,58. Ao verificar os itens que a compõe e que puxam a média para baixo, identifica-se primeiro a dificuldade por parte das empresas em cumprir prazos e orçamento. Em seguida, os processos que permitiriam gerenciar o desenvolvimento de um novo produto (da geração da ideia ao lançamento) não existem ou são inapropriados. E o terceiro item que teve uma alta incidência de respostas de discordância foi quanto ao sistema de seleção de projetos de inovação, que não são adequados.

Do outro lado, a dimensão que teve o maior escore médio foi Estratégia, com 3,95. Dentre os itens constantes no questionário, o que obteve maior pontuação e, consequentemente trouxe a média para cima, foi o compromisso da alta administração para a questão da inovação. Logo após, foi apontado que as pessoas dentro da organização compreendem como a inovação se traduz em maior competitividade. Em terceiro lugar, foi apontado que há coerência entre os projetos de inovação selecionados e a estratégia corporativa (apesar de aqueles não seguirem critérios definidos, sendo a seleção de caráter mais intuitivo).

A dimensão Cultura apresentou escore médio em um patamar intermediário, 3,82. Apesar disto, ela é única variável que entra no modelo de regressão múltipla, apresentando um $R$ Square de 0,948, o maior dentre seus pares. Dos itens que a compõe, constata-se que as empresas tratam erros e falhas como uma consequência natural do processo de aprendizagem. 
Em seguida, os respondentes citam que as pessoas na empresa são incentivadas a estar sempre buscando o aprendizado. E em terceiro lugar, existe um clima que favorece as pessoas a expressar suas ideias sem receio. De fato, Tidd (2008, p. 502) destaca o comprometimento com o desenvolvimento das pessoas como uma das características-chave das organizações inovadoras. $\mathrm{O}$ autor também cita a atmosfera adequada para a criatividade e o aprendizado como aspectos centrais.

Diferentemente da Gestão da Inovação, a variável dependente Desempenho Inovativo apresentou um comportamento bastante diverso, com as respostas se concentrando nos níveis mais altos de concordância, conforme apontado anteriormente no Gráfico 25. Em parte, isto pode ser justificado pela utilização de indicadores quantitativo-subjetivos, ou seja, baseados em julgamentos intuitivos convertidos em números, carregando, portanto, a subjetividade de quem os fornece (RAMOS et al., 2004, p. 2672). O Gráfico 26 apresenta um diagrama de dispersão que confronta a média dos escores das cinco dimensões da Gestão da Inovação com o Desempenho Inovativo.

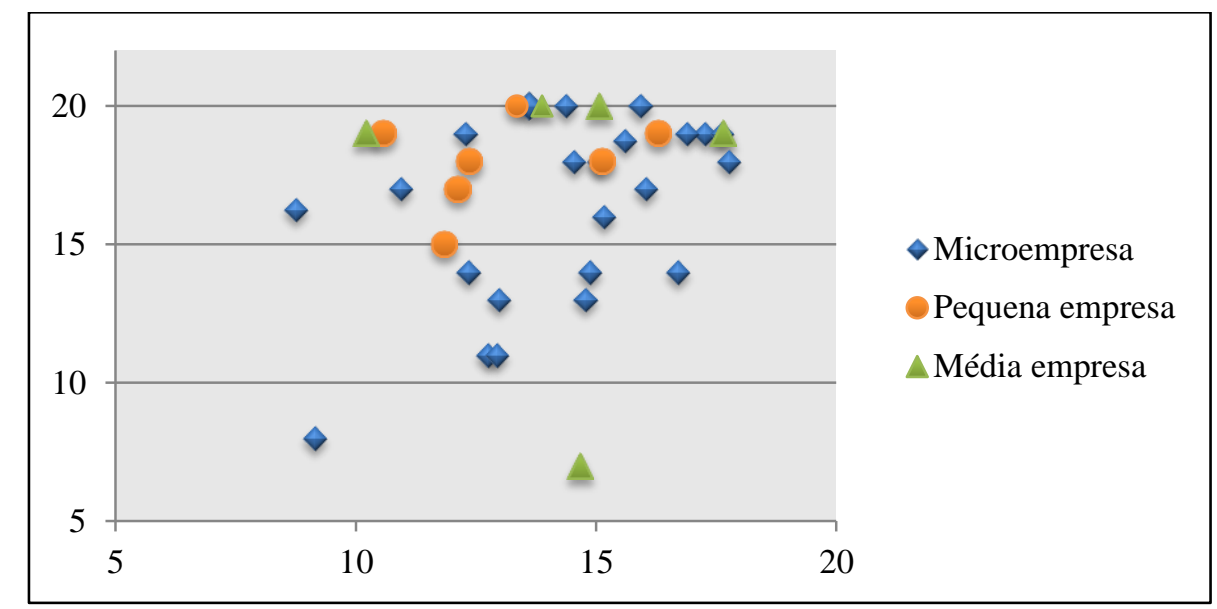

Gráfico 26 - Diagrama de dispersão entre Gestão da Inovação e Desempenho Inovativo

Há duas características importantes neste gráfico. A primeira diz respeito à concentração de observações na parte superior do gráfico, em outras palavras, respondentes que tem uma percepção de seu Desempenho Inovativo como sendo alta, mas que não necessariamente percebem suas práticas de Gestão da Inovação do mesmo modo. Esta percepção fica mais evidente nas empresas de maior faturamento desta amostra (pequeno e médio porte). A 
segunda característica do gráfico é a tendência de crescimento, principalmente quando considerado somente as microempresas (losangos azuis no gráfico acima).

Em síntese, em termos estatísticos, foi possível concluir que há relação linear e direta entre as cinco dimensões do modelo de Gestão da Inovação e os resultados em termos de Desempenho Inovativo, quando analisadas isoladamente. Por outro lado, mas também em termos estatísticos, concluiu-se que quando as mesmas cinco dimensões são postas em conjunto, basta a variável Cultura para explicar o modelo integrado (discussão sobre correlação na Seção 4.6.2). No entanto, como os próprios autores Jonash e Sommerlatte (2001), Tidd et al. (2001), Hansen e Birkinshaw (2007) defenderam em seus modelos conceituais, gerenciar eficazmente a inovação não se trata de ter sucesso em uma ou duas frentes, mas sim em todas as áreas e níveis dentro da organização, e também da interação desta com o meio que a envolve.

\subsection{Limitações da pesquisa e proposição para estudos futuros}

Uma das limitações deste estudo é em relação ao tipo de amostragem. As empresas que compõe a amostra são aquelas do projeto NAGIVALE, portanto do tipo por conveniência. O propósito de pesquisas, em geral, é poder inferir parâmetros da população a partir de uma amostra. Nesta pesquisa, extrapolações dos achados para o universo correspondente devem ser feitas com restrições. Além do tipo de amostragem, o seu tamanho não permitiu análises em subgrupos que poderiam assinalar diferenças entre os portes de empresa, ou entre os diferentes setores de atuação.

Outra limitação diz respeito aos itens e métricas que compuseram cada constructo. $\mathrm{O}$ questionário aplicado continha muitas perguntas (propósito de subsidiar a etapa de diagnóstico das empresas, pelo projeto NAGIVALE), assim foi preciso selecionar as mais alinhadas aos objetivos deste trabalho. Ademais, apesar da escala utilizada no instrumento de coleta facilitar sua compreensão por parte do respondente, a utilização de escalas métricas "verdadeiras" (em contraposição ao uso de Likert, ordinal, porém utilizada como intervalar para permitir maior leque de análises) poderia resultar em maior precisão dos dados, especialmente no caso de Desempenho Inovativo. 
Este estudo teve caráter exploratório. Para estudos futuros, sugere-se reduzir o foco para cada uma das dimensões e ainda estudar uma nova, o processo de aprendizagem das organizações. Também é importante aumentar o tamanho da amostra, para que outras análises estatísticas sejam possíveis, e, assim, estabelecer diferentes relações de interdependência das variáveis. 


\section{REFERÊNCIAS}

ASSOCIAÇÃO NACIONAL DE PESQUISA, DESENVOLVIMENTO E ENGENHARIA DAS EMPRESAS INOVADORAS - ANPEI. Indicadores de Pesquisa e Desenvolvimento (P\&D): Síntese dos Resultados. Resultados da Base de Dados ANPEI, ano base 2004, abril 2007.

BACHMANN, Dórian L.; DESTEFANI, Jully Heverly. Metodologia para estimar o grau de inovação nas MPE. Cultura do Empreendedorismo e Inovação. Curitiba, 2008.

BARNEY, Jay B.; HESTERLY, William S. Administração estratégica e vantagem competitiva. São Paulo: Pearson, 2008.

BAMPI, Sérgio (Coord.). Perspectivas do investimento em eletrônica. Rio de Janeiro: UFRJ, Instituto de Economia, 2008/2009. 272 p. Relatório integrante da pesquisa "Perspectivas do investimento no Brasil", em parceria com o Instituto de Economia da UNICAMP, financiada pelo BNDES.

BIRKINSHAW, Julian; HAMEL, Gary. Management innovation. Academy of Management Review, v. 33, n. 4, p. 825-845, 2008.

BOTELHO, Marisa dos Reis A.; CARRIJO, Michelle de Castro; OLIVEIRA, Olga Priscila Alves de. A evolução e dinâmica do arranjo produtivo local de eletroeletrônicos de Santa Rita do Sapucaí nos anos 2000. In: SEMINÁRIO SOBRE A ECONOMIA MINEIRA, 15., 2012, Diamantina. Anais eletrônicos. Diamantina: CEDEPLAR, 2012. Disponível em < http://web.cedeplar.ufmg.br/cedeplar/seminarios/ecn/ecn-mineira/2012/trabalhos/economia>. Acesso em 24/07/2013.

BOTELHO, Marisa dos Reis Azevedo; KAMASAKI, Gilsa Yumi. O arranjo produtivo local de eletrônica e telecomunicações em Santa Rita do Sapucaí/MG. SEBRAE, UFSC, NEITEC, FEPESEI, 2004.

BOTTER, Denise Aparecida; PAULA, Gilberto Alvarenga; LEITE, José Galvão; CORDANI, Lisbeth Kaiserlian. Noções de estatística. Instituto de Matemática e Estatística - USP. São Paulo, 1996.

BRASIL. Casa Civil. Subchefia para Assuntos Jurídicos. Decreto $n^{\circ}$ 5.798, de 7 de junho de 2006. Regulamenta os incentivos fiscais às atividades de pesquisa tecnológica e desenvolvimento de inovação tecnológica, de que tratam os arts. 17 a 26 da Lei $n^{\circ} 11.196$, de 21 de novembro de 2005. Brasília, 2006.

CHRISTENSEN, Clayton M. O Dilema da inovação: Quando as novas tecnologias levam empresas ao fracasso. São Paulo: M. Books do Brasil, 2012. 
CORAL, Eliza; OLIGARI, André; ABREU, Aline França (orgs.). Gestão integrada da inovação. São Paulo: Editora Atlas, 2011.

DIAS, Cora. Do café com leite à era eletrônica: Histórias como a de Santa Rita do Sapucaí, uma cidadezinha do sul de Minas, mostram a importância de se investir em educação para o desenvolvimento. Desafios do Desenvolvimento. Brasília, ano 8, n. 64, p. 78-80, 2011.

DINIZ, Clélio Campolina. Estudo da Competitividade da Indústria Brasileira competitividade e desenvolvimento regional no Brasil. Nota Técnica Extra - Blocos Temáticos. Convênio IE/UNICAMP, IEI/UFRJ, FDC, FUNCEX. Campinas, 1993.

DINIZ, Clélio Campolina; LEMOS, Mauro Borges. Sistemas Regionais de Inovação: o caso de Minas Gerais. Nota Técnica 06/98. Projeto MCT/OEA, IE/UFRJ. Rio de Janeiro, 1998 apud BOTELHO, Marisa dos Reis Azevedo; KAMASAKI, Gilsa Yumi. O arranjo produtivo local de eletrônica e telecomunicações em Santa Rita do Sapucaí/MG. SEBRAE, UFSC, NEITEC, FEPESEI, 2004.

FEDERAÇÃO DAS INDÚSTRIAS DE MINAS GERAIS - FIEMG; INSTITUTO EUVALDO LODI MINAS - IEL; SINDICATO DAS INDÚSTRIAS DE APARELHOS ELÉTRICOS, ELETRÔNICOS E SIMILARES DO VALE DA ELETRÔNICA - SINDVEL. Perfil da indústria do Vale da Eletrônica: Santa Rita do Sapucaí - MG. Belo Horizonte, 2010.

FINANCIADORA DE ESTUDOS E PROJETOS - FINEP. Chamada Pública MCT/FINEP - AT - Pró-Inova - Núcleos de Apoio à Gestão da Inovação - 11/2010. Rio de Janeiro: 2010.

GIL, Antônio Carlos. Como elaborar projetos de pesquisa. São Paulo: Atlas, 1988.

GIL, Antônio Carlos. Métodos e técnicas de pesquisa social. São Paulo: Atlas, 1999.

GOOGLE MAPS. Disponível em: <maps.google.com.br/>. Acesso em 02/10/2012.

GOVERnO DE MINAS. Plano de Desenvolvimento do Arranjo Produtivo Eletroeletrônico de Santa Rita do Sapucaí. SINDVEL, SEBRAE, IEL FIEMG. Belo Horizonte, 2007.

HAIR JUNIOR, Joseph F.; BABIN, Barry; MONEY, Arthur H.; SAMOUEL, Phillip. Fundamentos de métodos de pesquisa em administração. Porto Alegre: Bookman, 2005.

HAIR JUNIOR, Joseph F.; ANDERSON, Rolph E.; TATHAM, Ronald L.; BLACK, Willian C. Análise Multivariada de Dados. 5. ed. Porto Alegre: Bookman, 2006. 
HAIR JUNIOR, Joseph F.; ANDERSON, Rolph E.; TATHAM, Ronald L.; BLACK, Willian C. Análise Multivariada de Dados. 6. ed. Porto Alegre: Bookman, 2009.

HAMEL, Gary. PRAHALAD, Coimbatore Krishnarao. Competindo pelo Futuro Estratégias Inovadoras para obter o Controle do seu Setor e Criar os Mercados de Amanhã. 8 ed. Rio de Janeiro: Campus, 1995.

HANSEN, Morten T.; BIRKINSHAW, Julian. The Innovation Value Chain. Harvard Business Review, June, p. 121-130, 2007.

HEIMONEN, Tomi. What are the Factors that Affect Innovation in Growing SMES? European Journal of Innovation Management, v. 15, n. 1, p. 122 - 144, 2012.

HITT, Michael A.; IRELAND, R. Duane; HOSKISSON, Robert E. Administração estratégica: competitividade e globalização. $2^{a}$. ed. São Paulo: Pioneira Thomson Learning, 2008.

IBGE CIDADES@. Disponível em: <www.ibge.gov.br/cidadesat/painel/painel.php?codmun $=315960>$. Acesso em 04/10/2012.

INÁCIO JR., Edmundo. Padrões de inovação em pequenas e médias empresas e suas implicações para o desempenho inovativo e organizacional. Tese de Doutorado. Instituto de Geociências da Universidade Estadual de Campinas UNICAMP. Campinhas, 2008.

INSTITUTO BRASILEIRO DE GEOGRAFIA E ESTATÍSTICA - IBGE. Disponível em: <www.ibge.gov.br/home/presidencia/noticias/noticia_visualiza.php?id_noticia=1571\&id_pag ina=1>. Acesso em 04/10/2012.

INSTITUTO BRASILEIRO DE GEOGRAFIA E ESTATÍSTICA - IBGE. Disponível em: < http://www.ibge.gov.br/home/estatistica/indicadores/pib/pib-vol-val_201301_11.shtm>.

Acesso em 23/07/2013.

INSTITUTO BRASILEIRO DE GEOGRAFIA E ESTATÍSTICA - IBGE. Pesquisa Industrial de Inovação Tecnológica. Série Relatórios Metodológicos, v.30. Rio de Janeiro, 2004.

INSTITUTO BRASILEIRO DE GEOGRAFIA E ESTATÍSTICA - IBGE. Produto interno bruto dos municípios 2005-2009. Contas Nacionais n. 36. Rio de Janeiro, 2011.

INSTITUTO BRASILEIRO DE GEOGRAFIA E ESTATÍSTICA - IBGE. Produto interno bruto dos municípios 2010. Contas Nacionais n. 39. Rio de Janeiro, 2012.

INSTITUTO BRASILEIRO DE GEOGRAFIA E ESTATÍSTICA - IBGE. Pesquisa nacional por amostra domiciliar - Síntese de Indicadores 2011. Rio de Janeiro, 2012. 
INSTITUTO BRASILEIRO DE GOVERNANÇA CORPORATIVA - IBGC. Disponível em: <http://www.ibgc.org.br/>. Acesso em 18/06/2013.

INSTITUTO DE ECONOMIA DA UNIVERSIDADE FEDERAL DO RIO DE JANEIO - IE UFRJ. Glossário de arranjos e sistemas produtivos e inovativos locais. Disponível em: <http://www.desenvolvimento.gov.br/arquivos/dwnl_1289323549.pdf>. Acesso em 19/06/2013.

JONASH, Ronald S.; SOMMERLATTE, Tom. O valor da inovação: como as empresas manis avançadas atingem alto desempenho e lucratividade. Rio de Janeiro, Campus, 2001.

INTELLI. Diagnóstico de Inovação: Projecto FIVE. Portugal: 2004.

LIMA, Edmilson de Oliveira. As Definições de Micro, Pequena e Média Empresas Brasileiras como Base para a Formulação de Políticas Públicas. In ENCONTRO DE ESTUDOS SOBRE EMPREENDEDORISMO E GESTÃO DE PEQUENAS EMPRESAS, II, novembro/2001, Londrina. Anais do II EGEPE. Londrina, novembro/2001.

MARTINS, Gilberto de Andrade; THEÓPHILO, Carlos Renato. Metodologia da investigação científica para ciências sociais aplicadas. 2. ed. São Paulo: Atlas, 2009.

MARTINS, Gilberto de Andrade (coord.). Manual para formatação e edição de dissertações e teses. São Paulo: Faculdade de Economia, Administração e Contabilidade FEA, 2008. Disponível em: < http://www.fea.usp.br/media/fck/File/ManualTesesdez2008(1). pdf>. Acesso em: 01/06/2008.

MOVIMENTO BRASIL COMPETITIVO - MBC. Kit metodológico para a inovação empresarial. Brasília, 2008.

MOVIMENTO BRASIL COMPETITIVO - MBC. Manual de inovação. Brasília, 2008.

NATIONAL ENDOWMENT FOR SCIENCE, TECHNOLOGY AND THE ARTS NESTA. The Innovation Index: Measuring the UK's Investment in Innovation and its Effects. Inglaterra, 2009.

NEELY, Andy; HII, Jasper. Innovation and business performance: a literature review. Government Office of the Eastern Region. Cambridge: University of Cambridge, 1998.

NORUSIS, Marija J. SPSS 15.0 Statistical Procedures Companion. New Jersey: Prentice Hall, 2006.

OECD. Manual de Oslo: Diretrizes para Coleta e Interpretação de Dados sobre Inovação. 3 ed. Brasília: FINEP, 2005. 
PACHECO, Filipe. Fitch corta projeção de crescimento do Brasil para 1,5\% em 2012. Valor Econômico. São Paulo, 27/09/2012. Disponível em: < www.valor.com.br/financas/2846734/f itch-corta-projecao-de-crescimento-do-brasil-para-15-em-2012>. Acesso em: 03/11/2012.

PAPACONSTANTINOU, George. Technology and Industrial Performance. The OECD Observer, n. 204, feb-mar 1997.

PELL, G. Use and misuse of Likert scales. Medical Education, v. 39, n. 9, p. 867-973, set. 2005 apud VILHENA, Estela; PAIS RIBEIRO, José Luiz; MENDONÇA, D. Como trabalhar as variáveis ordinais como se fossem variáveis intervalares. In: LEAL, Isabel; PAIS RIBEIRO, José Luiz (Org.). Psicologia da saúde: sexualidade género e saúde. Lisboa: ISPA, 2010.

PEROBELLI, Fernando S. Transformações no Padrão Locacional Industrial: O Caso de Santa Rita do Sapucaí. Texto para discussão nº 414. Brasília: IPEA, 1996.

PREFEITURA MUNICIPAL DE SANTA RITA DO SAPUCAÍ. Disponível em: <www.pmsrs.mg.gov.br>. Acesso em 19/10/2012.

RAMOS, Milena Yuri; GARCEZ, Marcos Paixão; SBRAGIA, Roberto; DIAS, Marisa Villas Boas. Avaliação do desempenho do processo de desenvolvimento de novos produtos: proposição de uma tipologia para a construção de sistemas integrados de medidas. In: SIMPÓSIO DE GESTÃO DA INOVAÇÃO TECNOLÓGICA - XXIII., 2004, Curitiba, Anais eletrônicos... Curitiba: ANPAD, 2004.

REIS, Dálcio Roberto dos; CARVALHO, Hélio Gomes de; CAVALCANTE, Márcia Beatriz. Gestão da Inovação: Inovar para Competir. Brasília: SEBRAE, 2009.

ROBERTS, Edward B. Managing Invention and Innovation. Research Technology Management, v.31, n. 1, p. 11-29, jan/fev 1988.

ROTHWELL, Roy. Towards the Fifth-generation Innovation Process. International Marketing Review, v. 11, n. 1, p. 7-31, 1994.

SAMPIERI, Roberto Hernández; COLLADO, Carlos Fernández; LUCIO, Pilar Baptista. Metodologia de Pesquisa. 3 ed. São Paulo: McGraw-Hill, 2006.

SANTOS, Sandra Carvalho dos; TELLES, Renato; SARTURI, Greici. Contribuição à Avaliação de Clusters de Negócios: O Caso do Vale da Eletrônica Brasileiro. In: ENCONTRO ANUAL DA ASSOCIAÇÃO NACIONAL DOS PROGRAMAS DE PÓSGRADUAÇÃO EM ADMINISTRAÇÃO - ENANPAD, 36., 2012, Rio de Janeiro, Anais eletrônicos... Rio de Janeiro: ANPAD, 2012. Disponível em < http://www.anpad.org.br/diver sos/trabalhos/EnANPAD/enanpad_2012/GOL/Tema\%2006/2012_GOL2707.pdf〉. Acesso em: 13/06/2013. 
SANTOS, Sandra Carvalho dos. Estudo da relação entre inteligência, inovação e competitividade em clusters de tecnologia. Tese de Doutorado. Faculdade de Economia, Administração e Contabilidade FEA-USP. São Paulo, 2013.

SAWHNEY, Mohanbir; WOLCOTT Robert C.; ARRONIZ, Inigo. The 12 Different Ways for Companies to Innovate. MIT Sloan Management Review, v. 47, n. 3, p. 75-81, spring 2006.

SBRAGIA, Roberto. Um Estudo sobre Possíveis Indicadores para Apreciação de Resultados da Atividade de P\&D em contextos empresariais. Tese de Livre-Docência. Faculdade de Economia, Administração e Contabilidade FEA-USP. São Paulo, 1986.

SHIKID, Pery Francisco Assi; BACHA, Carlos José Caetano. Notas sobre o Modelo Schumpeteriano e suas Principais Correntes de Pensamento. Teoria e Evidência Econômica, Passo Fundo, RS, v. 5, n. 10, p. 107-126, 1998.

SILVA, Antônio Carlos Ribeiro. Metodologia da Pesquisa Aplicada à Contabilidade. São Paulo: Atlas, 2003.

SINDVEL. Disponível em: <www.sindvel.com.br/o-vale-da-eletronica>. Acesso em 04/10/2012.

TID, Joe. A Review of Innovation Models. Discussion Paper, SPRU, University of Sussex, 2006.

TIDD, Joe; BESSANT, John; PAVITT, Keith. Gestão da Inovação. 3 ed. Porto Alegre: Bookman, 2008.

TERRA, José Claudio (org); FREDERICK, Bjorn et al. 10 Dimensões da Gestão da Inovação - Uma Abordagem para a Transformação Organizacional. Rio de Janeiro: Elsevier, 2012.

TOMAZ, Rafael. Empresas do Polo do Sul de MG Terão Laboratório. Diário do Comércio. Belo Horizonte, 16/10/2012. Disponível em: <www.diariodocomercio.com.br/index.php?id=7 $0 \&$ conteudoId=126203\&edicaoId=1345>. Acesso em: 03/11/2012.

VERGARA, Sylvia Constant. Projetos e relatórios de pesquisa em administração. 10. ed. São Paulo: Atlas, 2009.

VILHENA, Estela; PAIS RIBEIRO, José Luiz; MENDONÇA, D. Como trabalhar as variáveis ordinais como se fossem variáveis intervalares. In: LEAL, Isabel; PAIS RIBEIRO, José Luiz (Org.). Psicologia da saúde: sexualidade género e saúde. Lisboa: ISPA, 2010. 
VINDING, Anker Lund. Absorptive capacity and innovation performance: a human capital approach. Economics of Innovation and New Technology, v. 15, n. 4-5, p. 507-517, 2006.

ZACARRELLI, Sérgio Baptista; TELLES, Renato; SIQUEIRA, João Paulo Lara de.; BOAVENTURA, João Maurício Gama; DONAIRE, Denis. Clusters e Redes de Negócios: uma nova visão para a gestão dos negócios. São Paulo: Atlas, 2008.

3M. A Culture of Innovation. Minneapolis: 3M, 2012. 


\section{APENDICES}

APÊNDICE 1 - CARACTERIZAÇÃO

APÊNDICE 2 - DESEMPENHO INOVATIVO

APÊNDICE 3 - MAPEAMENTO DA POSIÇÃO INOVATIVA 


\section{APENDICE 1 - CARACTERIZAÇÃO}

Esta atividade é parte do Projeto NAGIVALE - Núcleo de Apoio à Gestão da Inovação do Vale da Eletrônica e está sob a coordenação técnica dos professores da USP Roberto Sbragia e Moacir de Miranda Oliveira Jr.

O primeiro levantamento tem por objetivo coletar informações gerais de cada empresa. $\mathrm{O}$ acesso às respostas é restrito aos pesquisadores do Projeto e ao Agente de Inovação de cada empresa. O preenchimento do questionário é obrigatório àqueles que assinaram o termo de adesão. Os resultados serão tratados de forma individual para cada empresa e de forma agregada para o estudo do APL do Vale da Eletrônica.

O preenchimento deste questionário pode levar certo tempo e deverá ser feito em conjunto pelo Agente de Inovação e Facilitador. Procure fazê-lo sem interrupções. É muito importante que os dados sejam respondidos com a maior seriedade possível!

Agradecemos sua colaboração!

\section{IDENTIFICAÇÃO}

1. Razão social da empresa:

3. Nome do Facilitador:

4. Cargo ou posição do Facilitador dentro da empresa:

( ) Proprietário da empresa (único dono)

( ) Sócio-dirigente

( ) Diretor ou C-Level

( ) Presidente ou vice (mas não é sócio)

( ) Gerente ou Superintendente de Área

( ) Analista ou Operador

\section{CARACTERÍSTICAS DA EMPRESA}

11. Ano de início das operações:

12. Sua empresa possui filial ou alguma unidade a ela subordinada?

( ) Esta empresa é filial

( ) Sim, possui filial (com outro CNPJ)

( ) Sim, possui outra unidade (com o mesmo CNPJ)

( ) Não

Informe a localização da matriz/filial/unidade (estado ou país, conforme o caso):

Informe a principal função ou atividade da matriz/filial/unidade: 
13. Origem do capital controlador da empresa:
( ) Nacional
( ) Estrangeiro
( ) Nacional e Estrangeiro

No caso do capital controlador ser estrangeiro, qual a sua localização?
( ) Mercosul
( ) Estados Unidos
( ) Europa
( ) Outros países da América
( ) Ásia
( ) Canadá e México
( ) Oceania ou África

14. Sua empresa é ou já foi incubada?
( ) Sim, atualmente está incubada
( ) Sim, teve sua origem em uma incubadora mas atualmente é independente
( ) Não, nunca foi

Se sua empresa teve a origem em uma incubadora, mas atualmente é independente, informe em qual ano a empresa se desvinculou da incubadora:

15. Qual o principal mercado da empresa?
( ) Estadual
( ) Regional
( ) Estados Unidos
( ) Nacional
( ) Europa
( ) Mercosul
( ) Ásia
( ) Outros Países

17. Qual é o atual número de pessoas ocupadas na sua empresa em tempo integral (incluindo sócios, funcionários e prestadores de serviço em regime de tempo integral; e excluindo prestadores de serviços em regime de tempo parcial)?

18. Indique o principal segmento de atuação de sua empresa:
( ) Aparelhos para Radiodifusão
( ) Eletrônicos para Construção Civil
( ) Automação Comercial
( ) Embalagens
( ) Automação Industrial
( ) Informática
( ) Automação Predial
( ) Partes e Peças
( ) Educação
( ) Segurança
( ) Eletroeletrônicos
( ) Serviços
( ) Eletromecânicos
( ) Eletro médicos
( ) Tecnologia da Informação
( ) Telecomunicações

19. Qual é o tipo de administração/propriedade de sua empresa?
( ) Empresa gerida por membros de uma mesma família
( ) Administrada por profissionais contratados

20. Sua empresa possui algum tipo de certificação (por exemplo: ISO 9.001, ISO 14.001, OHSAS 18.001, SA 8.000 etc)?
( ) $\operatorname{Sim}$
( ) Não 
21. Qual foi o faturamento bruto de sua empresa no ano de 2011? (deverá ser expresso no formato "R\$ XXX.YYY,ZZ")

24. O principal produto (bem ou serviço) novo ou substancialmente aperfeiçoado, lançado por sua empresa no mercado nos últimos três anos é:

( ) Novo para a empresa, mas já existente no mercado nacional

( ) Novo para o mercado nacional, mas já existente no mercado mundial

( ) Novo para o mercado mundial

25. Em termos técnicos este produto é:

( ) Aprimoramento de outro produto já existente no portfólio da empresa

( ) Completamente novo para a nossa empresa

27. Entre 2009 e 2011, a empresa utilizou alguns dos seguintes meios para proteger as inovações de produto e/ou processo desenvolvidas?

\begin{tabular}{|l|c|c|}
\hline \multicolumn{1}{|c|}{ Métodos } & Sim & Não \\
\hline Patente de invenção & & \\
\hline Patente de modelo utilizado & & \\
\hline Registro de desenho industrial & & \\
\hline Marcas & & \\
\hline Direitos de autor & & \\
\hline
\end{tabular}




\section{APENDICE 2 - DESEMPENHO INOVATIVO}

Esta atividade é parte do Projeto NAGIVALE - Núcleo de Apoio à Gestão da Inovação do Vale da Eletrônica e está sob a coordenação técnica dos professores da USP Roberto Sbragia e Moacir de Miranda Oliveira Jr.

O segundo levantamento tem por objetivo coletar informações referentes ao desempenho da empresa em termos de inovação. $\mathrm{O}$ acesso às respostas é restrito aos consultores do Projeto e ao Agente de Inovação de cada empresa. O preenchimento do questionário é obrigatório àqueles que assinaram o termo de adesão. Os resultados serão tratados de forma individual para cada empresa e de forma agregada para o estudo do APL do Vale da Eletrônica.

O preenchimento deste questionário pode levar certo tempo e deverá ser feito em conjunto pelo Agente de Inovação e Facilitador. Procure fazê-lo sem interrupções. É muito importante que os dados sejam respondidos com a maior seriedade possível!

Agradecemos sua colaboração!

\section{DESEMPENHO INOVATIVO}

Analise cada sentença abaixo e marque o número que melhor representa sua percepção com relação à afirmação, segundo uma escala Likert onde 1 significa "Discordo totalmente", 2 "Discordo parcialmente", 3 "Não concordo, nem discordo", 4 "Concordo parcialmente" e 5 "Concordo totalmente".

\begin{tabular}{|c|c|c|c|c|c|c|c|}
\hline Afirmações & \multirow{11}{*}{ 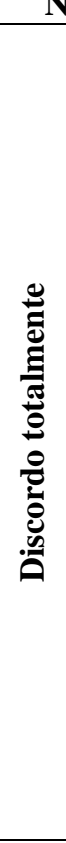 } & vel & de & on & or & ân & \\
\hline $\begin{array}{l}\text { 13. Nos últimos três anos (2009-2011), produzimos inovações que melhoraram a } \\
\text { qualidade dos bens ou serviços. }\end{array}$ & & 1 & 2 & 3 & 4 & 5 & \multirow{10}{*}{ 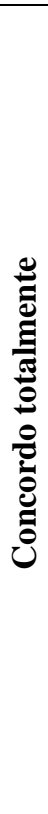 } \\
\hline $\begin{array}{l}\text { 14. Nos últimos três anos (2009-2011), realizamos inovações que ampliaram a } \\
\text { gama de bens ou serviços ofertados. }\end{array}$ & & 1 & 2 & 3 & 4 & 5 & \\
\hline $\begin{array}{l}\text { 15. Nos últimos três anos (2009-2011), realizamos inovações que ajudaram a } \\
\text { manter a participação da empresa no mercado. }\end{array}$ & & 1 & 2 & 3 & 4 & 5 & \\
\hline $\begin{array}{l}\text { 16. Nos últimos três anos }(2009-2011) \text {, criamos inovações que ampliaram a } \\
\text { participação da empresa no mercado. }\end{array}$ & & 1 & 2 & 3 & 4 & 5 & \\
\hline $\begin{array}{l}\text { 17. Nos últimos três anos (2009-2011), as inovações que realizamos permitiram } \\
\text { abrir novos mercados. }\end{array}$ & & 1 & 2 & 3 & 4 & 5 & \\
\hline $\begin{array}{l}\text { 18. Nos últimos três anos (2009-2011), realizamos inovações que aumentaram a } \\
\text { capacidade de produção ou de prestação de serviços. }\end{array}$ & & 1 & 2 & 3 & 4 & 5 & \\
\hline $\begin{array}{l}\text { 19. Nos últimos três anos (2009-2011), nossas inovações aumentaram a } \\
\text { flexibilidade da produção ou da prestação de serviços. }\end{array}$ & & 1 & 2 & 3 & 4 & 5 & \\
\hline $\begin{array}{l}\text { 20. Nos últimos três anos (2009-2011), as inovações de nossa empresa permitiu } \\
\text { reduzir os custos de produção/serviços prestados. }\end{array}$ & & 1 & 2 & 3 & 4 & 5 & \\
\hline $\begin{array}{l}\text { 21. Nos últimos três anos (2009-2011), realizamos inovações que reduziram os } \\
\text { custos do trabalho. }\end{array}$ & & 1 & 2 & 3 & 4 & 5 & \\
\hline $\begin{array}{l}\text { 22. Nos últimos três anos (2009-2011), as inovações reduziram o consumo de } \\
\text { matérias-primas e insumos. }\end{array}$ & & 1 & 2 & 3 & 4 & 5 & \\
\hline
\end{tabular}




\section{APENDICE 3 - MAPEAMENTO DA POSIÇÃO INOVATIVA}

Esta atividade é parte do Projeto NAGIVALE - Núcleo de Apoio à Gestão da Inovação do Vale da Eletrônica e está sob a coordenação técnica dos professores da USP Roberto Sbragia e Moacir de Miranda Oliveira Jr.

O terceiro levantamento tem por objetivo coletar informações sobre as diferentes dimensões da gestão da inovação da empresa. O acesso às respostas é restrito aos consultores do Projeto e ao Agente de Inovação de cada empresa. O preenchimento do questionário é obrigatório àqueles que assinaram o termo de adesão. Os resultados serão tratados de forma individual para cada empresa e de forma agregada para o estudo do APL do Vale da Eletrônica.

O preenchimento deste questionário pode levar certo tempo e deverá ser feito em conjunto pelo Agente de Inovação e Facilitador. Procure fazê-lo sem interrupções. É muito importante que os dados sejam respondidos com a maior seriedade possível!

Agradecemos sua colaboração!

\section{MAPEAMENTO DA POSIÇÃO INOVATIVA}

Analise cada sentença a seguir e marque o número que melhor representa sua percepção com relação à afirmação, segundo uma escala Likert onde 1 significa "Discordo totalmente", 2 "Discordo parcialmente", 3 "Não concordo, nem discordo", 4 "Concordo parcialmente" e 5 "Concordo totalmente".

\begin{tabular}{|c|c|c|c|c|c|c|c|}
\hline Afirmações & \multicolumn{7}{|c|}{ Nível de concordância } \\
\hline $\begin{array}{l}\text { 12) Em relação aos concorrentes, a sua empresa possui mais iniciativas da direção } \\
\text { da empresa para apoiar, estimular e envolver-se com a inovação. }\end{array}$ & \multirow{12}{*}{ 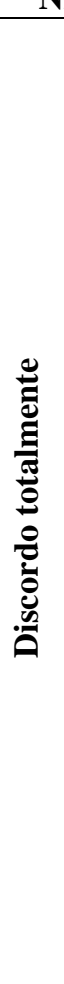 } & 1 & 2 & 3 & 4 & 5 & \multirow{12}{*}{ 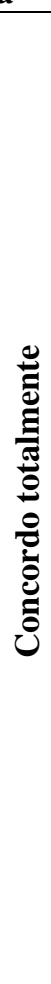 } \\
\hline $\begin{array}{l}\text { 13) As pessoas tem uma ideia clara de como a inovação pode nos ajudar a } \\
\text { competir.* }\end{array}$ & & 1 & 2 & 3 & 4 & 5 & \\
\hline $\begin{array}{l}\text { 14) Nossa estratégia de inovação é expressa de maneira clara; assim, todos } \\
\text { conhecem as metas de melhoria. }\end{array}$ & & 1 & 2 & 3 & 4 & 5 & \\
\hline $\begin{array}{l}\text { 15) As pessoas sabem qual é a nossa competência característica, isto é, aquilo que } \\
\text { nos proporciona uma vantagem competitiva. }\end{array}$ & & 1 & 2 & 3 & 4 & 5 & \\
\hline $\begin{array}{l}\text { 16) Olhamos para frente, em um caminho estruturado (utilizando ferramentas e } \\
\text { técnicas de previsão), para vislumbrar futuras oportunidades e ameaças. }\end{array}$ & & 1 & 2 & 3 & 4 & 5 & \\
\hline $\begin{array}{l}\text { 17) Em relação aos concorrentes, nossa empresa é rápida em incorporar } \\
\text { inovações em produtos, processos ou serviços e repassá-los aos clientes. }\end{array}$ & & 1 & 2 & 3 & 4 & 5 & \\
\hline $\begin{array}{l}\text { 18) Nossa equipe tem uma visão clara e disseminada sobre como a empresa se } \\
\text { desenvolverá por meio da inovação. }\end{array}$ & & 1 & 2 & 3 & 4 & 5 & \\
\hline 19) Existem comprometimento e suporte da alta gestão para promover inovação. & & 1 & 2 & 3 & 4 & 5 & \\
\hline $\begin{array}{l}\text { 20) Possuímos processos adequados para examinar novos desenvolvimentos } \\
\text { tecnológicos ou de mercado e determinar o que eles significam para a estratégia } \\
\text { de nossa empresa. }\end{array}$ & & 1 & 2 & 3 & 4 & 5 & \\
\hline $\begin{array}{l}\text { 21) Existe uma ligação clara entre os projetos de inovação que realizamos e a } \\
\text { estratégia geral do negócio. }\end{array}$ & & 1 & 2 & 3 & 4 & 5 & \\
\hline $\begin{array}{l}\text { 22) Há processos apropriados que nos ajudam a gerenciar o desenvolvimento de } \\
\text { um novo produto, de maneira eficaz, desde a ideia ate o lançamento. }\end{array}$ & & 1 & 2 & 3 & 4 & 5 & \\
\hline $\begin{array}{l}\text { 23) Nossos projetos de inovação geralmente são realizados no prazo e dentro do } \\
\text { orçamento. }\end{array}$ & & 1 & 2 & 3 & 4 & 5 & \\
\hline
\end{tabular}


24) Possuímos mecanismos eficazes para nos assegurar de que todos (e não apenas o setor de marketing) compreendam as necessidades do cliente.

25) Possuímos mecanismos eficazes para gerenciar a mudança de processo, desde a ideia até a implementação bem sucedida.

26) Pesquisamos sistematicamente ideias de novos produtos (por exemplo, através de: feiras, missões, revistas especializadas, congressos, etc).

27) Possuímos mecanismos adequados para assegurar o envolvimento prévio de todos os departamentos no desenvolvimento de novos produtos/processos.

28) Temos um sistema claro para escolha de projetos de inovação.

29) Existe flexibilidade o suficiente em nosso sistema de desenvolvimento de produto para permitir que pequenos projetos "rápidos" aconteçam.

32) Em relação aos concorrentes, a sua empresa apresenta maior capacidade de alocar recursos em desenvolvimento tecnológico face às necessidades do negócio. 33) A exigência dos consumidores brasileiros incentiva a criação de novos produtos.

36) É forte a importância de universidades ou outros centros de ensino superior como parceiros.

37) É forte a importância de institutos de pesquisa ou centros tecnológicos como parceiros.

38) É forte a importância dos centros de capacitação profissional e assistência técnica, enquanto parceiros.

39) É forte a importância das instituições de testes, ensaios e certificações.

62) Comparamos sistematicamente nossos produtos e processos com os de outras empresas.

64) Reunimo-nos e compartilhamos experiências com outras empresas para que nos ajudem a aprender.

d9. A aquisição externa de P\&D tem tido papel importante nos últimos três anos (2009-2011).

d10. A aquisição de outros conhecimentos externos nos últimos três anos (20092011) influenciou fortemente as atividades inovativas da empresa.

d11. A aquisição de software (por exemplo: de desenho, engenharia, de processamento e transmissão de dados, voz, gráficos, vídeos, para automatização de processos etc) realizada nos últimos três anos (2009-2011) influenciou fortemente as atividades inovativas da empresa.

d12. A aquisição de máquinas e equipamentos realizada nos últimos três anos (2009-2011) influenciou fortemente as atividades inovativas da empresa.

40) A estrutura de sua organização não reprime a inovação, pelo contrário, favorece a sua ocorrência.

41) As pessoas trabalham bem em conjunto além dos limites departamentais.

42) As pessoas estão envolvidas com sugestão de ideias para melhorias dos produtos ou processos.

43) Prevalece o conhecimento e competência em detrimento do peso da hierarquia.

44) A maneira como as pessoas estão organizadas (estrutura organizacional) ajuda a proporcionar o sucesso das inovações mais complexas e de maior valor.

45) Possuímos equipes/áreas com claras responsabilidades e que se dedicam para a condução de diversos tipos de inovação.

46) O modo pelo qual a empresa está estruturada permite que decisões sejam tomadas rapidamente.

47) A comunicação é eficaz e funciona bem em todas as direções da organização, isto é, de cima para baixo, de baixo para cima e diagonalmente entre as áreas.

48) A empresa possui canais de comunicação (por exemplo: e-mail corporativo, reuniões regulares, intranet, dentre outros) que de fato servem para as pessoas se comunicarem e se aproximarem.

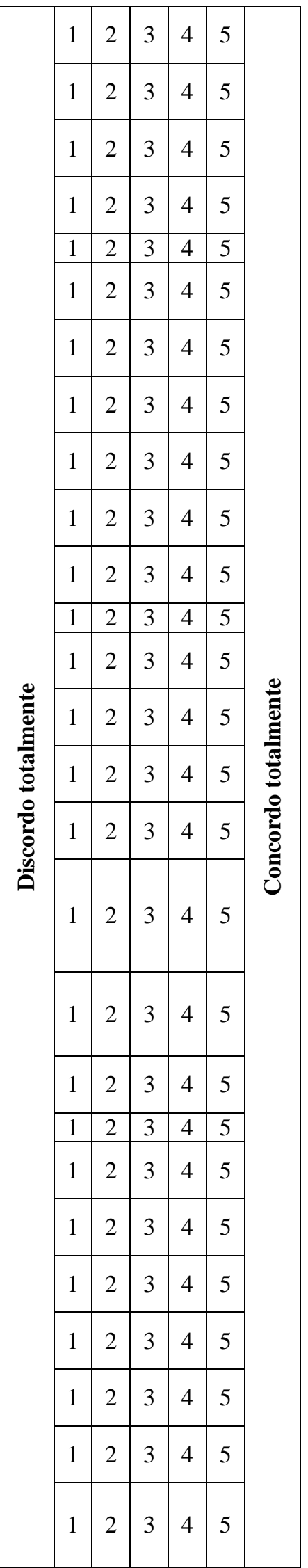


49) Nosso sistema de reconhecimento/recompensa favorece a ocorrência da inovação.

50) Sabemos integrar as atividades de inovação e desenvolvimento de novos produtos/processos com o restante da cadeia de valor interna à empresa, por exemplo com marketing e produção.

51) Nossos funcionários trabalham bem em equipe.

52) A estrutura organizacional é flexível e adequada para encaminhar projetos inovadores.

53) Há uma forte integração entre as diversas áreas da empresa.

54) Há uma grande flexibilidade da organização para responder às ações dos concorrentes.

55) Há uma grande flexibilidade da organização para responder às ações dos fornecedores.

56) Há uma grande habilidade da organização para captar e compreender comportamentos, tendências e atitudes dos clientes.

57) Há uma grande capacidade da organização em acompanhar e entender as ações das demais instituições (exemplos de outras instituições: agências regulatórias, de fomento, de exportação/importação etc, sindicatos, associações de classe, dentre outras).

58) Existe um clima de apoio para novas ideias. Em outras palavras, nossos funcionários sentem que a alta administração apoia a criatividade e permitem que as novas ideias sejam transformadas em realidade.

59) Há um forte comprometimento com treinamento e desenvolvimento de pessoas.

60) Aprendemos com cada projeto executado de modo que sempre melhoramos nosso desempenho no projeto seguinte.

61) Aprendemos a partir de nossos erros.

63) Nesta empresa, incentivamos a criatividade interna e o compartilhamento dos conhecimentos adquiridos entre as pessoas chave da organização.

65) Somos capazes de internalizar aquilo que aprendemos; deste modo permite-se que outros dentro da organização possam fazer uso deste conhecimento futuramente.

66) Somos capazes de aprender com as ações de outras organizações, sejam elas do mesmo setor, sejam elas de áreas alheias ao nosso negócio.

67) Nos processos de recrutamento e seleção de novos funcionários, perfis de pessoas empreendedoras e proativas são efetivamente buscados. 68) As pessoas se sentem com alto grau de autonomia e encorajadas para assumir responsabilidades.

69) A liderança intra-empreendedora pode surgir de qualquer departamento, área ou nível hierárquico da organização.

70) Existência de um ambiente propício ao exercício da criatividade.

71) Nossa cultura organizacional estimula que quaisquer pessoas de dentro da organização (independente do nível hierárquico ou área) exponham suas ideias sem receio.

72) Aqui, as pessoas são estimuladas a aprender de forma contínua.

73) Pequenos erros e falhas são tratados como parte integrante do processo de aprendizado.

74) A empresa oferece aos funcionários uma parte do tempo e recursos para que dediquem a atividades de pesquisa, geração de ideias e de conceitos e inovação de um modo geral.

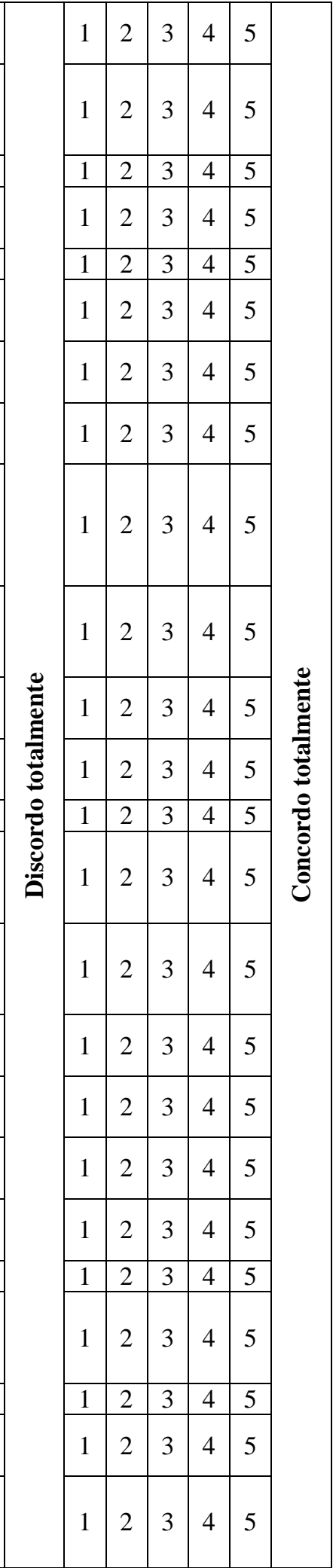

\section{QUESTIONÁRIO CONCLUÍDO!}

Caros Facilitador e Agente de Inovação, obrigado por responder ao questionário de mapeamento da posição inovativa da empresa. 